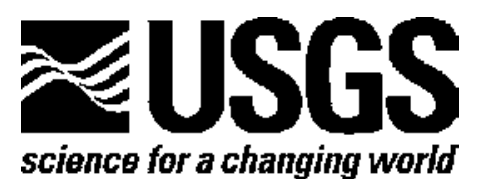

\title{
Fine-Scale Delineation of the Location of and Relative Ground Shaking within the San Andreas Fault Zone at San Andreas Lake, San Mateo County, California
}

Open-File Report 2013-1041

U.S. Department of the Interior U.S. Geological Survey 


\section{U.S. Department of the Interior \\ KEN SALAZAR, Secretary}

\section{U.S. Geological Survey}

Suzette M. Kimball, Acting Director

U.S. Geological Survey, Reston, Virginia: 2013

For more information on the USGS - the Federal source for science about the Earth, its natural and living resources, natural hazards, and the environment-visit http://www.usgs.gov or call 1-888-ASK-USGS

For an overview of USGS information products, including maps, imagery, and publications, visit $h$ ttp://www.usgs.gov/pubprod

Suggested citation:

Catchings, R.D., Rymer, M.J., Goldman, M.R., Prentice, C.S., and Sickler, R.R., 2013, Finescale delineation of the location of and relative ground shaking within the San Andreas Fault zone at San Andreas Lake, San Mateo County, California: U.S. Geological Survey Open-File Report 2013-1041, 53 p.

Any use of trade, product, or firm names is for descriptive purposes only and does not imply endorsement by the U.S. Government.

Although this report is in the public domain, permission must be secured from the individual copyright owners to reproduce any copyrighted material contained within this report. 


\section{Contents}

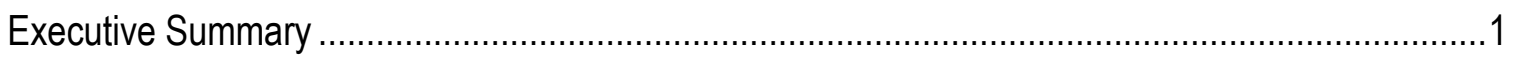

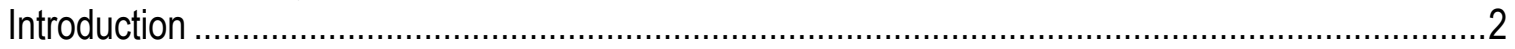

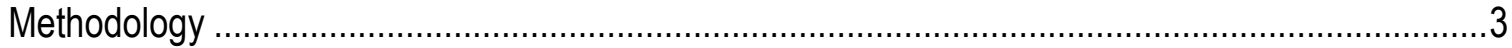

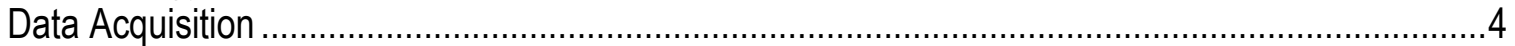

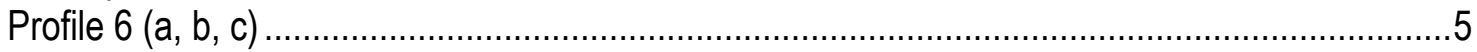

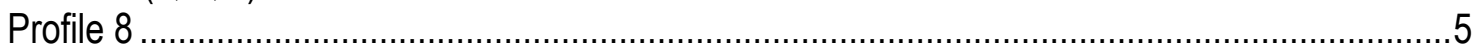

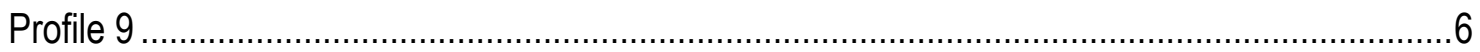

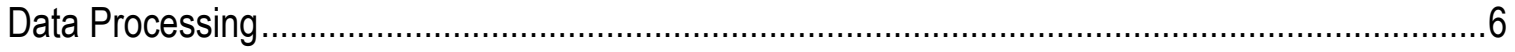

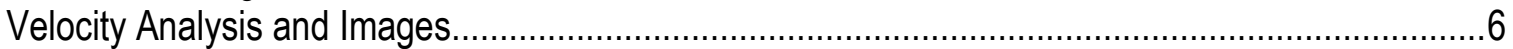

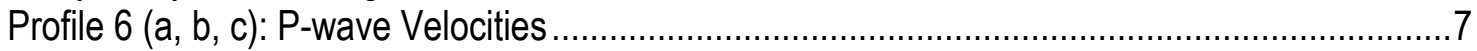

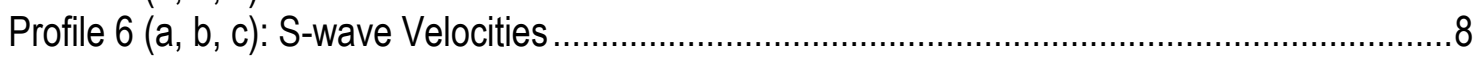

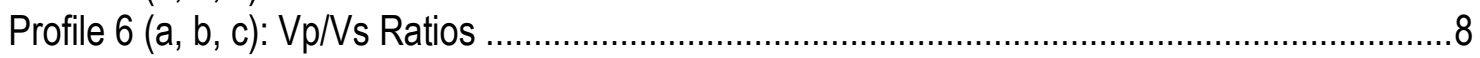

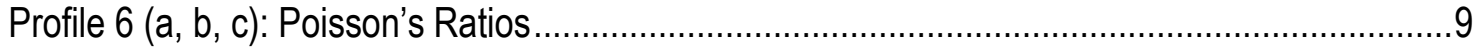

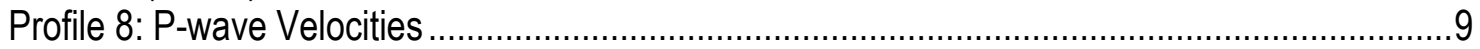

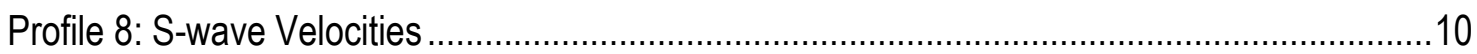

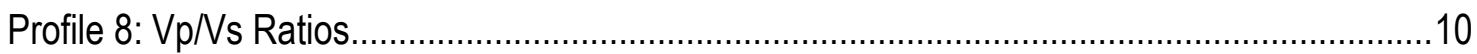

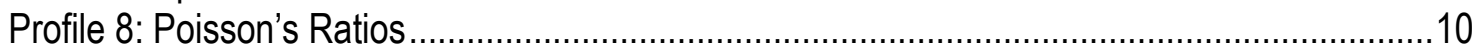

Profile 9: P-wave Velocities ...........................................................................................

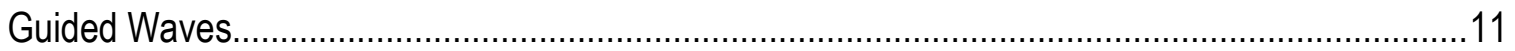

Recording Profile Line 6c: Guided Waves, P-Wave Sensors .................................................11

Recording Profile 8: Guided Waves, P-Wave Sensors ...........................................................11

Recording Profile 8: Guided Waves, S-Wave Sensors .........................................................12

Recording Profile 9: Guided Waves, P-Wave Sensors.........................................................12

Discussion and Summary of Structures Along the Profiles .....................................................13

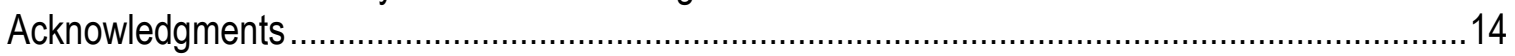

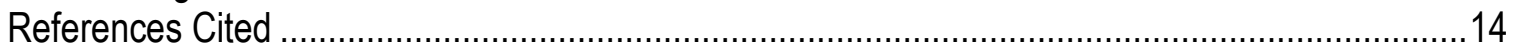

Appendix 1.Acquisition and Geometry for Profile 6a ...........................................................46

Appendix 2.Acquisition and Geometry for Profile 6b ...........................................................4

Appendix 3.Acquisition and Geometry for Profile 6c ...........................................................49

Appendix 4.Acquisition and Geometry for Profile 8 …..........................................................51

Appendix 5.Acquisition and Geometry for Profile 9 ................................................................52

\section{Figures}

1. (a) Google Earth photograph showing the locations of seismic profiles $6 a, 6 b, 6 c, 8$, and 9 that were acquired along the eastern shore of San Andreas Lake in 2008,

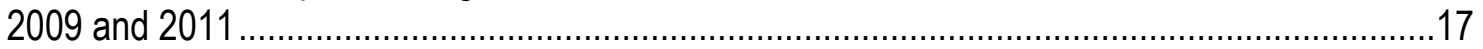

2. Google Earth photograph showing seismic profiles $6 a, 6 b$, and $6 c \ldots \ldots \ldots \ldots \ldots \ldots \ldots \ldots \ldots \ldots \ldots \ldots \ldots . . . .19$

3. (a) Google Earth photograph showing seismic profile 8 …................................................2

4. Google Earth photograph showing seismic profile $9 \ldots \ldots \ldots \ldots \ldots \ldots \ldots \ldots \ldots \ldots \ldots \ldots \ldots \ldots \ldots \ldots \ldots \ldots \ldots \ldots \ldots \ldots . .22$

5. (a) Refraction tomography P-wave velocity models for profiles $6(6 a, b, c) \ldots \ldots \ldots \ldots \ldots \ldots \ldots \ldots \ldots \ldots . .23$

6. (a) Refraction tomography S-wave velocity models for profiles $6(6 a, b, c)$ from data acquired in 2008 (profile 6a), 2009 (profile 6b) and 2011 (profile 6c). ..................................................25 
7. Photo near profile $6 \mathrm{c}$

8. (a) Vp/Vs models for profile $6(a, b, c)$, developed from the refraction tomography

$\mathrm{P}$ - and S-wave models of figures 5 and 6 .

9. (a) Poisson's ratio (PR) models for profile 6, developed from the refraction tomography P- and

S-wave models of figures 5 and 6 .

10. Refraction tomography P-wave velocity model for profile 8 with the locations of surface ruptures (at red arrows) mapped by Schussler (1906).

11. Refraction tomography S-wave velocity model for profile 8 with the locations of surface ruptures (at red arrows) mapped by Schussler (1906).

12. Vp/Vs model for profile 8 developed from the refraction tomography P- and S-waves models of figures 10 and 11

13. Poisson's Ratio (PR) model for profile 8 developed from the refraction tomography P- and Swaves models of figures 10 and 11 ...

14. Refraction tomography P-wave velocity model for profile 9 .

15. A comparison of peak-amplitude (horizontal-component) guided waves recorded along profile 8 with the S-wave velocity model for profile 6

16. A comparison of peak-amplitude (vertical-component) guided waves recorded along profile 8 with the P-wave velocity model for profile 6 .

17. A comparison of peak-amplitude (vertical-component) guided waves recorded along profile 9 with the P-wave velocity model for profile 9.

18. Map from Schussler (1906) showing off-fault displacements associated with the 1906 San Francisco earthquake at three separate locations (profiles L, N, and N') just south of San Andreas Lake (SAL). 


\section{Conversion Factors and Datums}

\section{Conversion Factors}

SI to Inch/Pound

\begin{tabular}{lll}
\hline \multicolumn{1}{c}{ Multiply } & \multicolumn{1}{c}{ By } & \multicolumn{1}{c}{ To obtain } \\
\hline millimeter $(\mathrm{mm})$ & Length & \\
meter $(\mathrm{m})$ & 0.03937 & inch (in.) \\
meter $(\mathrm{m})$ & 3.281 & foot $(\mathrm{ft})$ \\
kilometer $(\mathrm{km})$ & 1.094 & yard $(\mathrm{yd})$ \\
kilometer $(\mathrm{km})$ & 0.6214 & mile $(\mathrm{mi})$ \\
& 0.5400 & mile, nautical $(\mathrm{nmi})$ \\
\hline centimeter per second $(\mathrm{cm} / \mathrm{s})$ & Velocity & \\
meter per second $(\mathrm{m} / \mathrm{s})$ & 0.03281 & foot per second $(\mathrm{ft} / \mathrm{s})$ \\
\hline
\end{tabular}

\section{Datum}

Vertical coordinate information is referenced to the World Geodetic System of 1984 (WGS84) datum. 


\title{
Fine-Scale Delineation of the Location of and Relative Ground Shaking within the San Andreas Fault Zone at San Andreas Lake, San Mateo County, California
}

\author{
R.D. Catchings, M.J. Rymer, M.R. Goldman, C.S. Prentice, and R.R. Sickler
}

\section{Executive Summary}

The San Francisco Public Utilities Commission is seismically retrofitting the water delivery system at San Andreas Lake, San Mateo County, California, where the reservoir intake system crosses the San Andreas Fault (SAF). The near-surface fault location and geometry are important considerations in the retrofit effort. Because the SAF trends through highly distorted Franciscan mélange and beneath much of the reservoir, the exact trace of the 1906 surface rupture is difficult to determine from surface mapping at San Andreas Lake. Based on surface mapping, it also is unclear if there are additional fault splays that extend northeast or southwest of the main surface rupture. To better understand the fault structure at San Andreas Lake, the U.S. Geological Survey acquired a series of seismic imaging profiles across the SAF at San Andreas Lake in 2008, 2009, and 2011, when the lake level was near historical lows and the surface traces of the SAF were exposed for the first time in decades. We used multiple seismic methods to locate the main 1906 rupture zone and fault splays within about 100 meters northeast of the main rupture zone. Our seismic observations are internally consistent, and our seismic indicators of faulting generally correlate with fault locations inferred from surface mapping. We also tested the accuracy of our seismic methods by comparing our seismically located faults with surface ruptures mapped by Schussler (1906) immediately after the April 18, 1906 San Francisco earthquake of approximate magnitude 7.9; our seismically determined fault locations were highly accurate. Near the reservoir intake facility at San Andreas Lake, our seismic data indicate the main 1906 surface rupture zone consists of at least three near-surface fault traces. Movement on multiple fault traces can have appreciable engineering significance because, unlike movement on a single strike-slip fault trace, differential movement on multiple fault traces may exert compressive and extensional stresses on built structures within the fault zone. Such differential movement and resulting distortion of built structures appear to have occurred between fault traces at the gatewell near the southern end of San Andreas Lake during the 1906 San Francisco earthquake (Schussler, 1906). In addition to the three fault traces within the main 1906 surface rupture zone, our data indicate at least one additional fault trace (or zone) about 80 meters northeast of the main 1906 surface rupture zone. Because ground shaking also can damage structures, we used fault-zone guided waves to 
investigate ground shaking within the fault zones relative to ground shaking outside the fault zones. Peak ground velocity (PGV) measurements from our guided-wave study indicate that ground shaking is greater at each of the surface fault traces, varying with the frequency of the seismic data and the wave type (P versus S). S-wave PGV increases by as much as 5-6 times at the fault traces relative to areas outside the fault zone, and Pwave PGV increases by as much as 3-10 times. Assuming shaking increases linearly with increasing earthquake magnitude, these data suggest strong shaking may pose a significant hazard to built structures that extend across the fault traces. Similarly complex fault structures likely underlie other strike-slip faults (such as the Hayward, Calaveras, and Silver Creek Faults) that intersect structures of the water delivery system, and these fault structures similarly should be investigated.

\section{Introduction}

The active strand of the San Andreas Fault (SAF) trends beneath and along the eastern shore of San Andreas Lake on the San Francisco Peninsula near San Francisco, California (figs. 1a and 1b). Intake pipes used by the San Francisco Public Utilities Commission (SFPUC) extend from San Andreas Lake across the active strand of the SAF. To retrofit the water delivery system and make it more resistant to failure associated with ground rupture, knowledge of the location of the SAF and associated near-surface fault traces is needed. This report presents results from seismic imaging studies at San Andreas Lake that were undertaken in 2008, 2009, and 2011.

In June 2011, the U.S. Geological Survey acquired a series of seismic imaging profiles across the 1906 surface rupture area of the SAF at San Andreas Reservoir in San Mateo County, California, approximately 20 km southwest of downtown San Francisco. Each year when the seismic data were acquired, water levels were lowered to near historical levels, progressively exposing the surface traces of the 1906 SAF rupture zone at San Andreas Lake for the first time in decades. The relatively low water levels permitted detailed land-based imaging of the fault zone using advanced seismic techniques. The objectives of the seismic surveys were to:

1. Delineate in fine-scale (about $1 \mathrm{~m}$ ), near-surface principal and auxiliary traces of the SAF at San Andreas Lake (where possible) using seismic imaging methods, including (a) tomographic P-wave velocity imaging, (b) tomographic S-wave velocity imaging, (c) P-wave velocity divided by S-wave velocity $(\mathrm{Vp} / \mathrm{Vs})$ ratio imaging, (d) Poisson's ratio imaging, (e) seismic reflection imaging (where possible), and (f) fault-zone guided wave imaging.

2. Measure ground shaking and peak amplitudes of seismic waves within the nearsurface fault zone using fault zone guided waves and to compare the relative ground shaking within and outside of individual fault zones.

3. Correlate geologically mapped faults with seismic indicators (high $\mathrm{Vp} / \mathrm{Vs}$ and Poisson's ratios, diffractions, offset reflections, low S-wave velocities, changes in topography, and localized high amplitudes from guided waves) to evaluate the accuracy of previously mapped faults.

4. Determine the subsurface geometry of faults near the main surface rupture resulting from the 1906 earthquake.

We originally planned to accomplish these objectives by acquiring two faultcrossing seismic profiles near the proposed intake facility (see fig. 1). However, because 
of the unusual opportunity to directly image the SAF and to better understand its threedimensional complexities, we instead acquired three separate seismic profiles in 2011 and combined our 2011 findings with two additional profiles (profiles 6a and 6b, acquired in 2008 and 2009, respectively).

\section{Methodology}

In many locations, standard seismic reflection imaging is ideal for locating individual fault traces; however, at San Andreas Lake, rocks within and adjacent to the fault zone consist of highly deformed Franciscan mélange. Seismic reflection methods typically cannot image such complex structures, as they have little horizontal layering required for the reflection method to yield useful results. In this study, we used highresolution refraction tomography and measurements of guided waves to characterize the fault traces along three separate profiles, which we refer to as profile 6 , profile 8 , and profile 9 (figs. 1a and 1b). Our refraction tomography method uses both P-and S-waves along profiles 6 and 8, but because of a water body in the middle of profile 9, only Pwaves were used along that profile. The refraction tomography method measures the velocities at which seismic waves travel through the subsurface, and because general classes of subsurface materials propagate seismic waves at known velocities, the subsurface materials and their physical conditions can be inferred from the velocity measurements.

We also use $\mathrm{P}$ and $\mathrm{S}$ waves to identify zones of faulting based on several criteria. First, within hard rocks, fault zones are known to transmit P-waves at significantly lower velocities than adjacent rocks that are not faulted (Aki and Lee, 1976; Mooney and Luetgert, 1982; Mooney and Ginzburg, 1986; Jarchow and others, 1994; Catchings, 1999; Catchings and others, 2002). By imaging areas of relatively low velocities in hard rock, the fault location can be inferred, especially the main trace. Such low-velocity zones (LVZs) also can occur as abrupt lateral changes in velocity, with relatively higher velocities on either side of the fault (Catchings and others, 2002, 2008, 2009, 2010). Second, fault zones typically form barriers to the lateral flow of groundwater. As a result, groundwater is typically deeper on the downslope side of the fault. From numerous studies, we have identified the top of groundwater by modeling the $1,500-\mathrm{m} / \mathrm{s}$ velocity contour (Catchings and others, 1999a, 1999b, 2000, 2006a, 2006b, 2007, 2008, 2009), which is the velocity at which P-waves travel through water (Schon, 1996). Therefore, our empirical studies have shown that an abrupt vertical step in the 1,500 m/s velocity contour typically coincides with a near-surface fault. Third, near-surface, water-saturated sediments within fault zones can mask the low P-wave velocities of fault zones, such that no near-surface low P-wave velocity zone is observed, making the fault zone less obvious in the near-surface sediments (Catchings and others, written communication, 2013).

However, $\mathrm{S}$ waves, which are much less sensitive to groundwater saturation, can be used to image the low-velocity zones near the surface, whereby the fault zone will be lower in velocity than the adjacent rocks. Fourth, mechanical faulting of rocks causes a greater reduction in S-wave velocities than $\mathrm{P}$-wave velocities, such that the ratio of $\mathrm{P}$-to $\mathrm{S}$-wave velocities can be particularly diagnostic of fault zones. Poisson's ratio, which also can be calculated from the P- and S-waves (Thomsen, 1990), also will be locally high over the fault zones. Fifth, topography usually changes across a fault zone (Catchings and others, 2010). High-precision global positioning system (GPS) measurements of the geophones 
and shot point locations can be used to construct topographic profiles across the fault zones to better observe subtle changes in topography. Sixth, guided waves are known to travel along fault zones as high-amplitude energy when the seismic source originates within the fault zone (Cormier and Spudich, 1984; Li and others, 1994; Li and Vidale, 1996; Li and others, 1997; Spudich and Olsen, 2001; Fohrmann and others, 2004). Seismic sources, placed within fault zones at appreciable epicentral distances from densely spaced seismic recording arrays that are deployed across fault zones can be used to measure relative amplitudes of energy traveling along fault zones. The locations of seismic sensors that display high-amplitude energy can be used to infer fault traces in the near surface. Where all or several of these seismic indicators of faulting coincide, individual fault traces can be strongly inferred.

\section{Data Acquisition}

To acquire high-resolution $\mathrm{P}$-wave refraction data along each profile, we used an array of Mark Products ${ }^{\mathrm{TM}}$, single-element, 40-hertz (Hz), vertical-component geophones spaced at either 1-m increments (profiles 6 and 8) or 5-m increments (profile 9). The geophones were connected to refraction cables, which were connected to one or more 60channel Geometrics RX $60^{\mathrm{TM}}$ seismographs. Both P- and S-wave seismic data were acquired along profiles 6 and 8. However, because part of profile 9 was underwater, we acquired only P-wave data along profile 9. We used Mark Products ${ }^{\mathrm{TM}}$ single-element, horizontal-component, 4.5-Hz geophones to record the $\mathrm{S}$ waves. P-wave seismic sources consisted of either 200- or 400-grain Betsy Seisgun ${ }^{\mathrm{TM}}$ shots in boreholes or sledgehammer strikes to steel plates placed on the ground. S-wave sources were generated by striking a steel or wooden block horizontally with a sledgehammer. For each of the seismic profiles, a P-wave seismic source was placed at the location of each vertical-component geophone, and an S-wave seismic source was placed at the location of every other horizontal-component geophone, with both types of sources offset laterally from each geophone by $1 \mathrm{~m}$ or less. For seisgun blasts, shot timing was determined electronically at the seismic source when a hammer, used to trigger the seisgun, electrically closed contact with the Betsy Seisgun ${ }^{\mathrm{TM}}$, sending an electrical signal by radio to the seismograph. For hammer sources, we also used an electronic trigger, which initiated when the hammer closed contact with a metal strike plate on the ground surface. To enhance the recorded seismic energy generated by hammer sources, we used multiple hammer strikes and stacked (summed) the multiple strikes into a single shot gather. For S-wave sources, we recorded two hammer strikes on each side of the aluminum block and, in the laboratory, we reversed the polarity of two of the strikes. We then stacked all four hammer blows to generate one higher amplitude shot gather. Two seconds of data for each seismic source (seisgun blast and hammer strike) were recorded in SEG-2 format on the hard drive of the seismographs during field acquisition. The data were later transferred to 4-mm tape in SEGY format for long-term storage. Each shot and geophone location (latitude, longitude, and altitude) was surveyed using a high-precision GPS, with accuracies of a few centimeters (See appendixes 1-5).

We also acquired guided-wave data along seismic profiles 6c, 8, and 9 by recording seismic energy that was generated within the known fault zone (main 1906 surface rupture zone) at profiles $6 \mathrm{c}$ and 8 . The maximum source-receiver offset was approximately $1.6 \mathrm{~km}$ for profiles $6 \mathrm{c}$ and 8 . For guided waves measured along profile 6c, 
we left the profile-6c refraction array in position with vertical-component geophones, and a seismic source $(0.45 \mathrm{~kg}$ blast) was input into the known surface rupture zone at profile 8 . For guided waves measured along profile 8 , the seismic sources were located at profile $6 \mathrm{c}$, and the data were first recorded with vertical-component geophones. We then replaced the vertical-component geophones along profile 8 with horizontal-component geophones, and the seismic source (at profile 6c) was repeated. The data were recorded along both profiles for $\sim 16$ seconds. The location of the main fault trace at profile $6 \mathrm{c}$ was determined from previous seismic measurements made prior to 2011, and the location of the main fault trace located at profile 8 was determined from the mapping of ground rupture by Schussler (1906) shortly after the 1906 earthquake.

\section{Profile $6(a, b, c)$}

Profile 6 consisted of three separate seismic profiles that were acquired in three separate phases, an approximately 120-m-long profile in October 2008 (profile 6a), an approximately 60-m-long profile in November 2009 (profile 6b), and an approximately 120-m-long profile in June 2011 (profile 6c). All these seismic profiles geographically overlapped to some degree. In 2008, we acquired the easternmost segment of profile 6 (profile 6a), which extended from the SFPUC paved access road to the 2008 San Andreas Lake shoreline (fig. 2). In 2009, the San Andreas Lake level was near historical lows, which allowed us to extend profile $6 \mathrm{~b}$ an additional $~ 50 \mathrm{~m}$ west of the 2008 seismic profile (profile 6a). In 2011, the lake level was lowered even more relative to its 2009 level, which allowed us to extend profile 6c an additional $12 \mathrm{~m}$ west of the 2009 seismic profile (profile 6b). When profile 6a was acquired in 2008, the westernmost $2 \mathrm{~m}$ of profile 6a were within water at the lake shoreline, and the westernmost $\sim 10-15 \mathrm{~m}$ of profile 6a were acquired in wet (muddy) conditions at the surface. When profile 6b was acquired, all of profile $6 \mathrm{~b}$ was dry at the surface except for the westernmost $\sim 5 \mathrm{~m}$. Thus, the geographically overlapping area with profile 6a was dry at the surface. When profile 6c was acquired, all of profile 6c was dry at the surface, except for the westernmost $7 \mathrm{~m}$. Thus, the geographically overlapping area with profiles 6a and 6b was dry at the surface. For guided waves, data were recorded on the inline recording array of profile 6c, and seismic sources (blasts) originated in the fault zone of the main SAF surface rupture at profile 8. We recorded the blasts located at profile 8 with only P-wave geophones that were deployed along profile 6. Prior to acquiring the data, we surveyed geophone and shot locations using a measuring tape. After acquisition, more precise (within plus-or-minus several centimeters) geophone and shot locations were surveyed using a GPS receiver. The geometry data for profiles $6 \mathrm{a}, 6 \mathrm{~b}$, and $6 \mathrm{c}$ are presented in appendixes 1,2 , and 3 , respectively.

\section{Profile 8}

In November 2009, we acquired an approximately 60-m-long, high-resolution, combined reflection and refraction profile (profile 8) across the SAF at a westward salient that projects into the eastern shore of San Andreas Lake, approximately $800 \mathrm{~m}$ from its southern end (fig. 3a). Profile 8 was located in the area mapped by Schussler (1906) after the 1906 earthquake, where surface rupturing occurred along several secondary traces, as well as along a main surface rupture. Profile 8 crossed the main surface rupture, a secondary rupture west of the main surface rupture, and along the projection of a secondary rupture east of the main rupture (fig. 3b). The 
refraction/reflection data along profile 8 were acquired in the same manner as described for profile 6 . The geometry data for profile 8 are presented in appendix 4 . For guided waves, data were recorded on the inline recording array of profile 8, and seismic sources (blasts) originated in the rupture zone of the 1906 main SAF surface rupture at profile 6c. We recorded the blasts at profile 6c with both $\mathrm{P}$-wave and S-wave geophones that were deployed along profile 8 . Prior to acquiring the data, we surveyed geophone and shot locations using a measuring tape. After acquisition, more precise (several centimeters) geophone and shot locations were surveyed using a GPS receiver. The geometry data for profile 8 are presented in appendix 4.

\section{Profile 9}

In June 2011, we acquired an approximately 120-m-long, high-resolution, combined reflection and refraction profile (profile 9), located approximately $1.3 \mathrm{~km}$ southeast of profile 6 and about 350 m northwest of profile 8 . Profile 9 extended from a topographic high (then a small island) within San Andreas Lake to the easternmost shore of San Andreas Lake (fig. 4). Acquisition parameters for profile 9 are included in appendix 5. P-wave seismic sources were generated by Betsy-Seisgun ${ }^{\mathrm{TM}}$ blasts (400 grain). The data were acquired in the same manner as described for profile 6 , except the shot and sensor spacing was $5 \mathrm{~m}$ instead of $1 \mathrm{~m}$ so that a longer profile could be imaged. Additionally, for the submerged section of profile 9 , geophones were placed on wooden closet rods that were inserted into the muddy bottom to prevent electrical shorts in the cable and geophone attachment. Along the area of profile 8 that was covered by water at the surface, seismic sources were placed directly within the water column, instead of in shallow boreholes. For guided waves, data were recorded on the inline recording array of profile 9, and seismic sources (blasts) originated in the rupture zone of the 1906 main SAF surface rupture at profile 8 . We recorded the blasts at profile 8 with vertical-component geophones that were deployed along profile 9 . Prior to acquiring the data, we surveyed geophone and shot locations using a measuring tape. After acquisition, more precise (several centimeters) geophone and shot locations were surveyed using a GPS receiver. The geometry data for profile 9 are presented in appendix 5. S waves were not recorded along profile 9 because of the water body located in the middle of the seismic profile.

\section{Data Processing}

Shots along each seismic profile were assembled into shot gathers by merging data from each seismograph, where needed. We developed refraction tomography velocity images by measuring the first-arrival seismic energy on each seismogram from each shot along each of the seismic profiles and inverting those arrivals for velocity structure using the refraction tomography code of Hole (1992). Because of the relatively long recording array (240 channels or 1,200 m), both reflection and refraction data were simultaneously acquired. We processed the seismic data as shallow-depth refraction tomography velocity images and reflection images. However, as expected, the reflection images did not provide usable results because of the complex geology.

\section{Velocity Analysis and Images}

To develop tomographic P-wave seismic velocity models of the subsurface along the SFPUC seismic profiles, we inverted first-arrival travel times using seismograms 
from shot gathers along each seismic profile. In parameterizing the models for profiles 6 and 8 , we used 1-m by 1-m horizontal and vertical grid spacings, and for profile 9, we used 5-m by 5-m horizontal and vertical grid spacings. All models used 2-D starting models derived from composite 1-D velocity models, calculated from shot gathers. Multiple 2-D starting velocity models consistently yielded similar 2-D final velocity models, suggesting that the velocity structures are well resolved. Although only two reversing raypaths are required to obtain accurate velocities, the model is best resolved where we have the highest density of ray coverage. The minimum depth of velocity imaging is related to the shot and geophone spacings, the model grid spacing, the frequency of the data, and the amount of smoothing used in modeling. The maximum distance that clear first-arrival refractions could be measured on the shot gathers limited the maximum depth of velocity imaging. P-wave refractions typically penetrate to depths equal to about 25 percent of the maximum distance first arrivals can be measured, resulting in maximum imaging depths of about 10-40 m along most of our profiles.

\section{Profile 6 (a, b, c): P-wave Velocities}

Because profiles $6 \mathrm{a}, 6 \mathrm{~b}$, and 6c were acquired along the same approximate trend, we show the profiles as a composite (figs. 5a, 5b, 6a, 6b, 8a, 8b, 9a, and 9b). The presence of water in the subsurface significantly increases seismic P-wave velocities. As a result, areas that were wet during the acquisition phase (2008) of profile 6a have higher P-wave velocities than the same areas that were dry in 2009 and 2011, when the lake level had been lowered. Such a change in velocity is observed at the overlapping southwestern end of profile 6a and the northeastern ends of profiles $6 \mathrm{~b}$ and 6c. These differences in P-wave velocities necessarily affect the Vp/Vs and Poisson's ratios (figs. 8a, 8b, 9a, and 9b). However, at multiple locations along the profile-6 composite, abrupt lateral P-wave velocity variations occur that are consistent with faulting. Along profile 6a, P-wave velocities in the upper $40 \mathrm{~m}$ range from about 500 to 4,200 m/s (fig. 5a). Because water-saturated sediments typically have a minimum P-wave velocity of 1,500 $\mathrm{m} / \mathrm{s}$, empirical observations have shown that the $1,500-\mathrm{m} / \mathrm{s}$ velocity contour coincides with the top of groundwater in the subsurface. Empirical data also show that abrupt vertical variations in the depth to the top of groundwater $(1,500-\mathrm{m} / \mathrm{s}$ contour; see white contour in fig. 5a) often coincide with the subsurface faulting. Along profile 6, the top of groundwater $(1,500 \mathrm{~m} / \mathrm{s}$, not including perched or thin aquifers) is offset by about $5 \mathrm{~m}$ near meter 45 of the profile $6 a$ (fig. 5a). The increase in depth of the $1,500 \mathrm{~m} / \mathrm{s}$ velocity contour coincides with the edge of a local basin between meters 20 and 40 of the seismic profile and also is near an abrupt change in topographic slope. Additionally, at depths of about 10-20 m below the surface, there is a well-defined low-velocity zone with a slight dip to the east. From the surface to the base of the P-wave velocity model for profile 6a, there is a large collective change in the velocity model near meter 45 that is consistent with other seismically imaged known fault zones. Along profile $6 \mathrm{~b}$ (fig. 5a), there are similar abrupt variations in P-wave velocities near meters 23, 42, and 60 of the seismic profile. At each of those locations, there is a near-surface thickening of low-velocity rocks, an abrupt vertical step in the $1,500 \mathrm{~m} / \mathrm{s}$ velocity contour (groundwater), and abrupt lateral variations (or a pronounced low-velocity zone) in the higher velocity rocks at depth. The location of the main 1906 surface rupture of the SAF, as inferred by geomorphic evidence, is approximately located near meter 23 of seismic profile $6 \mathrm{~b}$. 
There, near-surface higher P-wave velocities (including the $1,500 \mathrm{~m} / \mathrm{s}$ velocity contour) abruptly deepen to the west, and there is an overall westward decrease in P-wave velocities to the base of the velocity model. Similar variations near meters 35-40 and 5560 suggest the presence of additional near-surface fault traces within about $20 \mathrm{~m}$ of the main trace.

\section{Profile $6(a, b, c)$ : S-wave Velocities}

Along profile 6a, S-wave velocities in the upper $15 \mathrm{~m}$ range from about 160 to $650 \mathrm{~m} / \mathrm{s}$ (fig. 6a). The subsurface materials with the lowest S-wave velocities are at the easternmost end of the seismic profile (on top of the hill) and at the westernmost part of the profile, where low-velocity (less than $250 \mathrm{~m} / \mathrm{s}$ ) deposits are about $7 \mathrm{~m}$ thick. The rocks with the highest velocities occur within a few meters of the surface along the slope of the hill along profile 6 a. These higher velocity rocks appear to be segmented at about meter 60 of profile $6 \mathrm{a}$, with an apparent 5-m-wide low-velocity zone that likely results from faulting. At about meter 40, the high-velocity rocks abruptly deepen, which also is consistent with faulting at that location. Along profile $6 \mathrm{~b}$, the $\mathrm{S}$-wave velocities range from about 160 to about $340 \mathrm{~m} / \mathrm{s}$ (fig.6a). Near-surface S-wave velocity contours are highly variable, which is consistent with the highly variable rock types and distorted strata observed at the surface (fig. 7). Below about $5 \mathrm{~m}$ depth, relatively higher velocity rocks also form complex structures, with an eastward-dipping wedge of higher velocity rocks that projects toward the surface near about meter 15 of the seismic profile. Velocities along profile 6c range from about 180 to about $480 \mathrm{~m} / \mathrm{s}$ (fig. 6b). In the near surface, the velocity contours are highly variable, as observed along profile $6 \mathrm{~b}$, and the deeper, higher velocity rocks are offset to greater depths west of meter 30 on the western side of the seismic profile. The observed S-wave velocity structures along profile 6a suggest near-surface faults between meters 30 and 50 and possibly another fault near the western end of profile 6a. Along profiles $6 \mathrm{~b}$ and 6c, there are similar indicators of nearsurface faults near meter 0 of profile $6 \mathrm{~b}$ ( meter 15 of profile $6 \mathrm{c}$ ), meter 15 of profile $6 \mathrm{~b}$ ( meter 35 of profile $6 \mathrm{c}$ ), and meters $33-40$ of profile $6 \mathrm{~b}$ ( meters $53-60$ of profile $6 \mathrm{c}$ ).

\section{Profile $6(a, b, c)$ : Vp/Vs Ratios}

We developed tomographic models of $\mathrm{Vp} / \mathrm{Vs}$ ratios along profile 6 by dividing $\mathrm{P}$ wave velocities at each of the model nodes by the corresponding $S$-wave velocities (fig. 8). Along profile 6a, S-wave propagation was not as efficient as P-wave propagation, owing to the weaker source and the surface vegetation on the side of the hill. As a result, $\mathrm{S}$-wave refractions did not propagate along the entire profile, resulting in a shallower depth of velocity imaging relative to $\mathrm{P}$-wave imaging. Because the $\mathrm{Vp} / \mathrm{Vs}$ ratios are calculated on the basis of both $\mathrm{P}$ - and S-wave measurements, the $\mathrm{Vp} / \mathrm{Vs}$ ratio model could be calculated only to the maximum depth of S-wave imaging ( 10-15 $\mathrm{m}$ in depth). The highest $\mathrm{Vp} / \mathrm{Vs}$ ratios range from about 7-8.6 at depths of 5-10 m, but relatively high $\mathrm{Vp} / \mathrm{Vs}$ ratios ( 2-5) occur in the near surface at multiple locations along the three seismic profiles. In near-surface consolidated materials, we have found that relatively high $\mathrm{Vp} / \mathrm{Vs}$ ratios typically correlate with near-surface fault traces. Along profile 6a, relatively high $\mathrm{Vp} / \mathrm{Vs}$ ratios are observed near meters 50 and 10 . High near-surface $\mathrm{Vp} / \mathrm{Vs}$ ratios are observed near meters $0-10,18-$ 25 , 35-45, and 60 of profile 6b, correlating approximately with meters 18-22, 38-48, 55-65, respectively, of profile 6c (fig $8 \mathrm{~b}$ ). These areas of relatively high $\mathrm{Vp} / \mathrm{Vs}$ ratios also correlate 
with areas of relatively low S-wave velocities and vertical steps in the 1,500 m/s P-wave velocity contour (top of groundwater), all of which are consistent with the presence of nearsurface fault traces. Vp/Vs ratios vary slightly between the profiles, which likely reflect differences in the degree of groundwater saturation during the 3-year period over which the seismic data were acquired.

\section{Profile 6 (a, b, c): Poisson's Ratios}

As done with $\mathrm{Vp} / \mathrm{Vs}$ ratios, we developed tomographic models of Poisson's ratios (PR) by calculating PR (fig. 9a) from Vp and Vs at each node of the seismic models using the following calculation from Thomsen (1990):

$$
v=\mathrm{E} / 2 \mu-1=(3 \mathrm{~K}-2 \mu) /(6 \mathrm{~K}+2 \mu)=\left((\mathrm{Vp} / \mathrm{Vs})^{2}-2\right) / 2\left((\mathrm{Vp} / \mathrm{Vs})^{2}-2\right)
$$

where $v$ is Poisson's Ratio (PR),

$\mu$ is shear modulus,

E is Young's modulus,

$\mathrm{K}$ is bulk modulus,

$\mathrm{Vp}$ is P-wave velocity, and

Vs is S-wave velocity.

Poisson's ratio ranges from about 0 to 0.5 for most materials. Values near 0.5 are typical of water, but a few special rocks and minerals can have significantly higher or lower values of PR. For example, cristobalite (in volcanic rocks) can have a negative PR. Most competent rocks have variable values of PR, ranging from about 0.25 to about 0.30 . However, highly water-saturated sediments and rocks can have significantly higher values of PR, and quartz-rich rocks can have significantly lower values of PR. As related to this study, our empirical observations have shown that sediments and near-surface rocks with values of $\mathrm{PR} \sim 0.44$ generally outline the top of groundwater, and higher values coincide with highly saturated sediments and rocks. PR along the seismic profiles varies in a manner similar to that of $\mathrm{Vp} / \mathrm{Vs}$ ratios. Along profile $6 \mathrm{a}, \mathrm{PR}$ ranges from about 0.28 to about 0.49 . Relatively high near-surface values of PR are observed near meters $10-20,50$, and 115-120 in the near surface, and the highest values occur at depths about 5-10 m beneath the center of the seismic profile and beneath the western end of profile 6a. The zones of relatively high PR at depth and in the near surface also coincide with zones of faulting inferred from the other seismic images. Along profiles $6 \mathrm{~b}$ and $6 \mathrm{c}, \mathrm{PR}$ is high, ranging from about 0.46-0.49 (figs. 9a and 9b). When the seismic data were acquired, most of these rocks were highly saturated within about $0.3 \mathrm{~m}$ of the surface, so high values of PR are expected. The highest near-surface values of PR occur near meters $\sim 5-10, \sim 40-50$, and $\sim 60-65$ along profile $6 \mathrm{~b}$, with similar geographic locations along profile 6c.

\section{Profile 8: P-wave Velocities}

Along profile 8, P-wave velocities in the upper $15 \mathrm{~m}$ range from about 350 to $3,000 \mathrm{~m} / \mathrm{s}$ (fig. 10). Low-velocity (less than 1,500 m/s) deposits vary along the profile, with a maximum thickness of about $8 \mathrm{~m}$ near the middle of the seismic profile. The 1,500 $\mathrm{m} / \mathrm{s}$ velocity contour generally coincides with the top of groundwater, and because of the importance of groundwater in delineating fault structures, the $1,500 \mathrm{~m} / \mathrm{s}$ contour is 
highlighted here in white. At the time of data acquisition, the top of groundwater $(1,500$ $\mathrm{m} / \mathrm{s}$ ) (not including perched or thin aquifers) was about $3 \mathrm{~m}$ deeper beneath the area of the main SAF trace, near the middle of the profile, and near the westernmost end of the seismic profile. The depth to the top of groundwater was not only determined on the basis of the $1,500 \mathrm{~m} / \mathrm{s}$ velocity contour but also measured near the center of the seismic profile by auguring. However, because the area of the seismic profile is a salient that extends outward into San Andreas Lake and the topography is relatively flat, there is not a general downslope flow of groundwater. As a result, abrupt vertical offsets of the top of groundwater are absent, as seen along profile 6 . The approximate known location of the main trace of the SAF coincides with a 5- to 10-m-wide P-wave low-velocity zone near the center of the profile at a depth of 5-10 m.

\section{Profile 8: S-wave Velocities}

Along profile 8, S-wave velocities in the upper $15 \mathrm{~m}$ range from about 180 to 450 $\mathrm{m} / \mathrm{s}$ (fig. 11). Near the center of the seismic profile, S-wave velocities show a welldefined, low-velocity zone approximately centered over the 1906 main surface rupture of the SAF. The low-velocity zone is about $25 \mathrm{~m}$ wide based on matching highest velocities on either side, but it is about $5 \mathrm{~m}$ wide based on the lowest velocities near the surface. Unlike P-waves, which are influenced by the presence of water, S-wave low-velocity zones can indicate faulted strata and rocks from the surface to great depths. The abrupt termination of higher velocity rocks on either side of the low-velocity zone suggests individual faults at those locations. Relative to the remainder of the seismic profile, the westernmost end of the profile has the highest velocities, where Franciscan rocks are exposed at the surface. The overall relatively low S-wave velocities suggest that most of the subsurface materials are sediments or sedimentary rocks.

\section{Profile 8: Vp/Vs Ratios}

$\mathrm{Vp} / \mathrm{Vs}$ ratios for profile 8 were determined in much the same manner as described for profile $6 . \mathrm{Vp} / \mathrm{Vs}$ ratios range from about 2 near the surface to more than 9 at depths of about 8-10 $\mathrm{m}$ below the surface (fig. 12). The two highest zones of $\mathrm{Vp} / \mathrm{Vs}$ ratios are separated by a relatively low $\mathrm{Vp} / \mathrm{Vs}$ zone, where $\mathrm{P}$ and $\mathrm{S}$ waves infer a low-velocity zone (fault). The nearest surface materials have $\mathrm{Vp} / \mathrm{Vs}$ ratios of about 2 and are not suggestive of strata disrupted by faulting. However, at a depth of about $6 \mathrm{~m}$, prominent zones of high $\mathrm{Vp} / \mathrm{Vs}$ ratios are centered below the eastern areas of faulting observed in 1906 . The westernmost zone of surface rupturing, however, does not include high $\mathrm{Vp} / \mathrm{Vs}$ ratios at the scale of our image.

\section{Profile 8: Poisson's Ratios}

Poisson's ratios for profile 8 were determined in much the same manner as described for profile 6 . PR values range from less than 0.1 in the very near surface to 0.48 at depths of about 5-7 $\mathrm{m}$ (fig. 13). The general pattern of PR largely coincides with the $1,500 \mathrm{~m} / \mathrm{s}$ velocity contour, suggesting that $\mathrm{PR}$ is most sensitive to groundwater along profile 8. In the near surface, relatively high values of PR are associated with the 1906 main trace and a mapped surface break near the western end of the seismic profile, but the projected fault east of the 1906 main trace does not show such high PR values. 


\section{Profile 9: P-wave Velocities}

Along profile 9, P-wave velocities in the upper $30 \mathrm{~m}$ range from about $800 \mathrm{~m} / \mathrm{s}$ to $3,600 \mathrm{~m} / \mathrm{s}$ (fig. 14). Near-surface, low-velocity (less than 1,500 m/s) deposits are concentrated at the 2011 San Andreas Lake shoreline and on the high topographic (island) feature to the northwest. Based on P-wave velocities, we interpret unconsolidated sediments to be up to about 5-10 m thick. The top of groundwater $(1,500 \mathrm{~m} / \mathrm{s})$ varies considerably along the profile, ranging from the near surface at the eastern end of the seismic profile, beneath the water body, and near the western end of the profile, to about 5-10 m thick beneath the island topographic high and at the 2011 shoreline. Abrupt changes in the depth of the $1,500 \mathrm{~m} / \mathrm{s}$ velocity contour occur a few meters east of the 1906 mapped main fault trace, at the western end of the seismic profile, and a few meters east of the water body. At depth, relative low-velocity zones are located at about meter 100 and about meter 20 of the seismic profile. The presence of the higher velocity rocks suggests that near-surface faults are located near meters 20, 70, and 140 . The P-wave seismic tomography velocity image largely coincides with the P-wave velocity image seen along profile 8, particularly near the main 1906 rupture.

\section{Guided Waves}

We recorded seismic energy along profiles 6c, 8, and 9 from sources that were located within the known SAF zone at profiles 6 and 8. For data recorded along profiles $6 \mathrm{c}$ and 8 , the source was about $1.6 \mathrm{~km}$ from the recording arrays. For profile 9 , the source was about $0.35 \mathrm{~km}$ from the recording array.

\section{Recording Profile Line 6c: Guided Waves, P-Wave Sensors}

We recorded guided waves along profile 6c using only vertical-component geophones, with sources located at profile 8 (figs. 5, 6, 8, and 9). For each geophone along profile 6c, we measured peak amplitudes at varying frequencies, and we recorded the time after the first arrival that the peak amplitude (velocity) was measured. In general, peak amplitudes typically were measured between 1 and 3 seconds (s) after the first arrival for $\mathrm{S}$ waves and about $0.2-1 \mathrm{~s}$ after the first arrival for $\mathrm{P}$ waves, suggesting that most of the high-amplitude energy likely resulted from seismic energy trapped within the fault zone. Plots of peak amplitude as a function of distance along profile 6c show that relatively high amplitudes are localized at multiple locations along the profile. In particular, relatively high amplitudes are located within a range of discrete distances, such as meters 16-18, 28-40, and 50-62, which approximately coincide with the faulttrace locations inferred from other data and discussed above in sections on P- and S-wave velocities, $\mathrm{Vp} / \mathrm{Vs}$ ratios, and Poisson's ratios. At higher frequencies, amplitude peaks generally become more localized (figs. 5, 6, 8, and 9), suggesting that individual nearsurface fault traces are imaged at progressively shallower depths with the increasingly higher frequencies. Peak ground velocities were about 2.5-3 times greater over the fault traces relative to the other areas of the seismic profile.

\section{Recording Profile 8: Guided Waves, P-Wave Sensors}

Guided waves were recorded along profile 8 using vertical and horizontal geophones along profile 8 and sources located at profile 6c (figs. 15 and 16). The peak 
amplitude energy was recorded between 0.1 and $0.5 \mathrm{~s}$ after the first arrivals on the vertical-component geophones (fig. 15). Because we observed this energy with verticalcomponent geophones, we theorize that the localized zones of high-amplitude energy correspond to P-wave seismic energy that is trapped within fault strands in the shallow subsurface. The locations of the highest amplitude energy vary from about meter 50 to about meter 28 of the seismic profile when the data are filtered from about 1 to $40 \mathrm{~Hz}$. We interpret the lateral variation in peak amplitude as resulting from a northeast-dipping fault zone, whereby the lower frequencies respond to deeper parts of the fault, and the higher frequencies correlate with shallower and narrower parts of the fault. At higher frequencies, there are areas of peak amplitude centered near meters 5 and 53 of the seismic profile, consistent with the locations of known secondary smaller fault traces (fig. 3) mapped by Schussler (1906). Peak ground velocities were about 6 to 8 times greater over the fault traces relative to the other areas of the seismic profile.

\section{Recording Profile 8: Guided Waves, S-Wave Sensors}

After recording the vertical-component guided waves along profile 8, we substituted horizontal-component geophones for the vertical-component geophones and repeated the shots located at profile 6 . We measured peak amplitudes along profile 8 for each set of geophones at differing frequencies (figs. 16a-c). Typically, peak amplitude energy was recorded between 1 and $6 \mathrm{~s}$ after the first arrival, demonstrating that these are relatively slow-moving seismic waves, as expected of guided waves traveling along the fault zone. Although surface waves conceivably could generate the same strong amplitudes, surface waves would likely generate uniformly strong amplitudes along the entire recording array. Instead, we observed relatively high-amplitude seismic energy near the surface ruptures mapped by Schussler (1906). As observed with the verticalcomponent seismic energy, the apex of the peak amplitudes near the main surface rupture varied laterally with frequency, such that the apex varied from west to east across the rupture zone and became more localized with increasing frequency. Strong peak amplitudes also were observed near meter 7 and near meter 50 for higher frequency data. Peak ground velocities were about 3-5 times greater over the fault traces relative to the other areas of the seismic profile.

\section{Recording Profile 9: Guided Waves, P-Wave Sensors}

We recorded vertical-component guided waves along profile 9 for sources located at profile 8 (fig. 17). Because part of profile 9 was recorded within water, we limited the frequency content of the guided waves to values greater than $10 \mathrm{~Hz}$ to avoid the highamplitude, low-frequency waves in water. Generally, there are high peak amplitudes located between meters 25 and 90 (channels 5 and 18) and between meters 125 and 160 (channels 35 and 32) of the seismic profile. The main fault trace, as indicated by geomorphology, was mapped at about meter 70 of the seismic profile. The guided waves suggest multiple fault traces along the seismic profile, with fault traces associated with the topographic high within the lake and at least one fault trace near the shoreline at about meter 150 (fig. 17). These relatively high amplitudes also coincide with the edges of lowvelocity zones below about $10 \mathrm{~m}$ depth, consistent with subsurface faulting in the deeper, higher velocity rocks. Peak ground velocities were about 6-10 times greater over the fault traces relative to the other areas of the seismic profile. 


\section{Discussion and Summary of Structures Along the Profiles}

The seismic profiles show evidence of complex faulting within about $100 \mathrm{~m}$ of the 1906 surface rupture zone of the San Andreas Fault at San Andreas Lake. Our most detailed seismic information was at profile 6, which is our closest seismic imaging site to the intake system at San Andreas Lake. Along profile 6, our data indicate at least three near-surface fault traces within about $20 \mathrm{~m}$ of the main 1906 surface rupture and an apparent fault zone located about 80 m east of the main 1906 surface rupture. A relatively wide zone of faulting near the main 1906 surface rupture also is consistent with observations by Schussler (1906) shortly after the 1906 San Francisco earthquake (fig. 18). Our seismic indications of multiple near-surface fault traces included:

Abrupt variations in the depth of P-wave velocity contours in the near surface, particularly the $1,500 \mathrm{~m} / \mathrm{s}$ velocity contour, which also is consistent with the depth to the top of groundwater. Because most faults form barriers to groundwater flow, vertical variations in the depth to groundwater across faults, such as those observed, are expected.

Abrupt variations in deeper, higher-velocity P-wave velocity rocks, including lowvelocity zones. At depths of approximately 5-10 m below the surface, we observe multiple zones with an abrupt termination of the higher velocity rocks, which generally coincide with other indicators of faulting.

Abrupt topographic variations that coincide with the seismic variations described in item numbers 1 and 2.

Abrupt variations in S-wave velocities; the presence of S-wave low-velocity zones that coincide with item numbers $1-3$; or both.

Areas of relatively high Vp/Vs and Poisson's ratios that coincide with items numbers 14.

Geographical locations of high peak amplitudes, consistent with guided-wave energy traveling along the fault zones, which coincide geographically with item numbers 15.

Collectively, these indicators delineate several near-surface fault traces that extend over distances of at least $80 \mathrm{~m}$ from the main 1906 surface rupture. We also observed similar evidence of a wide $(\sim 80 \mathrm{~m})$ area of faulting along profiles 8 and 9 . For example, along profile 8, multiple mapped surface breaks associated with the 1906 San Francisco earthquake (Schussler, 1906) coincide with our seismic indicators described above. On the basis of the coincidence of the seismic indicators and Schussler's map, we suggest three near-surface fault strands within $20 \mathrm{~m}$ of the main 1906 surface rupture along profile 8. Along profile 9, we have fewer data, but there is similar evidence for multiple zones of near-surface faulting. For example, in addition to the 1906 main surface rupture located near meter 70 of the seismic profile, our data suggest an additional nearsurface fault trace located about $80 \mathrm{~m}$ to the east and a third near-surface fault trace near the apex of the topographic high located within San Andreas Lake. Based on the apparent fault geometry, the topographic high likely is a result of differential movement on the faults, resulting in a "push-up ridge."

Our study suggests that there are multiple near-surface fault traces within about 80-100 m of the 1906 main surface rupture, and based on observations after the 1906 
earthquake (Schussler, 1906), these fault traces should be considered capable of moving during future earthquakes (fig. 18). Furthermore, differential movement on sub-parallel fault strands can result in complex shearing involving both compressive and extensional stresses. Similar shearing appears to have occurred at the southern end of San Andreas Lake at the gatewell structure during the 1906 San Francisco earthquake (see fig. 3). There, the gatewell was located between two faults, and the structure was transformed from a circular structure to a northwest-southeast-oriented oblong structure after the earthquake (Schussler, 1906). Because our studies did not extend beyond about $100 \mathrm{~m}$ from the 1906 main surface rupture, we cannot determine if there are additional secondary faults that extend beyond the area of our study. Engineering efforts and probabilistic seismic hazard assessment studies should, however, address the possibility of additional fault traces beyond $100 \mathrm{~m}$ from the main 1906 surface rupture and the types of shearing that might ensue from such fault geometries.

The guided-wave data show that ground shaking is enhanced over the individual fault traces, varying with the frequency of the seismic data and the wave type (P versus S). S-wave ground shaking increases by about 5-6 times at the fault traces relative to areas outside the fault zone, and P-wave shaking appears to increase by about 3-10 times across the same fault traces. In addition to the surface rupture hazard associated with large-magnitude earthquakes, these data suggest (assuming linearity) that such strong shaking may also pose a hazard to built structures that extend across the fault traces.

\section{Acknowledgments}

This work was jointly funded by the San Francisco Public Utilities Commission (SFPUC) and the U.S. Geological Survey's Earthquake Hazards Program through a Cooperative Research and Development Agreement (CRADA). We thank the SFPUC for field site access. We especially thank Leroy Gullette and his team for CRADA assistance, helpful suggestions, and field assistance. Thanks to John Tinsley and John Reeder for helpful reviews.

\section{References Cited}

Aki, K., and Lee, W.H.K., 1976, Determination of three-dimensional velocity anomalies under a seismic array using P-arrival times from location earthquakes-1. A homogeneous initial model: Journal of Geophysical Research, v. 81, p. 4381-4399.

Catchings, R.D., 1999, Regional Vp, Vs, Vp/Vs, and Poisson's ratios across earthquake source zones from Memphis, Tennessee to St. Louis, Missouri: Bulletin of the Seismological Society America, v. 89 p. 1591-1605.

Catchings, R.D., Borchers, J.W., Goldman, M.R., Gandhok, G., Ponce, D.A., and Steedman, C., 2006b, Subsurface structure of the East Bay Plain ground-water basin: San Francisco Bay to the Hayward fault, Alameda County, California: U.S. Geological Survey Open-File Report 2006-1084, 68 p. (Also available at http://pubs.usgs.gov/of/2006/1084/.)

Catchings, R.D., Cox, B.F., Goldman, M.R., Gandhok, G., Rymer, M.J., Dingler, J., Martin, P., Christensen, A., and Horta, E., 2000, Subsurface structure and seismic velocities as determined from high-resolution seismic imaging in Victorville, California area-Implications for water resources and earthquake hazards: U.S. Geological 
Survey Open-File Report 2000-123, 53 p. (Also available at http://pubs.er.usgs.gov/publication/ofr00123.)

Catchings, R.D., Gandhok, G., Goldman, M.R., Horta, E., Rymer, M.J., Martin, P., and Christensen, A., 1999a, Subsurface, high-resolution, seismic images from Cherry Valley, San Bernardino County, California-Implications for water resources and earthquake hazards: U.S. Geological Survey Open-File Report 99-26, 57 p. (Also available at http://pubs.er.usgs.gov/publication/ofr9926.)

Catchings, R.D., Gandhok, G., Goldman, M. R., Okaya, D., Rymer, M.J., and Bawden, G.W., 2008, Near-surface location, geometry, and velocities of the Santa Monica fault zone, Los Angeles, California: Bulletin of the Seismological Society of America, v. 98, p. 124-138.

Catchings, R.D., Gandhok, G., Goldman, M.R., and Steedman, C., 2007, Near-surface structure and velocities of the northeastern Santa Cruz Mountains and the western Santa Clara Valley, California, from seismic imaging: U.S. Geological Survey OpenFile Report 2007-1039, 70 p. (Also available at $h t t p: / / p u b s . u s g s . g o v / o f / 2007 / 1039 /$.

Catchings, R.D., Goldman, M.R., and Gandhok, G., 2006a, Structure and velocities of the northeastern Santa Cruz Mountains and the western Santa Clara Valley, California, from the SCSI-LR seismic survey: U.S. Geological Survey Open-File Report 20061014, 78 p. (Also available at $h t t p: / / p u b s . u s g s . g o v / o f / 2006 / 1014 /$.)

Catchings, R.D., Goldman, M.R., Gandhok, G., Horta, E., Rymer, M.J., Martin, P., and Christensen, A., 1999b, Structure, velocities, and faulting relationships beneath San Gorgonio Pass, California—Implications for water resources and earthquake hazards: U.S. Geological Survey Open-File Report 99-568, 53 p. (Also available at http://pubs.er.usgs.gov/publication/ofr99568.)

Catchings, R.D., Rymer, M.J., Goldman, M.R., and Gandhok, G., 2009, San Andreas Fault geometry at Desert Hot Springs, California, and its effects on earthquake hazards and groundwater: Bulletin of the Seismological Society of America, v. 99, p. 21902207.

Catchings, R.D., Rymer, M.J., Goldman, M.R., Gandhok, G., and Bawden, G.W., 2010, Reply to "Comment on 'Near-surface location, geometry, and velocities of the Santa Monica fault zone, Los Angeles, California' by R.D. Catchings, G. Gandhok, M.R. Goldman, D. Okaya, M.J. Rymer, and G.W. Bawden” by T.L. Pratt and J.F. Dolan: Bulletin of the Seismological Society of America, v. 100, p. 2338-2347.

Catchings, R.D., Rymer, M.J., Goldman, M.R., Hole, J.A., Huggins, R., and Lippus, C., 2002, High-resolution seismic velocities and shallow structure of the San Andreas Fault Zone at Middle Mountain, Parkfield, California: Bulletin of the Seismological Society of America, v. 92, p. 2493-2503.

Cormier, V.F., and Spudich, P., 1984, Amplification of ground motion and waveform complexity in fault zones-Examples from the San Andreas and Calaveras Faults: Geophysical Journal of the Royal Astronomical Society, v. 79, no. 1, p. 135-152 Fohrmann, M., Ingel, H., Jahnke, G., and Ben-Zion, Y., 2004, Guided waves from sources outside faults-An indication for shallow fault zone structure?: Pure and Applied Geophysics, v. 161, p. 2125-2137,doi:10.1007/s00024-004-2553-y.

Hole, J.A., 1992, Nonlinear high-resolution three-dimensional seismic travel time tomography: Journal of Geophysical Research, v. 97, p. 6553-6562. 
Jarchow, C.M., Catchings, R.D., and Lutter, W.J., 1994, Large-explosive source, widerecording aperture, seismic profiling on the Columbia Plateau, Washington:

Geophysics, v. 59, p. 259-271.

Li, Y.-G., Aki, K., Adams, D., Hasemi, A., and Lee, W.H.K., 1994, Seismic guided waves trapped in the fault zone of the Landers, California, earthquake of 1992: Journal of Geophysical Research, v. 99, p. 11705-11725.

Li, Y.-G., Ellsworth, W.L., Thurber, C.H., Malin, P.E., and Aki, K., 1997, Fault-zone guided waves from explosions in the San Andreas Fault at Parkfield and Cienega Valley, California: Bulletin of the Seismological Society of America, v. 87, p. 210221.

Li, Y.-G., and Vidale, J.E., 1996, Low-velocity fault-zone guided waves-Numerical Investigations of trapping efficiency: Bulletin of the Seismological Society of America, v. 86, p. 371-378.

Mooney, W.D., and Ginzburg, A., 1986, Seismic measurements of the internal properties of fault zones: Pure and Applied Geophysics, v. 124, p. 141-157.

Mooney, W.D., and Luetgert, J.H., 1982, A seismic refraction study of the Santa Clara Valley and southern Santa Cruz Mountains, west-central California: Bulletin of the Seismological Society of America, v. 72, p. 901-909.

Schon, J.H., 1996, Physical properties of rocks-Fundamentals and principles of petrophysics, Handbook of geophysical exploration-Seismic Exploration, Volume 18: Tarrytown, New York, Elsevier Science, Inc.

Schussler, H., 1906, The water supply of San Francisco, California, before, during, and after the earthquake of April 18, 1906 and the subsequent conflagration: New York, Martin B. Brown Press, 103 p.

Spudich, P., and Olsen, K.B., 2001, Fault zone amplified waves as a possible seismic hazard along the Calaveras fault in central California, Geophysical Research Letters, v. 28, p. 2533-2536.

Thomsen, L., 1990, Poisson was not a geophysicist!: The Leading Edge, v. 9, no. 12, p. 27-29, doi:10.1190/1.1439706. 


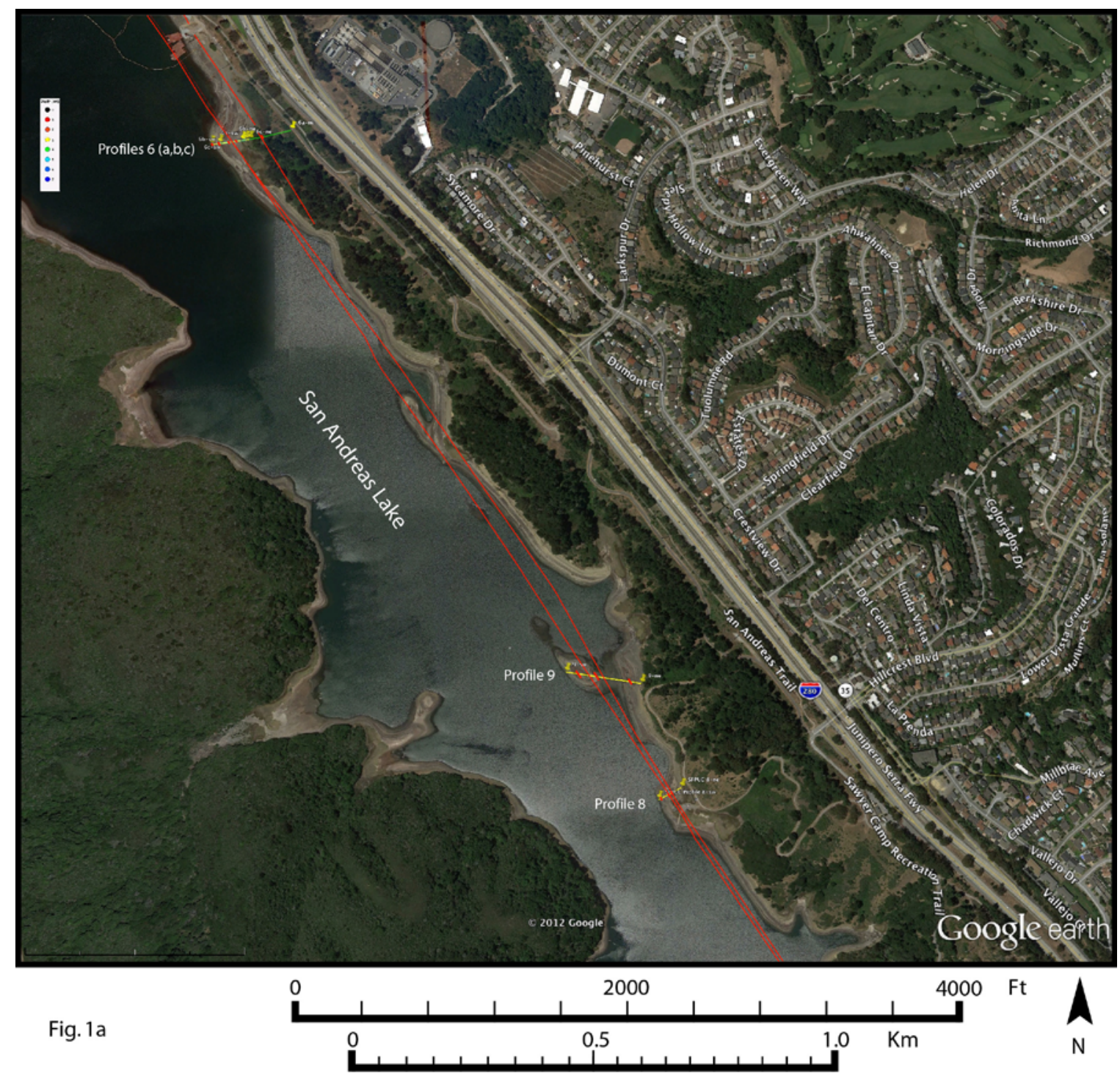

Figure 1. (a) Google Earth ${ }^{\mathrm{TM}}$ photograph showing the locations of seismic profiles $6 \mathrm{a}, 6 \mathrm{~b}, 6 \mathrm{c}, 8$, and 9 that were acquired along the eastern shore of San Andreas Lake in 2008, 2009 and 2011. The northeast-southwest-oriented yellow and green lines show the locations of the seismic profiles. The thin red lines trending through the seismic profiles are the mapped (California Holocene Fault database) locations of the principal surface traces of the San Andreas Fault. (b) Same figure as shown in figure 1a, with the locations of small charges (stars) used to generate guided waves are shown. 


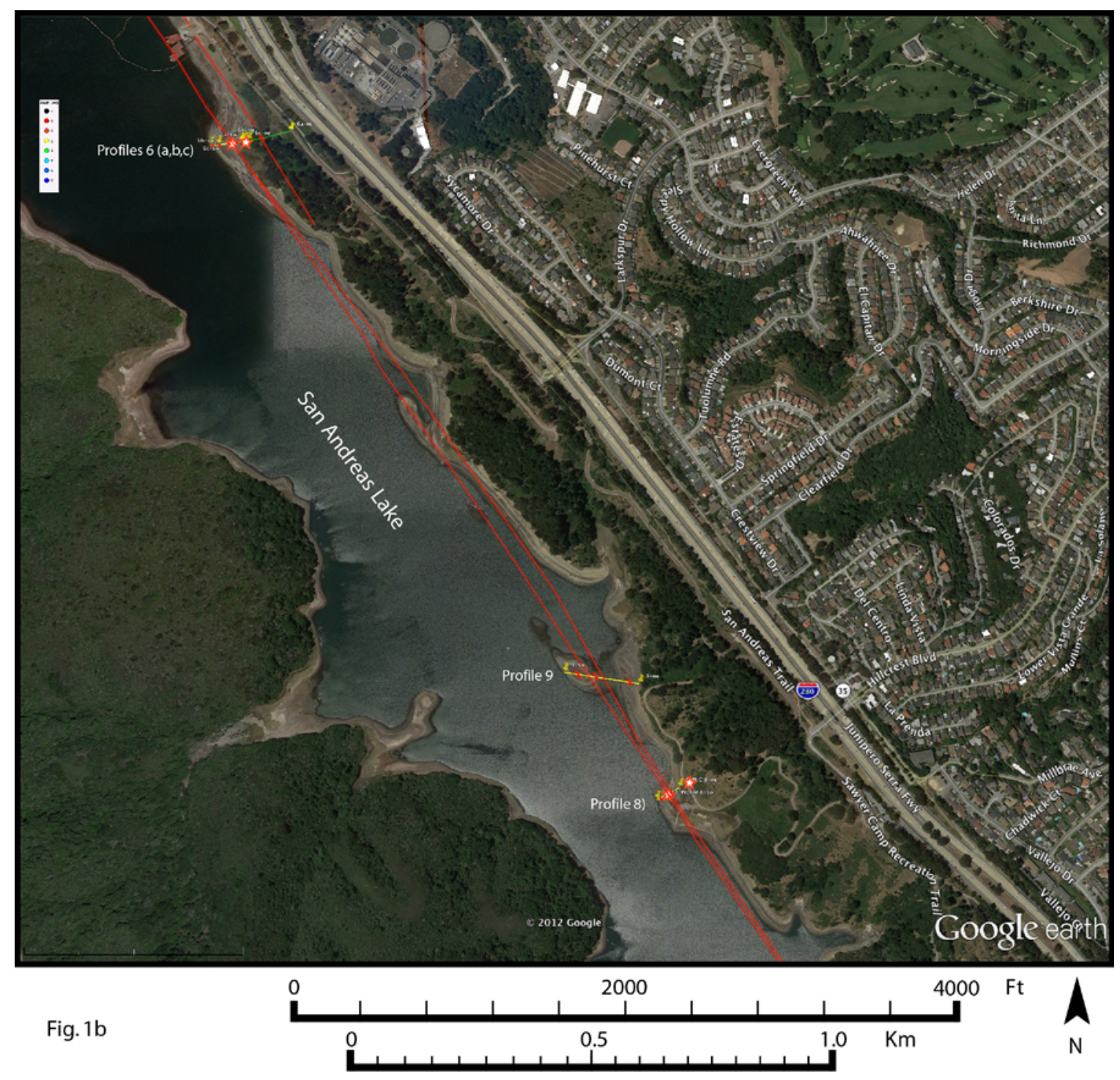

Figure 1. -Continued 


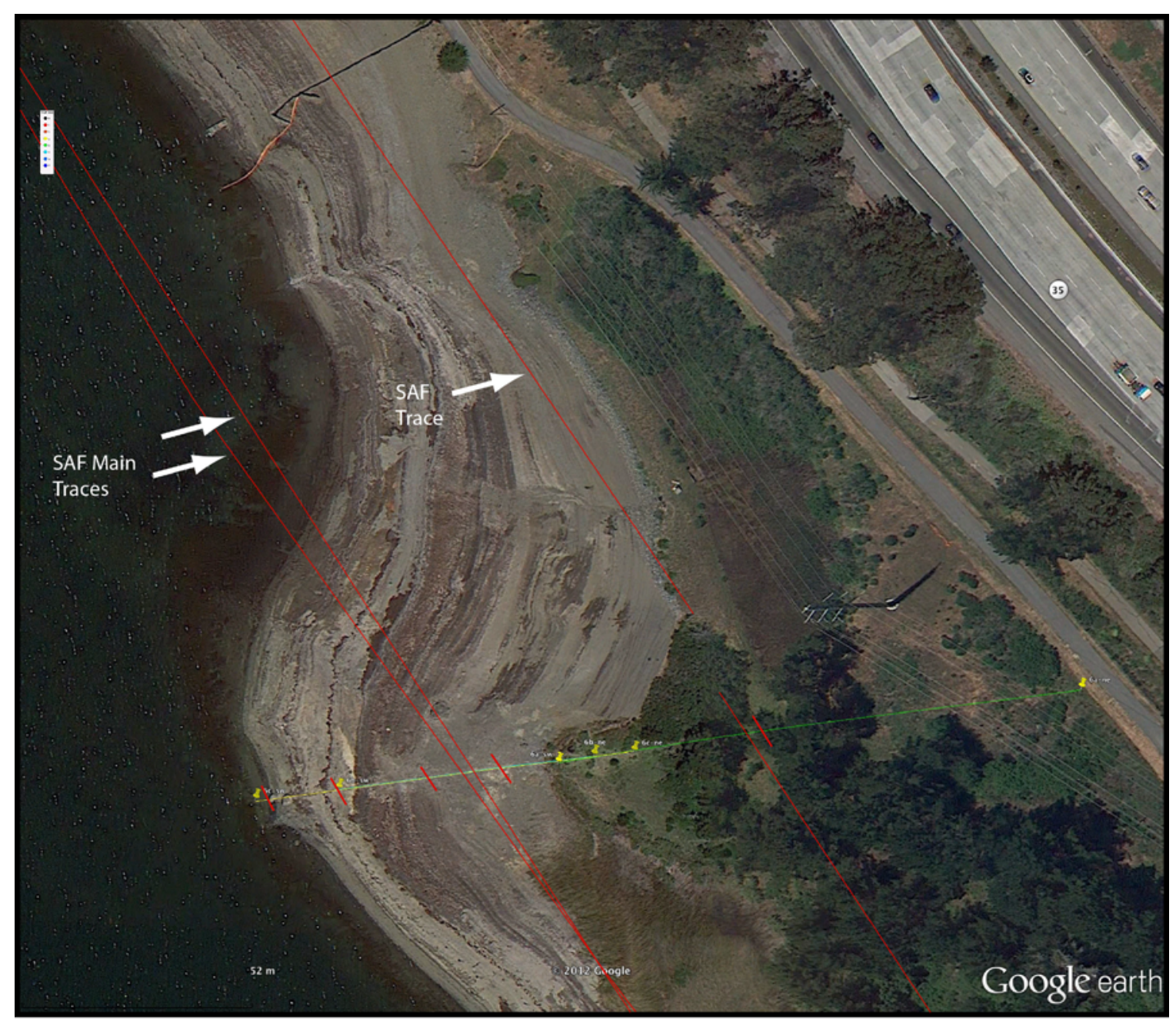

Fig. 2

Figure 2. Google Earth ${ }^{\mathrm{TM}}$ photograph showing seismic profiles $6 \mathrm{a}, 6 \mathrm{~b}$, and $6 \mathrm{c}$ (yellow and green lines). The approximate locations of faults inferred from geomorphology are shown as the thin red lines (California Holocene Fault database). White arrows also point to the mapped faults. The locations of faults imaged seismically are shown as the short and thicker red line segments. Multiple near-surface faults are imaged near the main 1906 surface rupture and at least one additional fault is imaged about 80 meters northeast of the 1906 surface rupture area. 


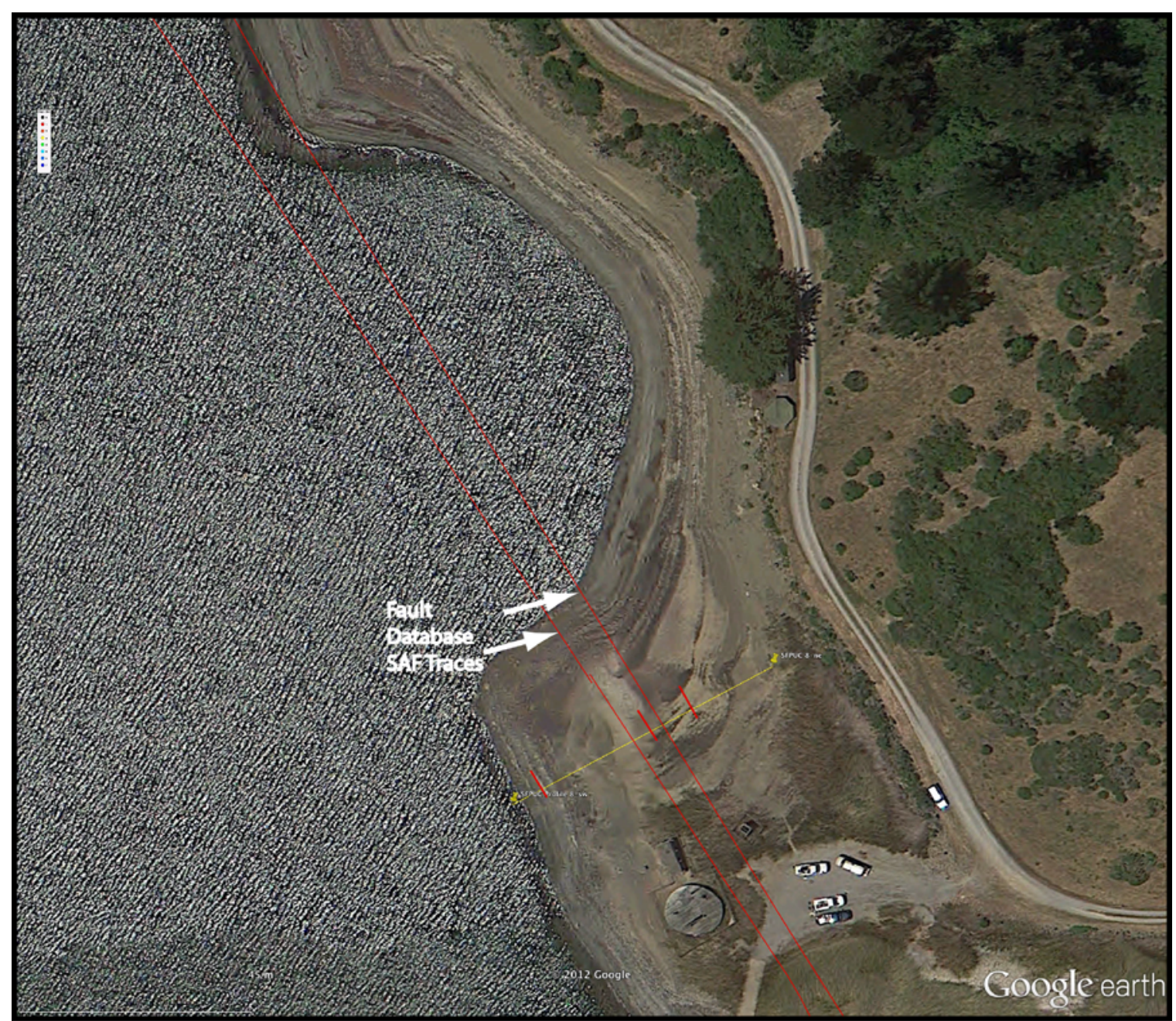

Fig. 3a

Figure 3. (a) Google Earth ${ }^{\mathrm{TM}}$ photograph showing seismic profile 8 (yellow line). The approximate locations of faults inferred (mapped) from geomorphology are shown as the thin red lines (Holocene Fault database). The white arrows also point to the mapped faults. Faults imaged seismically and mapped by Schussler (1906) are shown as the shorter and thicker red lines. (b) Sketch map of faulting that occurred on the eastern shore of San Andreas Lake during the 1906 magnitude 7.9 San Francisco earthquake (map by Schussler, 1906). Faulting occurred over at least an $\sim 35$-meter-wide area, with multiple traces of surface rupture. Note that the structures in the central fault area were deformed. The thick red line with distance scales shows the location of our seismic profile 8. 


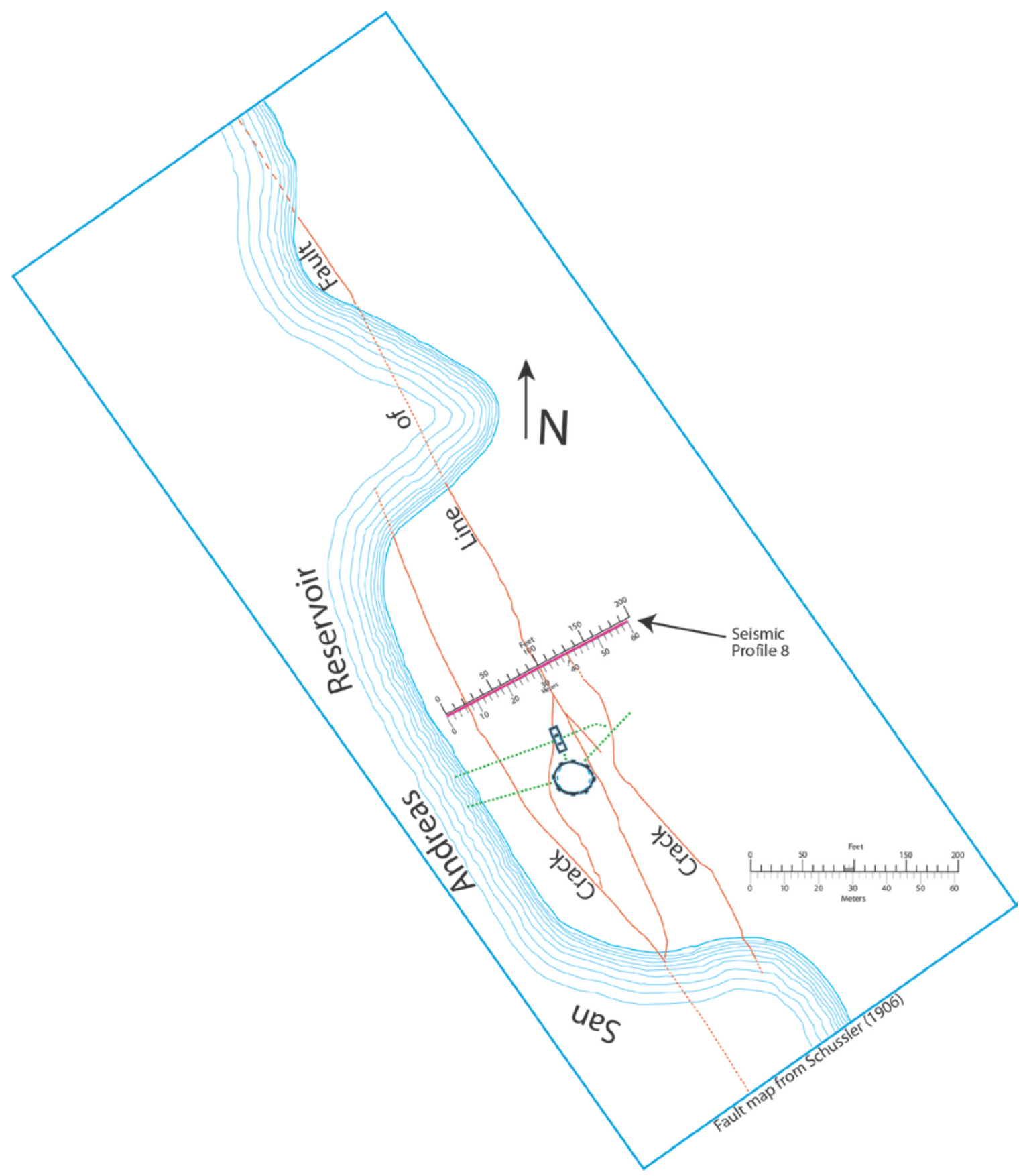

Fig. 3b.

Figure 3.-Continued 


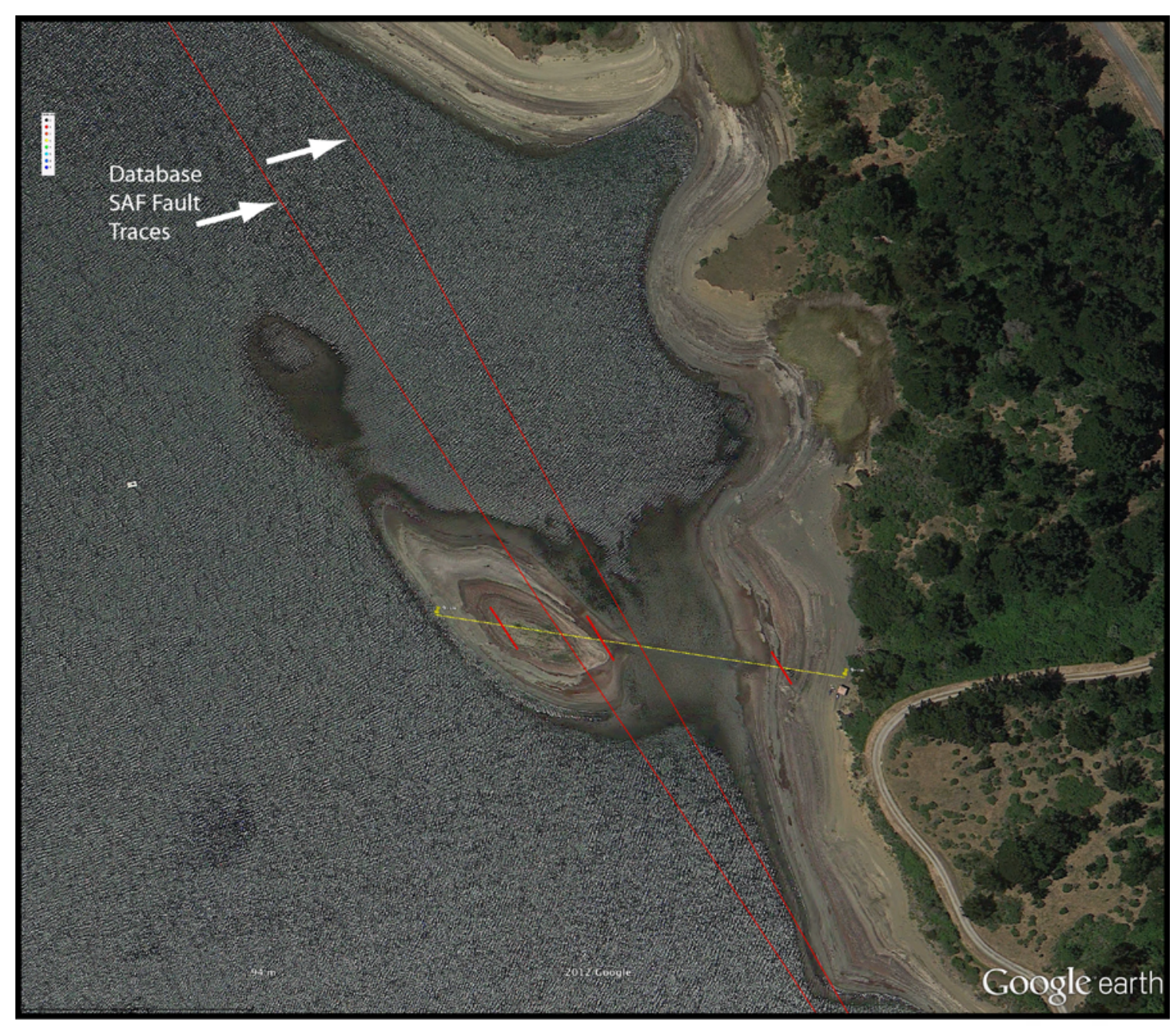

Fig. 4

Figure 4. Google Earth ${ }^{\mathrm{TM}}$ photograph showing seismic profile 9 (yellow line). The approximate locations of faults inferred from geomorphology are shown as the thin red lines (Holocene Fault database). White arrows also point to the mapped faults. Faults imaged seismically are shown as the thicker red lines. 


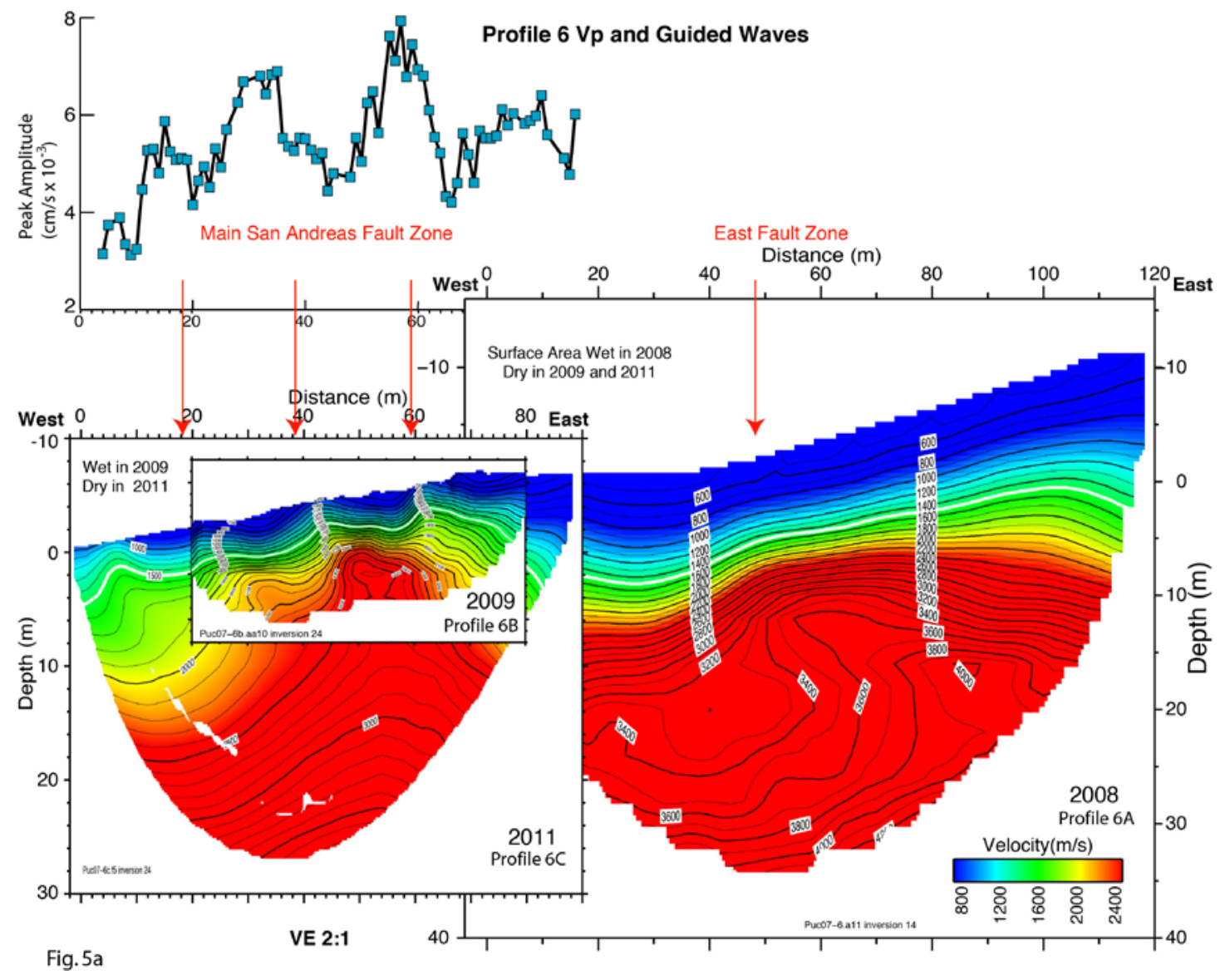

Figure 5. (a) Refraction tomography P-wave velocity models for profiles 6 (6a, b, c). The data for profile $6 a$ were acquired in 2008, profile $6 \mathrm{~b}$ in 2009 , and profile $6 \mathrm{c}$ in 2011. The lake level was progressively lowered during each year of acquisition. The general location (based on geomorphology) of the main surface rupture area of the San Andreas Fault during the 1906 magnitude 7.9 San Francisco earthquake is shown along profiles $6 \mathrm{~b}$ and $6 \mathrm{c}$. The seismically imaged fault locations are shown by the arrows. We interpret an additional "East Fault Zone" along profile $6 \mathrm{a}$, based on seismic velocity and topographic anomalies. The 1,500 meter per second velocity contour is shown in white. A plot of peak amplitudes (guided waves) as a function of distance along profile $6 \mathrm{c}$ is shown above profile $6 \mathrm{c}$. The peak amplitudes were measured on vertical component geophones. (b) Same plot as shown in figure 5a, except profile $6 \mathrm{~b}$ has been removed to show details of profile $6 \mathrm{c}$. 


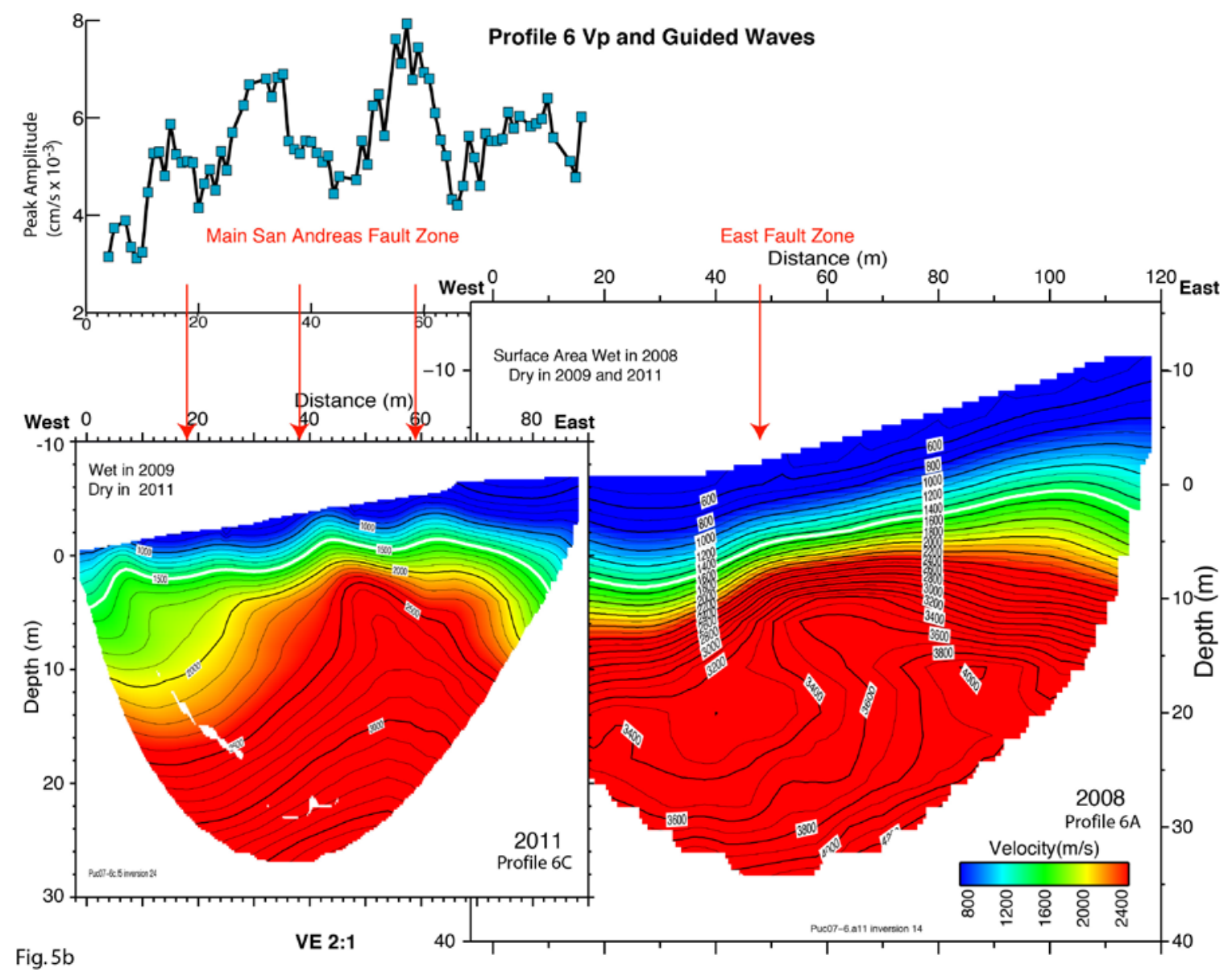

Figure 5.-Continued. 


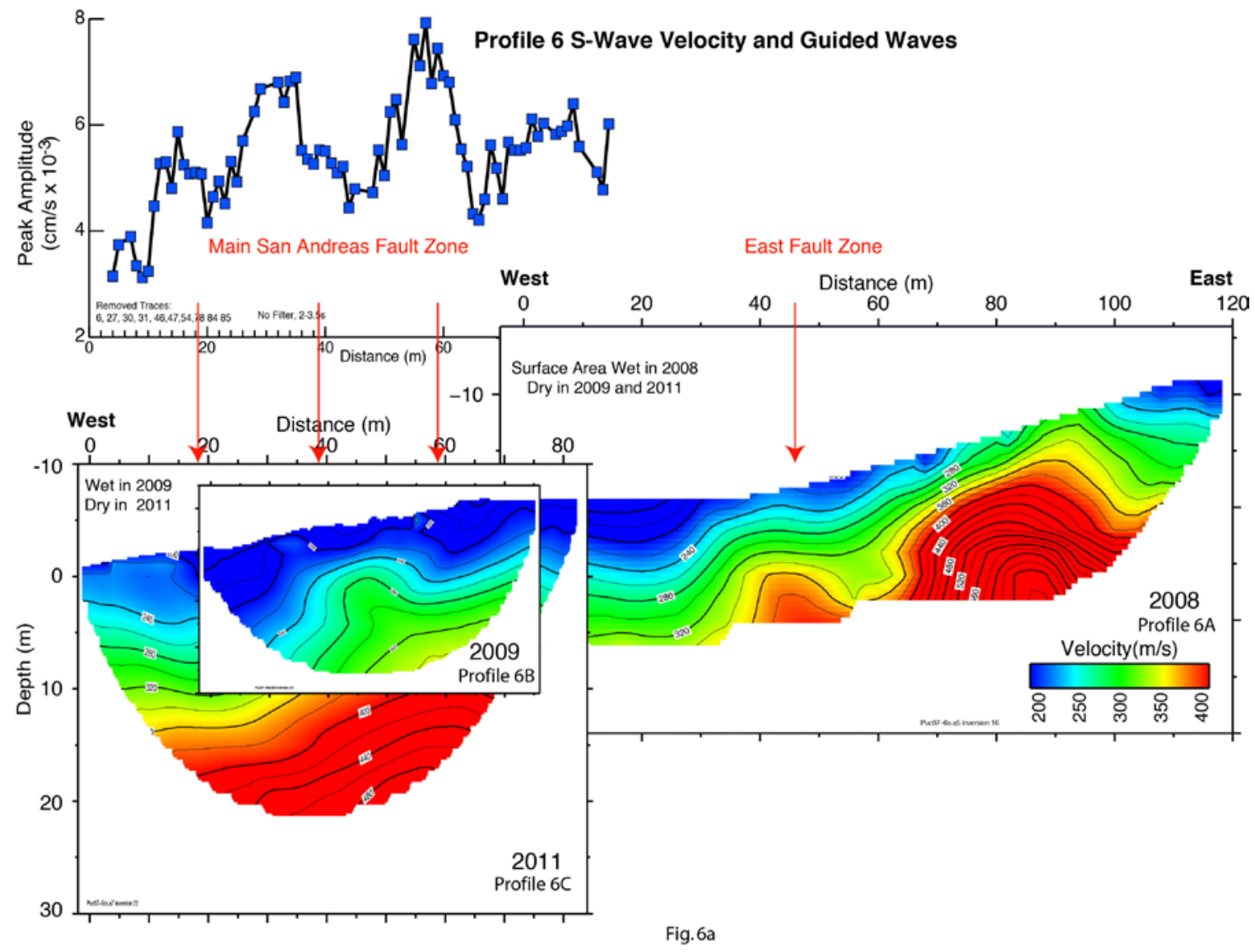

Figure 6. (a) Refraction tomography S-wave velocity models for profiles $6(6 a, b, c)$ from data acquired in 2008 (profile 6a), 2009 (profile 6b) and 2011 (profile 6c). The general location (based on geomorphology) of the main surface rupture area of the San Andreas Fault during the $1906 \sim$ magnitude 7.9 San Francisco earthquake is shown along profiles $6 \mathrm{~b}$ and $6 \mathrm{c}$. The seismically imaged fault locations are shown by the arrows. We interpret an additional "East Fault Zone" along profile 6a on the basis of offset velocity anomalies, low-velocity zones, and altitude variations. The seismic profiles were acquired with varying degrees of water saturation and solidification of surface materials. Peak-amplitude measurements of vertical-component seismic (guided wave) data are shown along profile 6a. The highest amplitudes coincide with the seismic velocity indicators of faulting and the interpreted (on the basis of geomorphology) main surface rupture area associated with the 1906 magnitude 7.9 San Francisco earthquake. (b) Same plot as shown in figure 6a, except profile $6 \mathrm{~b}$ has been removed to show details of profile 6c. 


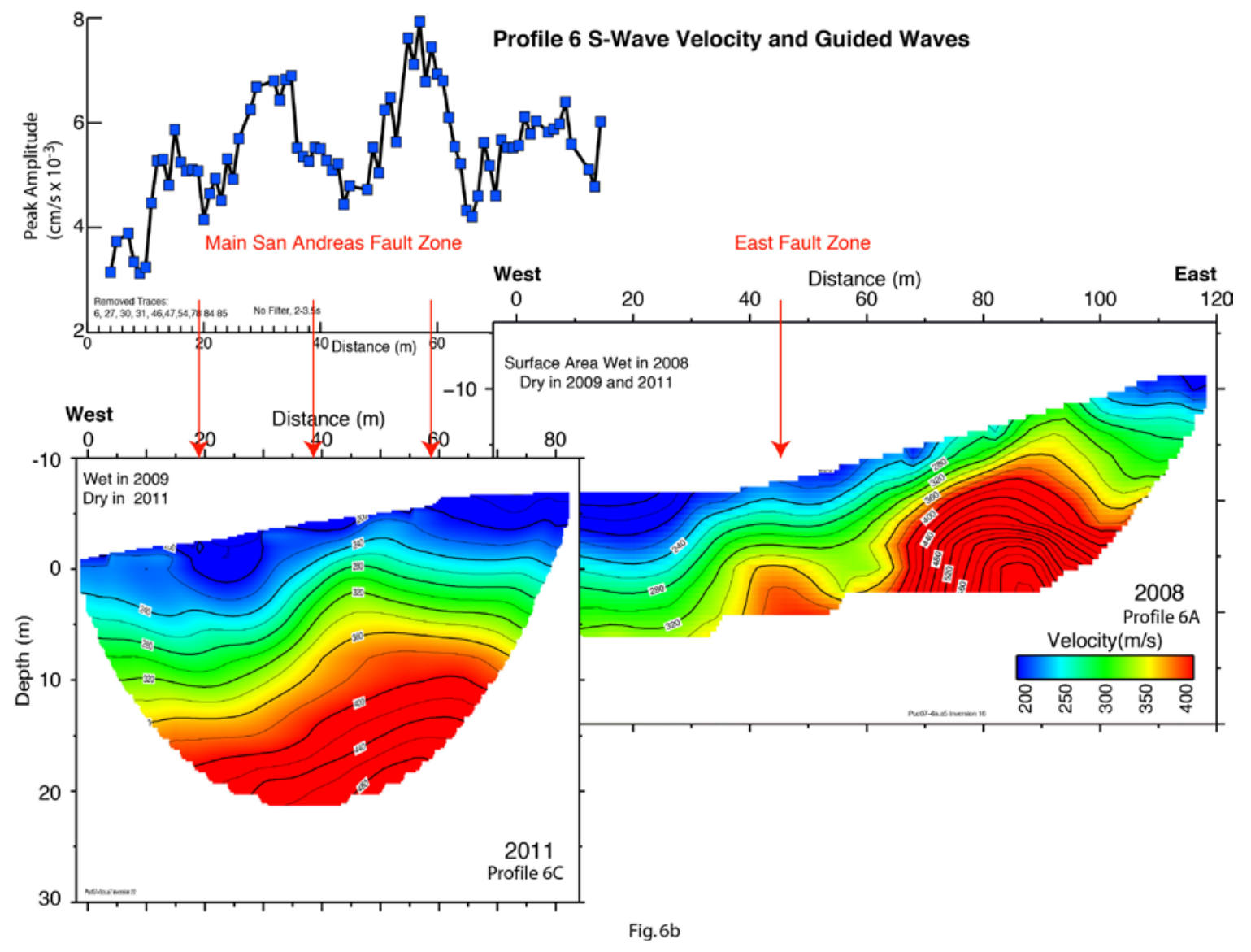

Figure 6.-Continued. 

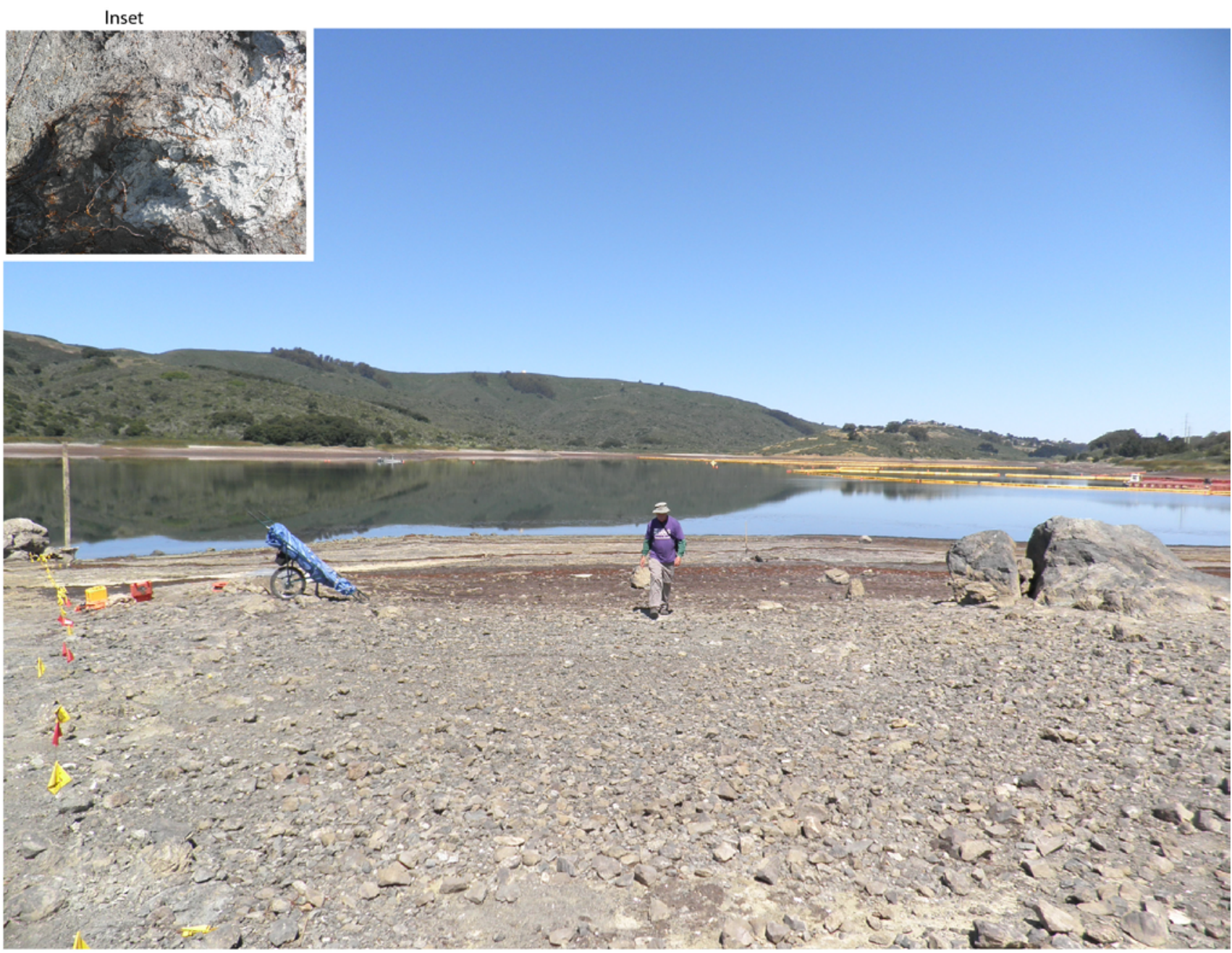

Fig.7.

Figure 7. Photograph showing area near profile 6c. The flags on the left side of the photograph show the locations of shot and recording sites along the seismic profile. The surface materials along most of profile $6 c$ consisted of highly brecciated rocks, including serpentinite (see inset). 

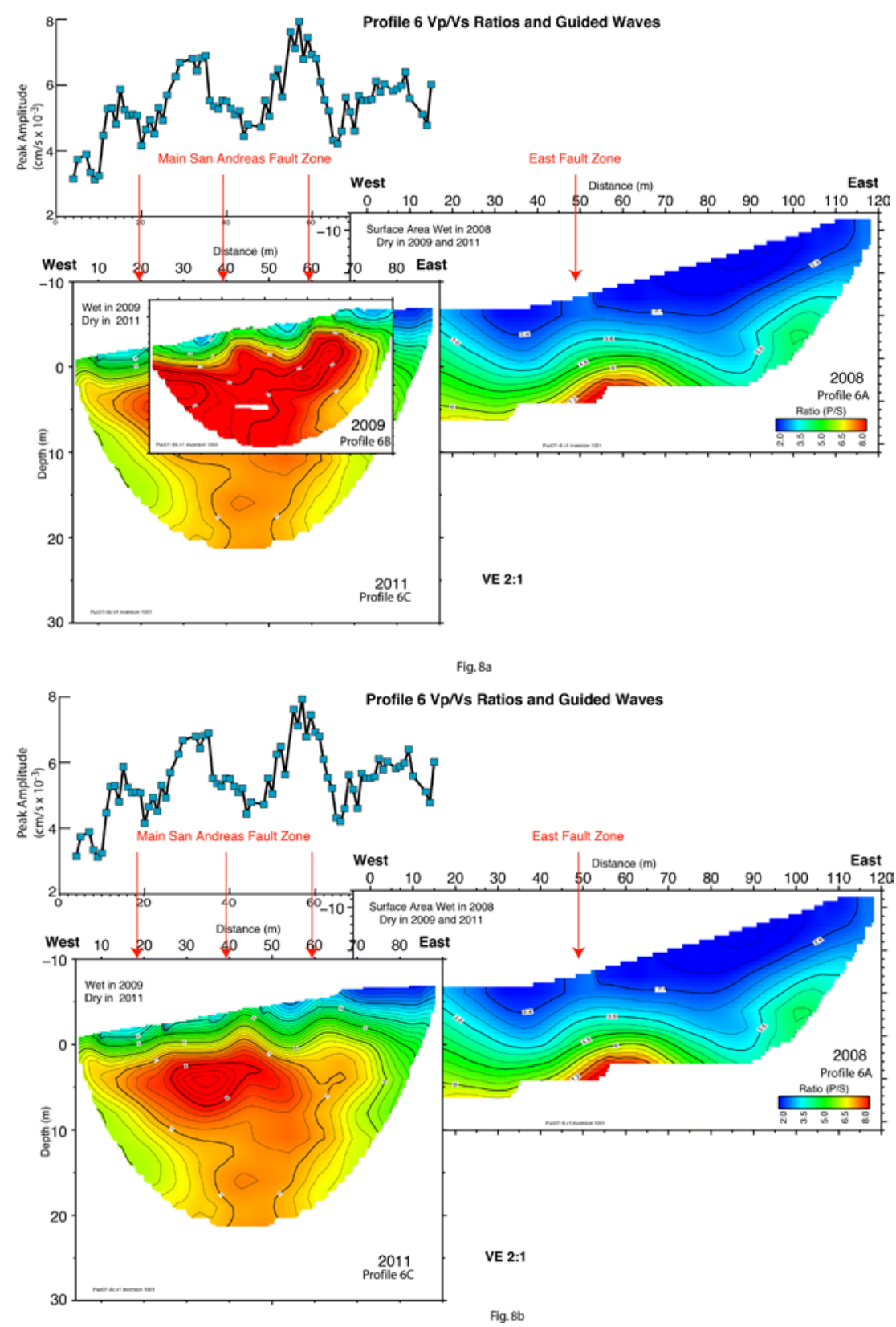

Figure 8. (a) P-wave velocity divided by S-wave velocity $(\mathrm{Vp} / \mathrm{Vs})$ models for profile $6(\mathrm{a}, \mathrm{b}, \mathrm{c})$, developed from the refraction tomography $\mathrm{P}$ - and S-wave models of figures 5 and 6 . Relatively high near-surface $\mathrm{Vp} / \mathrm{Vs}$ ratios correlate with known fault zones when the near-surface materials are composed of consolidated sediments or hard rocks (Catchings and others, in prep.). High $\mathrm{Vp} / \mathrm{Vs}$ ratios are observed at the main surface rupture zone along profiles $6 \mathrm{~b}$ and $6 \mathrm{c}$, and along profile $6 \mathrm{a}$ near meters $45-50$. At depth along profile $6 \mathrm{~b}$ and $6 \mathrm{c}$, the high $\mathrm{Vp} / \mathrm{Vs}$ ratios become narrow, extending to the base of the model near the central 1906 surface rupture area. Peak amplitudes measured along profile $6 \mathrm{c}$ approximately coincide with areas of high $\mathrm{Vp} / \mathrm{Vs}$ ratios. The seismically imaged fault locations are shown by the arrows. (b) Same plot as shown in figure 8a, except profile $6 \mathrm{~b}$ has been removed to show details of profile $6 \mathrm{c}$. 


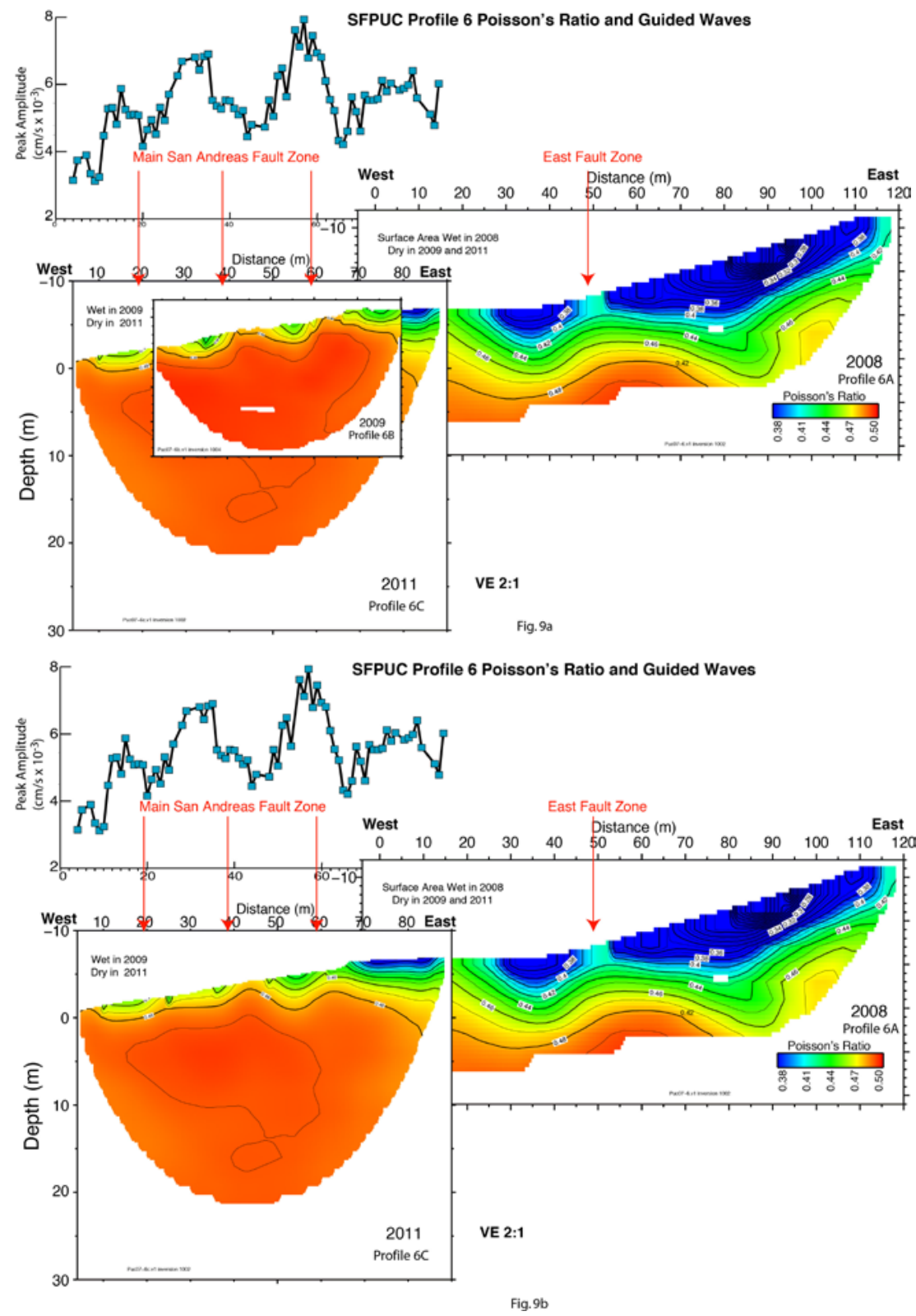

Figure 9. (a) Poisson's ratio (PR) models for profile 6, developed from the refraction tomography P- and S-wave models of figures 5 and 6 . PR is most sensitive to the presence of groundwater, and the model points out anomalous areas where groundwater is likely most affected by faults. The greatest changes in near-surface PR largely coincide with the inferred areas of nearsurface faulting. At depths ranging from a few meters along profile $6 \mathrm{~b}$ and $6 \mathrm{c}$ to about $5-10 \mathrm{~m}$ along profile $6 \mathrm{c}$, the highest values of PR largely follow the 1,500 meter per second velocity contour. The seismically imaged fault locations are shown by the arrows. (b) Same plot as shown in figure $9 a$, except profile $6 b$ has been removed to show details of profile $6 c$. 


\section{SFPUC Profile 8 P-wave Velocities}

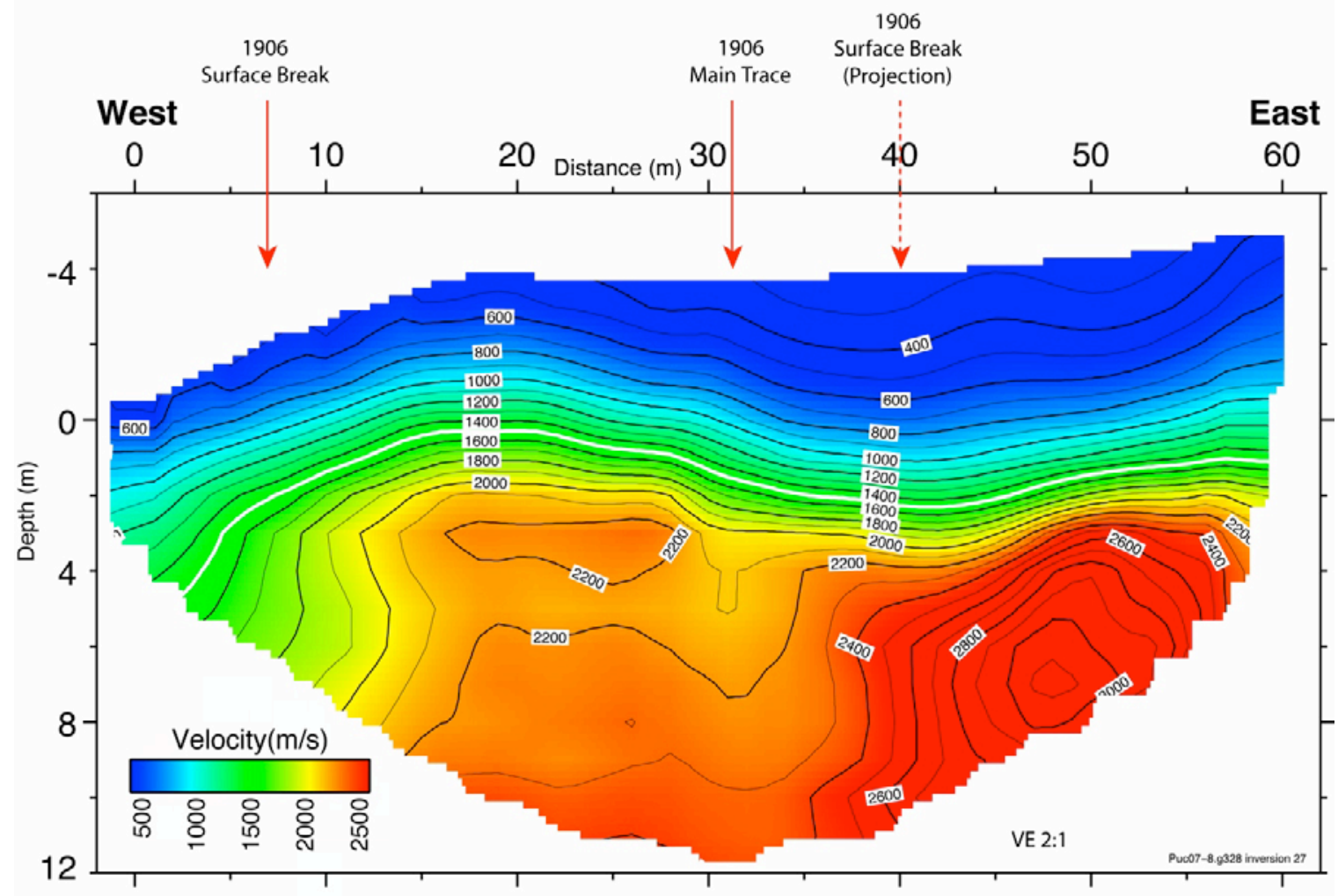

Fig. 10

Figure 10. Refraction tomography P-wave velocity model for profile 8 with the locations of surface ruptures (at red arrows) mapped by Schussler (1906). For velocities greater than 1,500 meter per second, there are abrupt lateral changes in velocity west of the surface ruptures. The seismically imaged fault locations are shown by the arrows. 


\section{SFPUC Profile 8 S-wave Velocities}

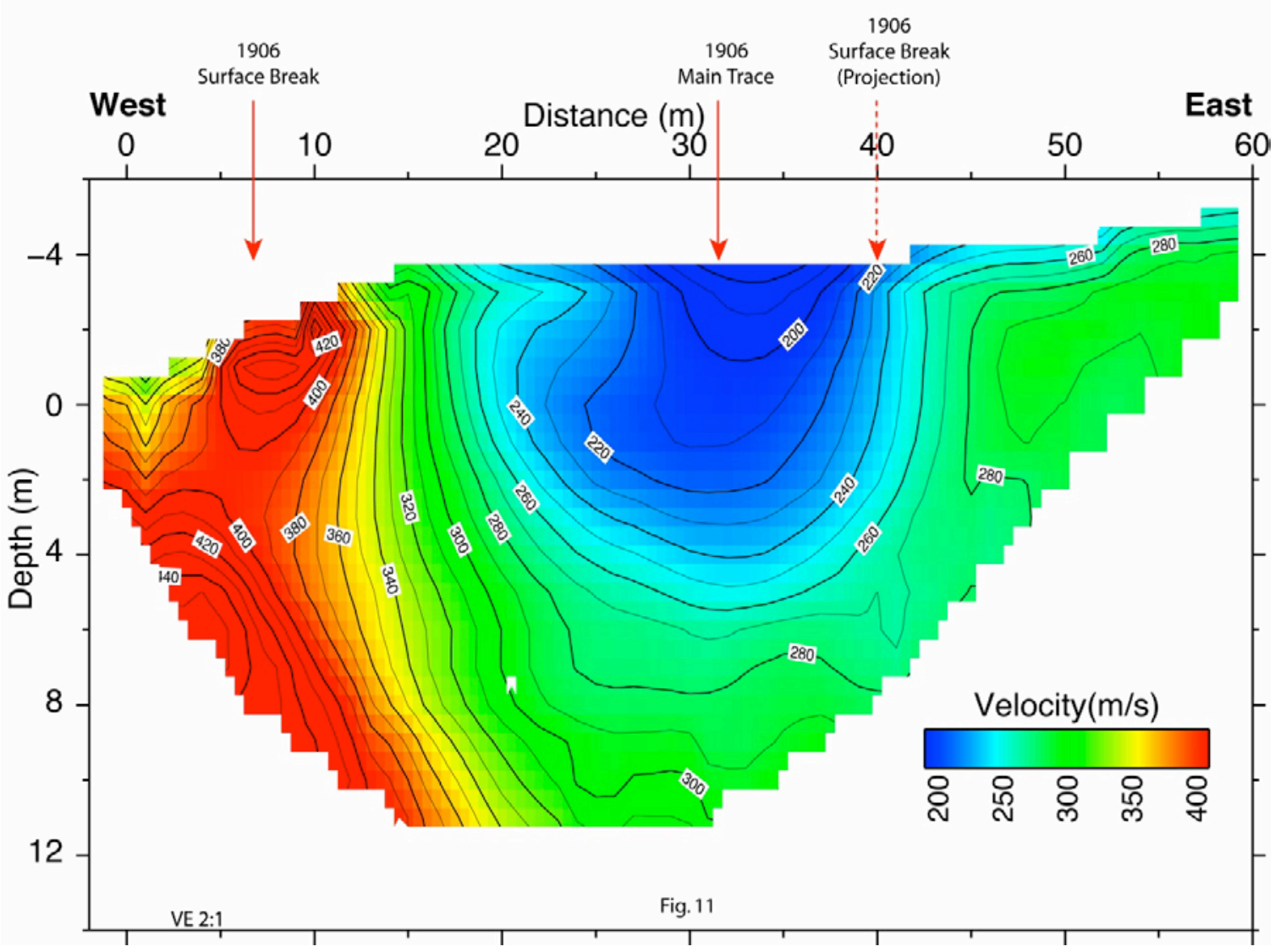

Figure 11. Refraction tomography S-wave velocity model for profile 8 with the locations of surface ruptures (at red arrows) mapped by Schussler (1906). A prominent low-velocity zone is concentrated along the eastern surface rupture area, and an apparent west-dipping structure coincides with the westernmost surface rupture. The seismically imaged fault locations are shown by the arrows. 


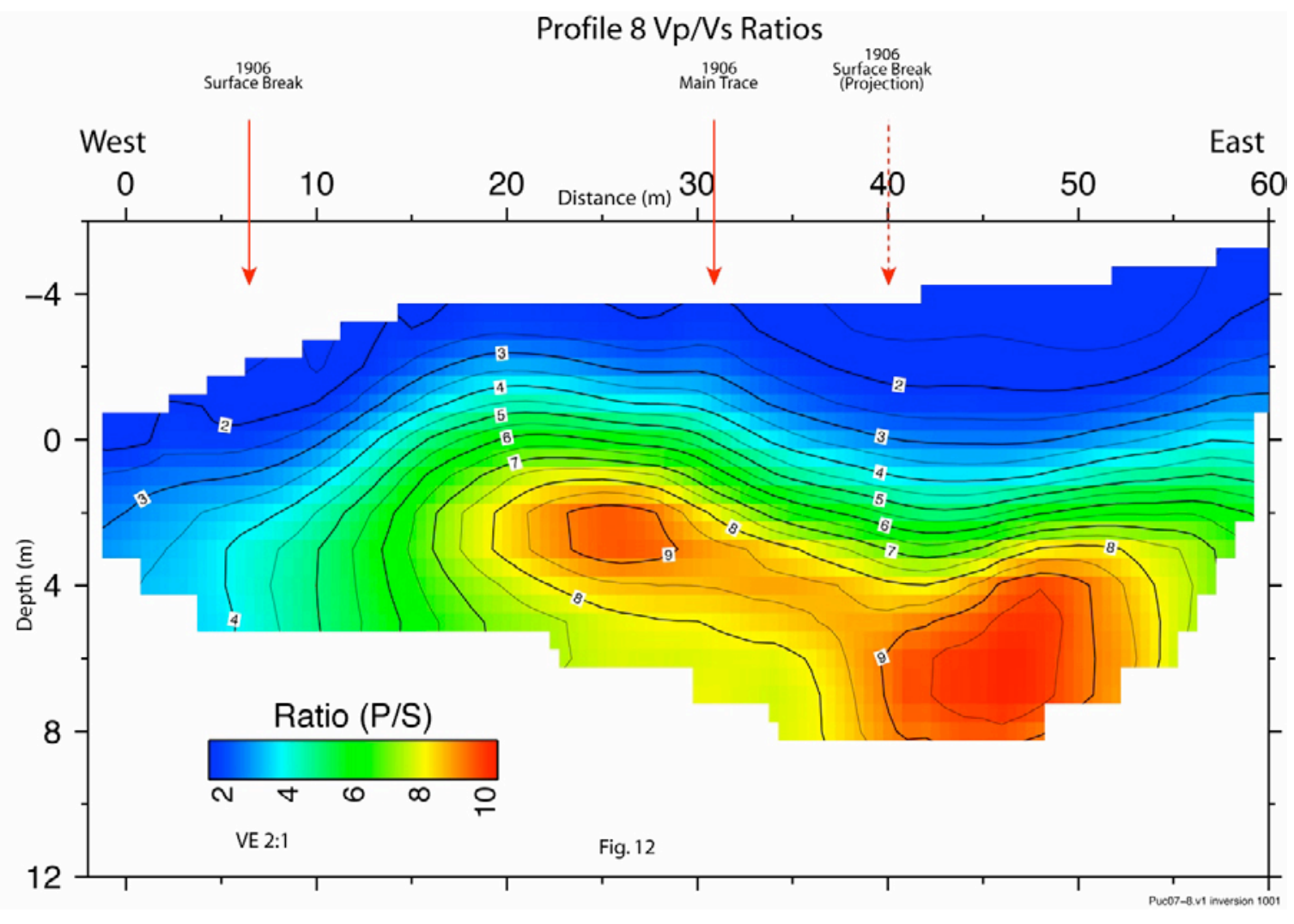

Figure 12. P-wave velocity divided by S-wave velocity (Vp/Vs) model for profile 8 developed from the refraction tomography $\mathrm{P}$ - and S-waves models of figures 10 and 11 . The highest $\mathrm{Vp} / \mathrm{Vs}$ ratios occur at about 5-10 m below the surface, but localized, near-surface, high Vp/Vs ratios of $\sim 2$ coincide with the 1906 main and westernmost surface ruptures. Unconsolidated sediments are present in the near surface along the entire seismic profile, resulting in particularly high $\mathrm{Vp} / \mathrm{V}$ s ratios in fault zones. The seismically imaged fault locations are shown by the arrows. 


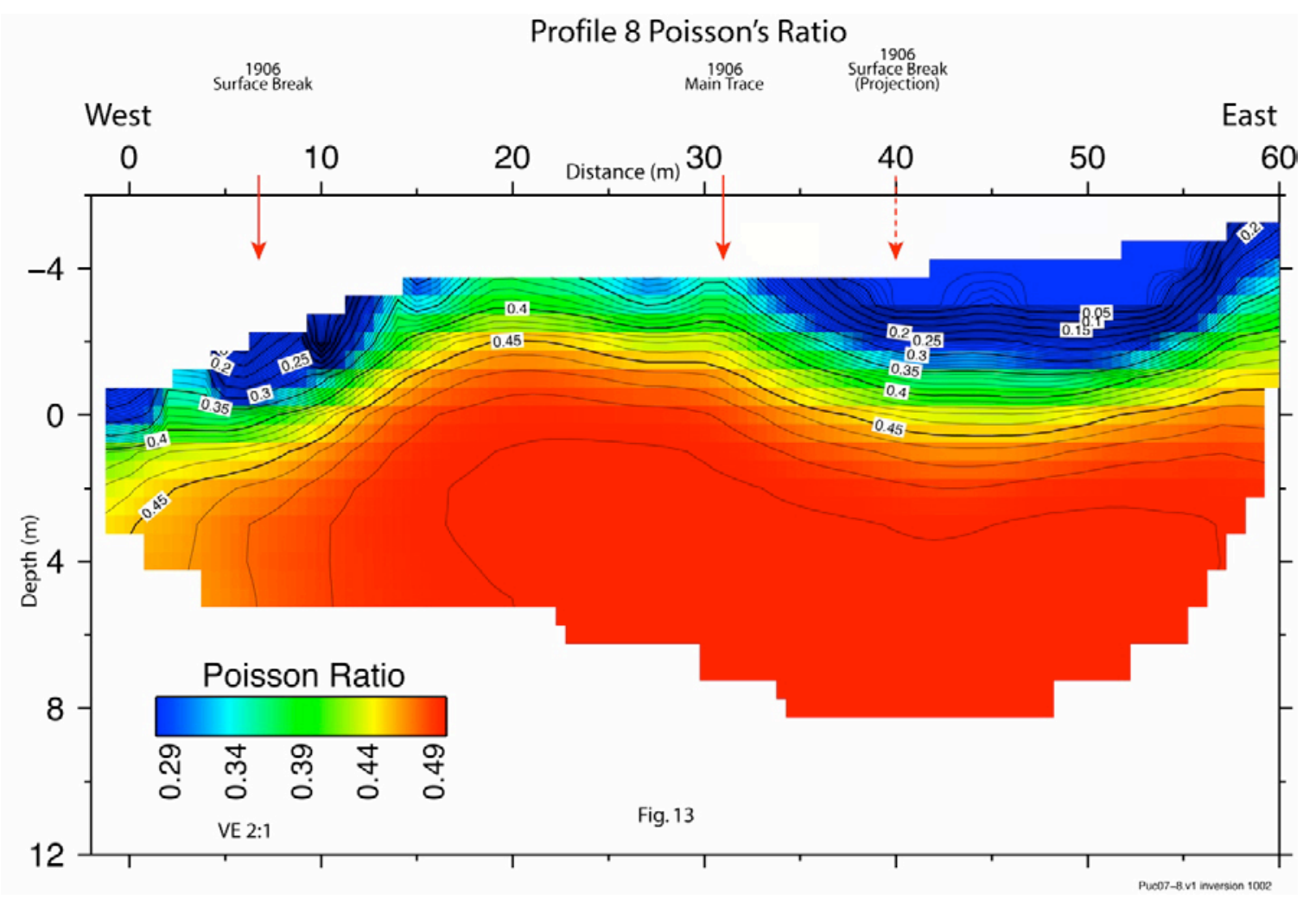

Figure 13. Poisson's Ratio (PR) model for profile 8 developed from the refraction tomography Pand S-waves models of figures 10 and 11. The high values of PR largely follow the trend of the 1,500 meter per second velocity contour (top of groundwater). There are relatively high PR values near the 1906 main and westernmost surface ruptures. The seismically imaged fault locations are shown by the arrows. 


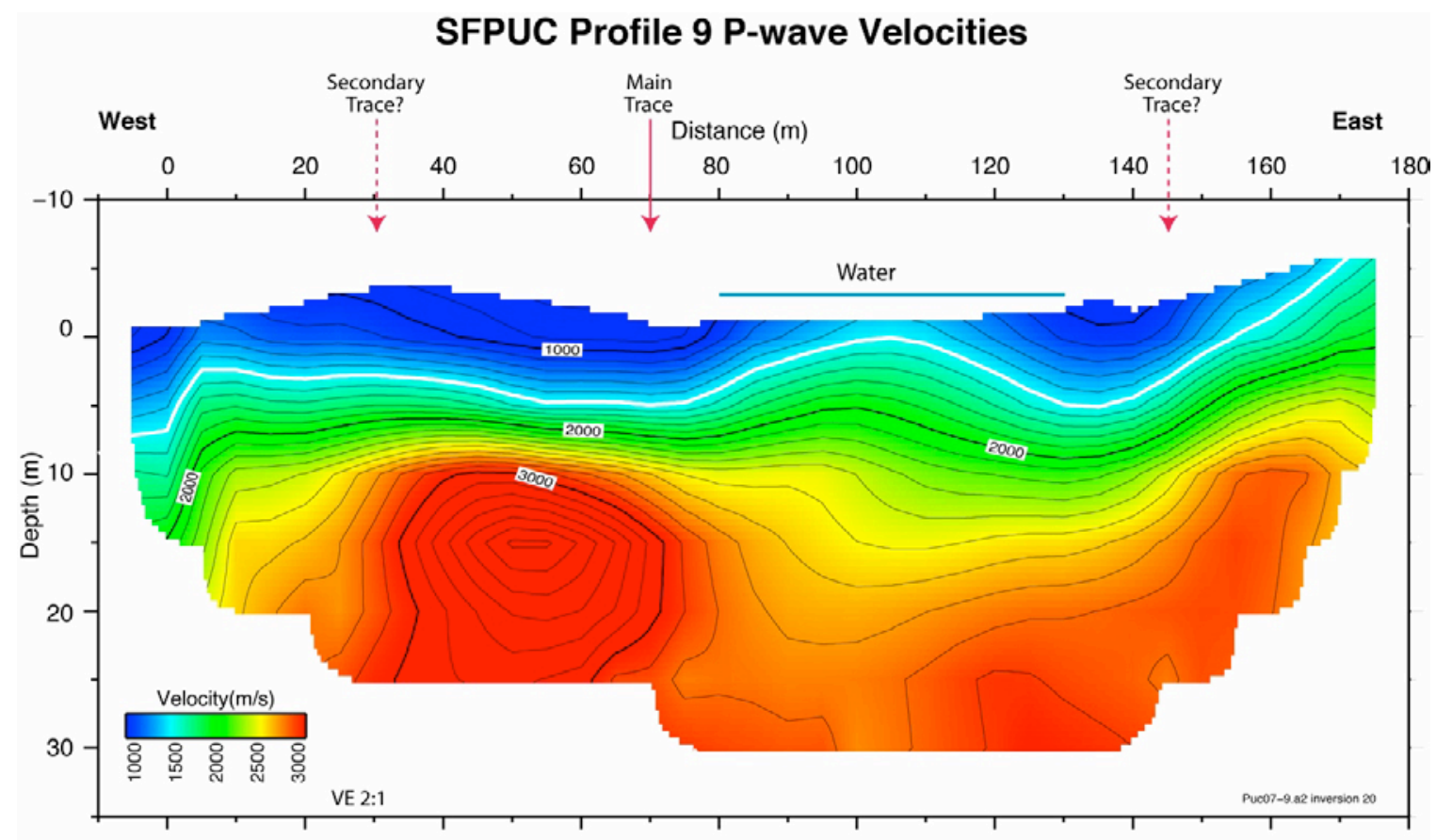

Fig. 14

Figure 14. Refraction tomography P-wave velocity model for profile 9 . The 1906 main surface rupture area is shown near meter 70 , and two additional rupture zones (at meters 30 and 145) are inferred from this study. Higher velocities are discontinuous or disrupted near the inferred faults. The seismically imaged fault locations are shown by the arrows. 


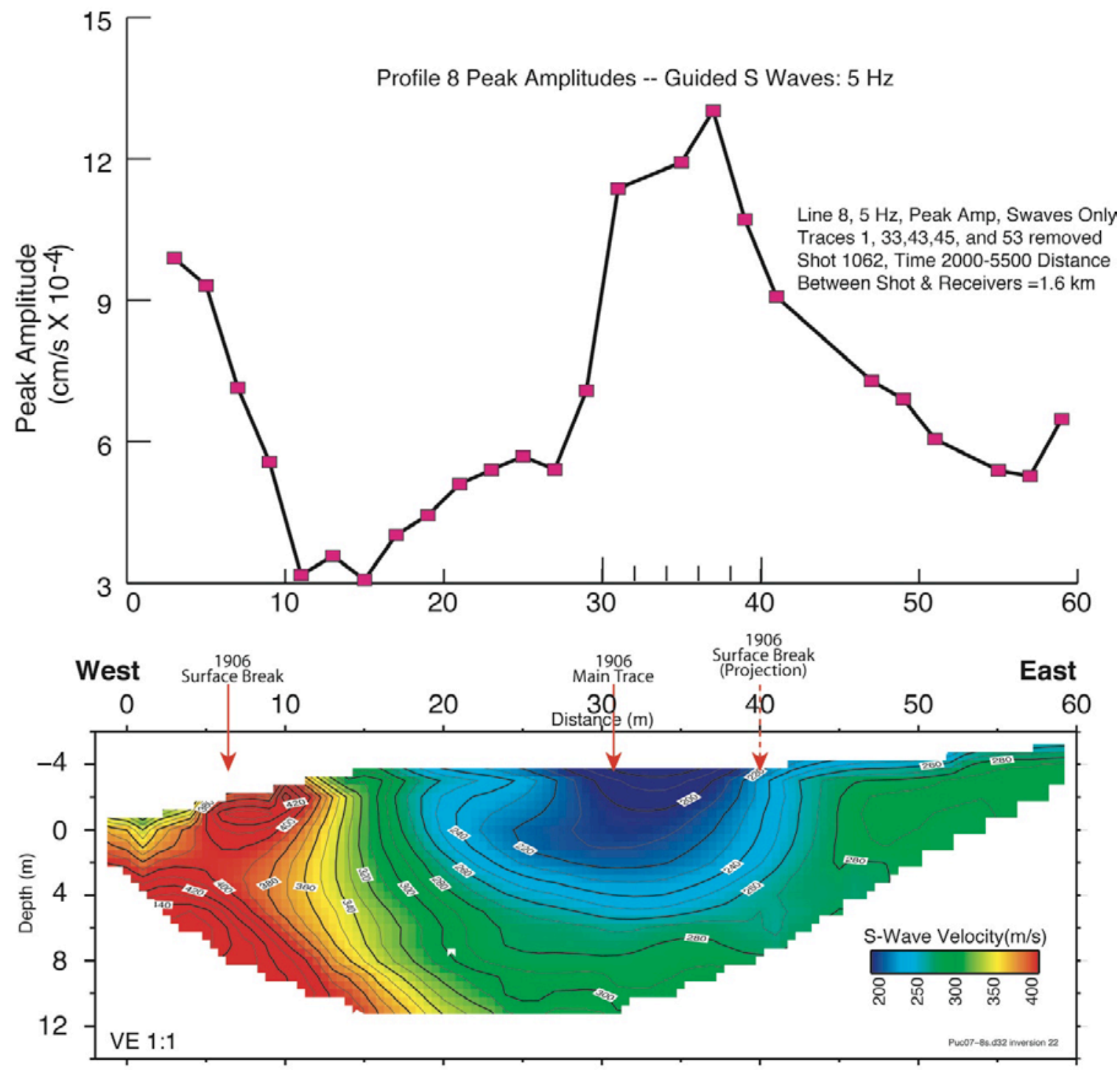

Fig. 15a

Figure 15. A comparison of peak-amplitude (horizontal-component) guided waves recorded along profile 8 with the S-wave velocity model for profile 6 . The highest amplitudes coincide with the surface rupture areas mapped by Schussler (1906) at predominant frequencies of (a) 5 hertz (Hz), (b) $4 \mathrm{~Hz}$, and (c) $2 \mathrm{~Hz}$. (d) However, at very low frequencies (1 Hz), the peak amplitudes are largely concentrated over the deeper low-velocity (fault) zone. The seismically imaged fault locations are shown by the arrows. 
Profile 8 Peak Amplitudes -- Guided S Waves: $4 \mathrm{~Hz}$

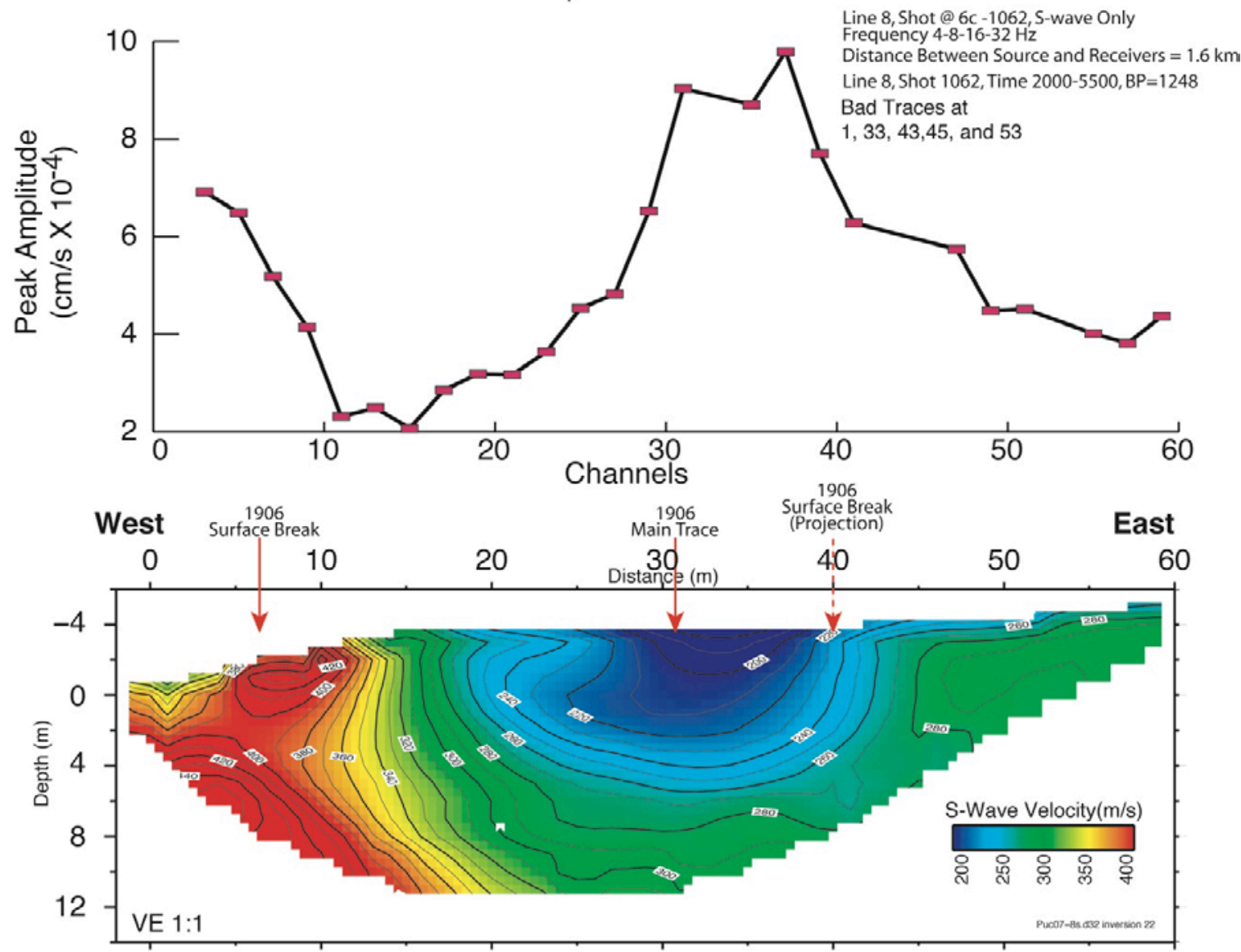

Fig. $15 b$

Figure 15.-Continued. 


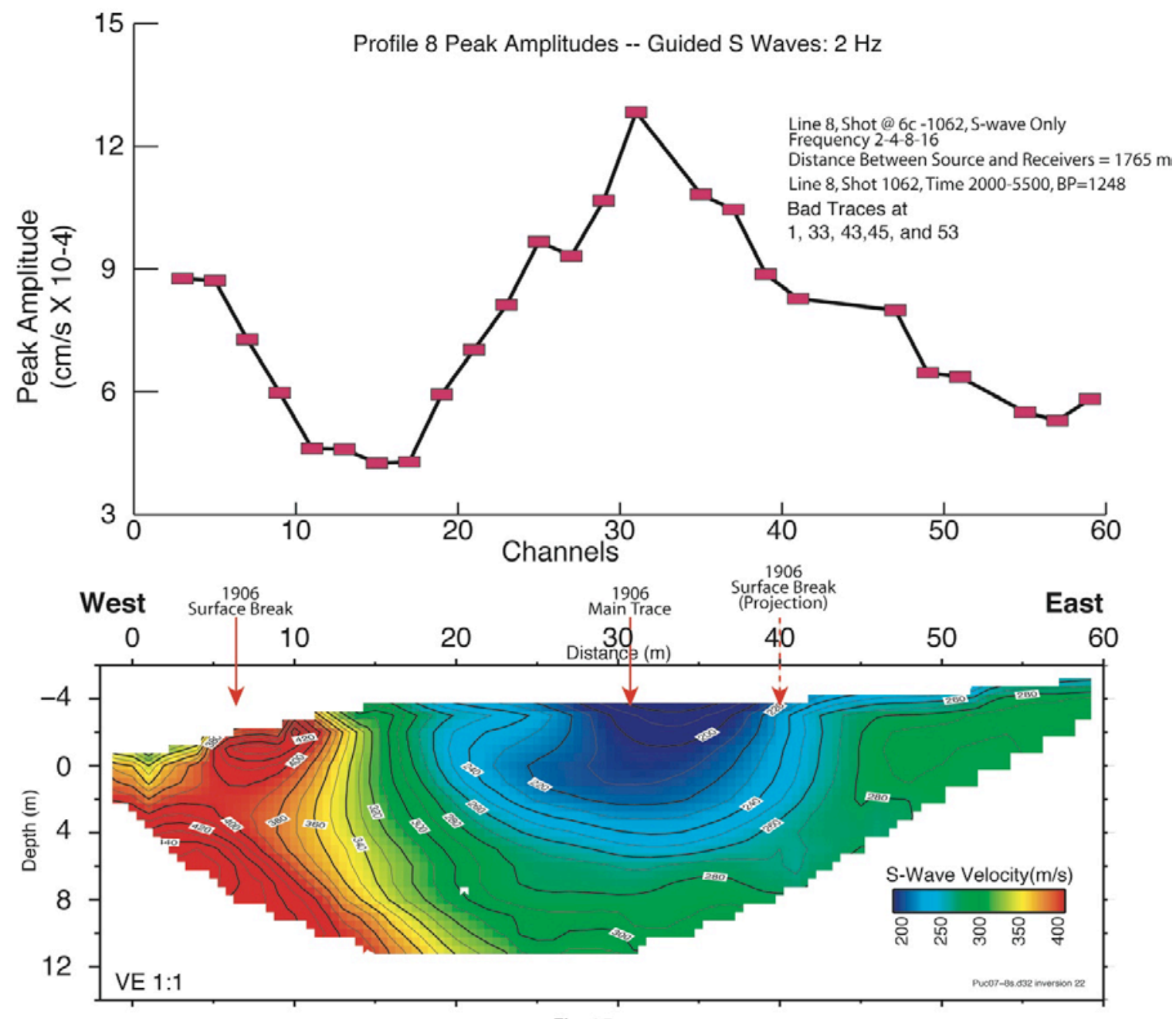

Fig. $15 \mathrm{c}$

Figure 15.-Continued. 


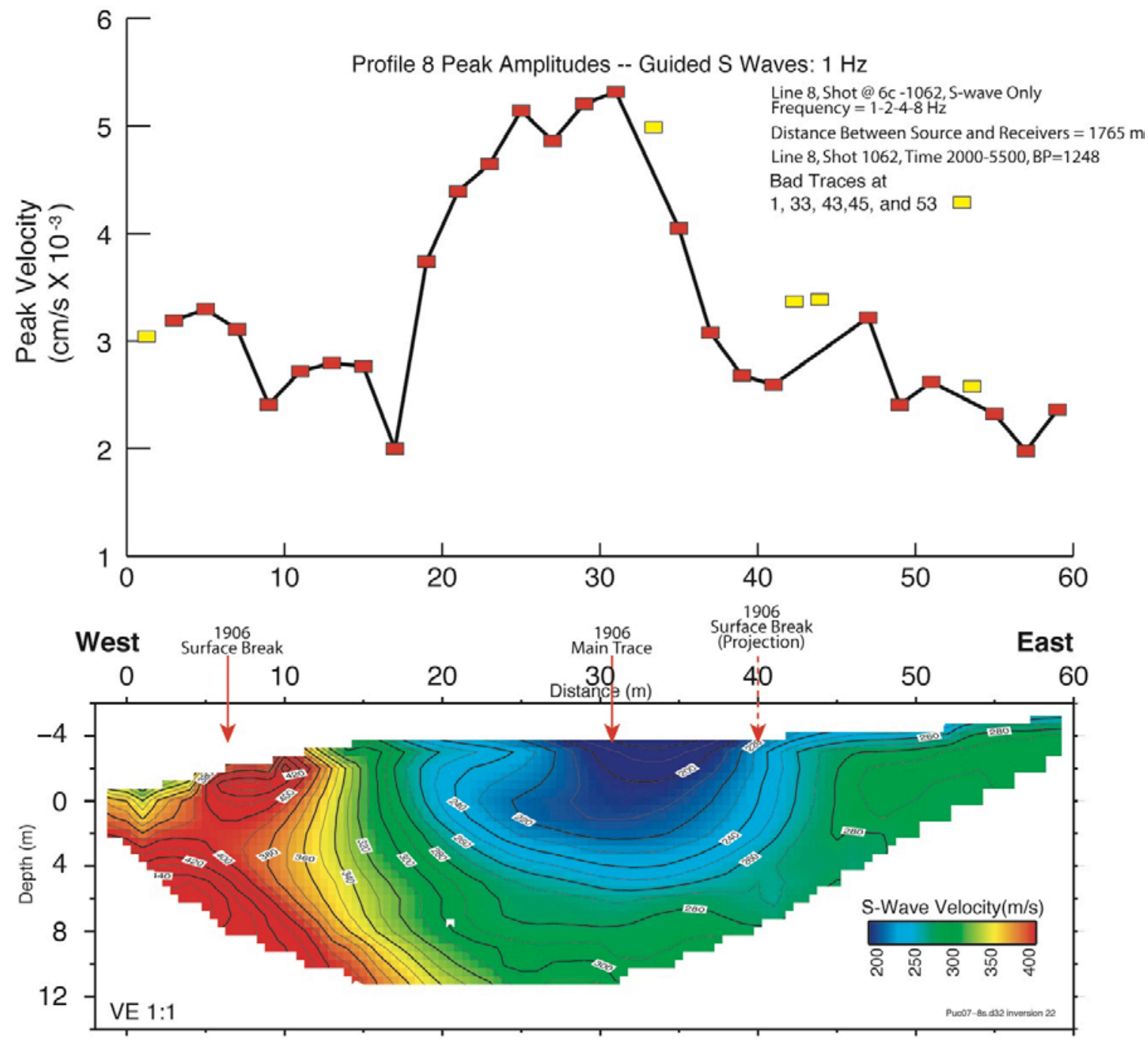

Fig. 15d

Figure 15.-Continued. 


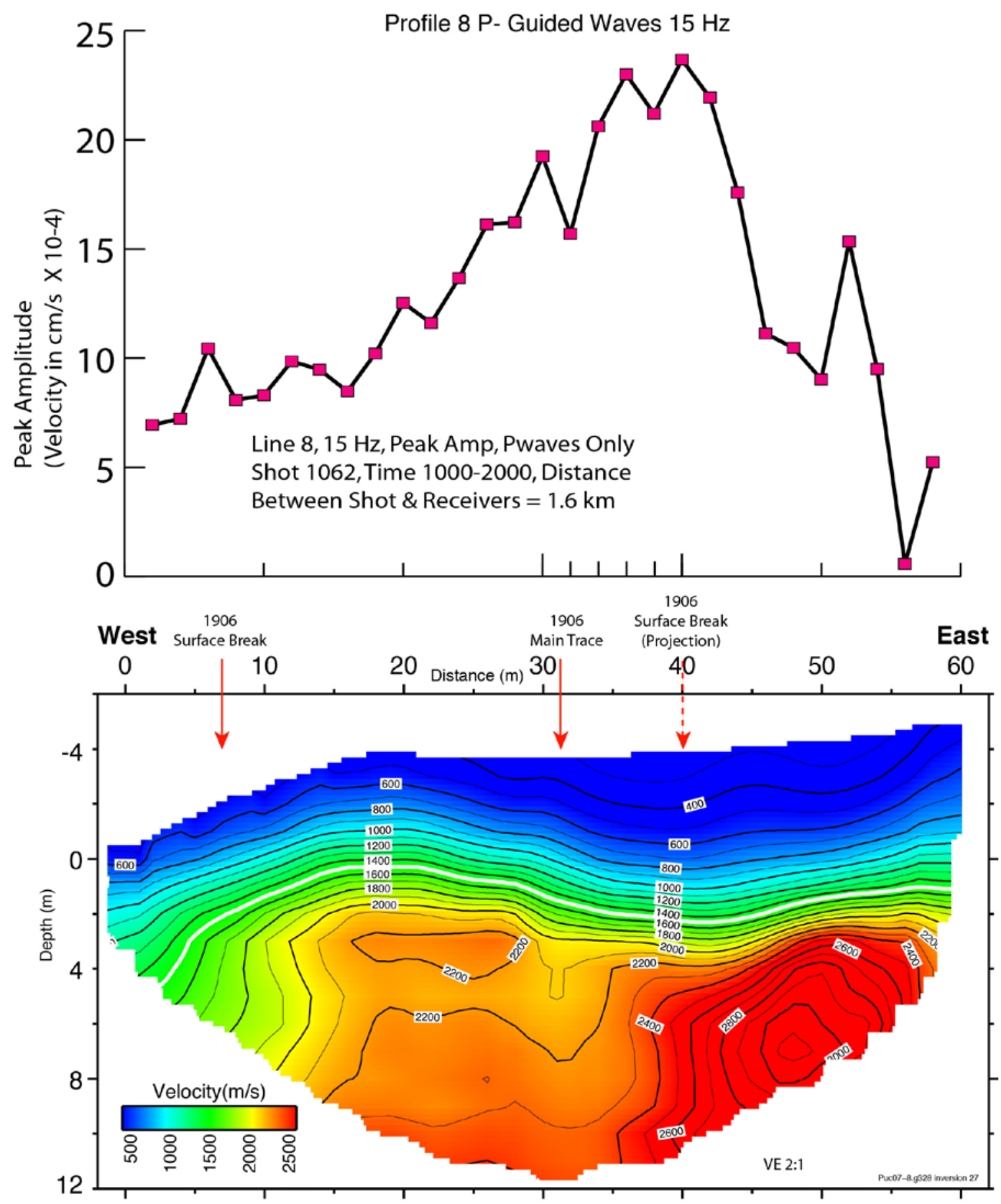

Fig. 16a

Figure 16. A comparison of peak-amplitude (vertical-component) guided waves recorded along profile 8 with the $P$-wave velocity model for profile 6 . The highest amplitudes coincide with the surface rupture areas mapped by Schussler (1906) at predominant frequencies of (a) 15 hertz (Hz), (b) $20 \mathrm{~Hz}$, and (c) $30 \mathrm{~Hz}$. The seismically imaged fault locations are shown by the arrows. 


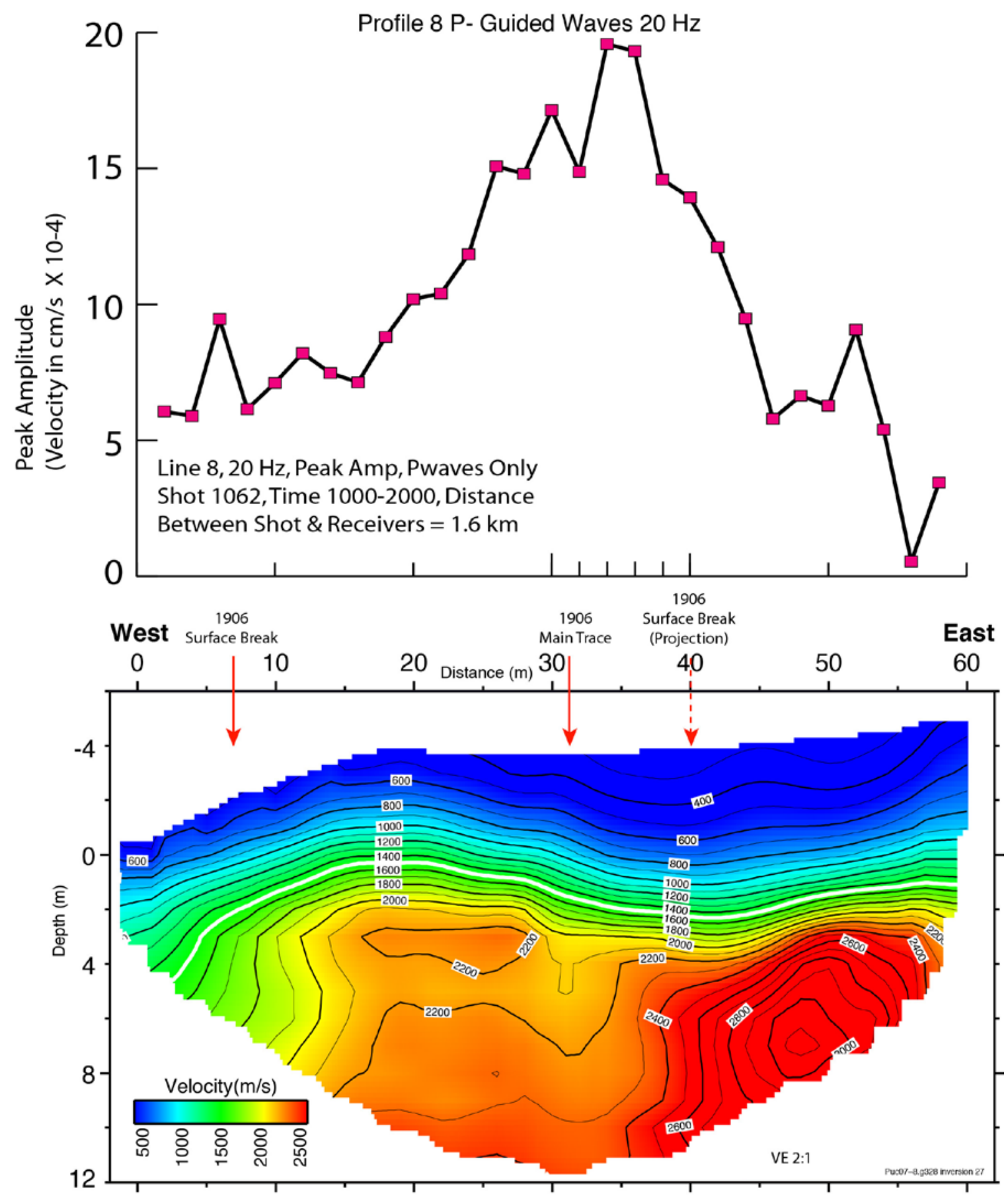

Fig. 16b

Figure 16.-Continued. 


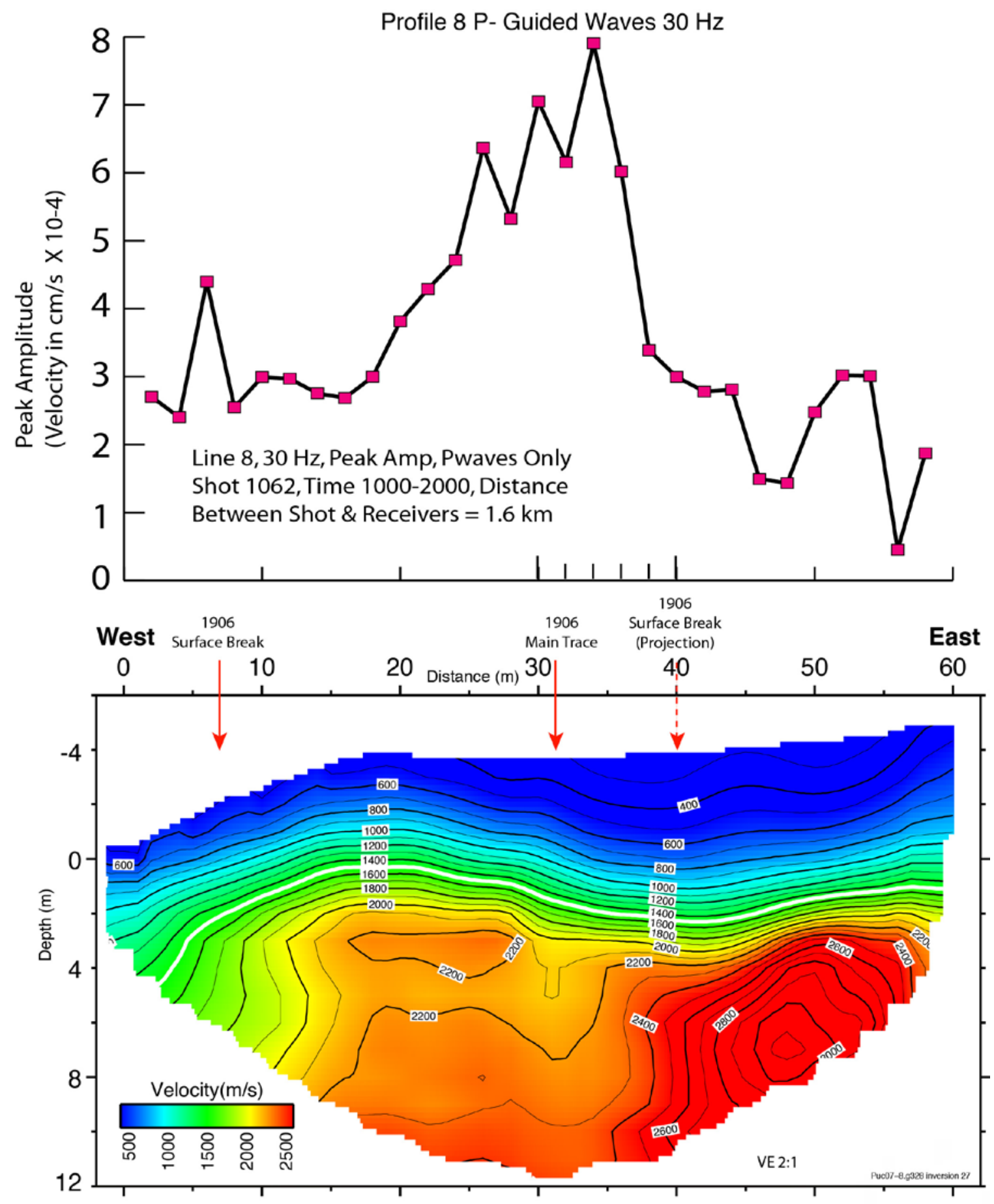

Fig. 16c

Figure 16.-Continued. 


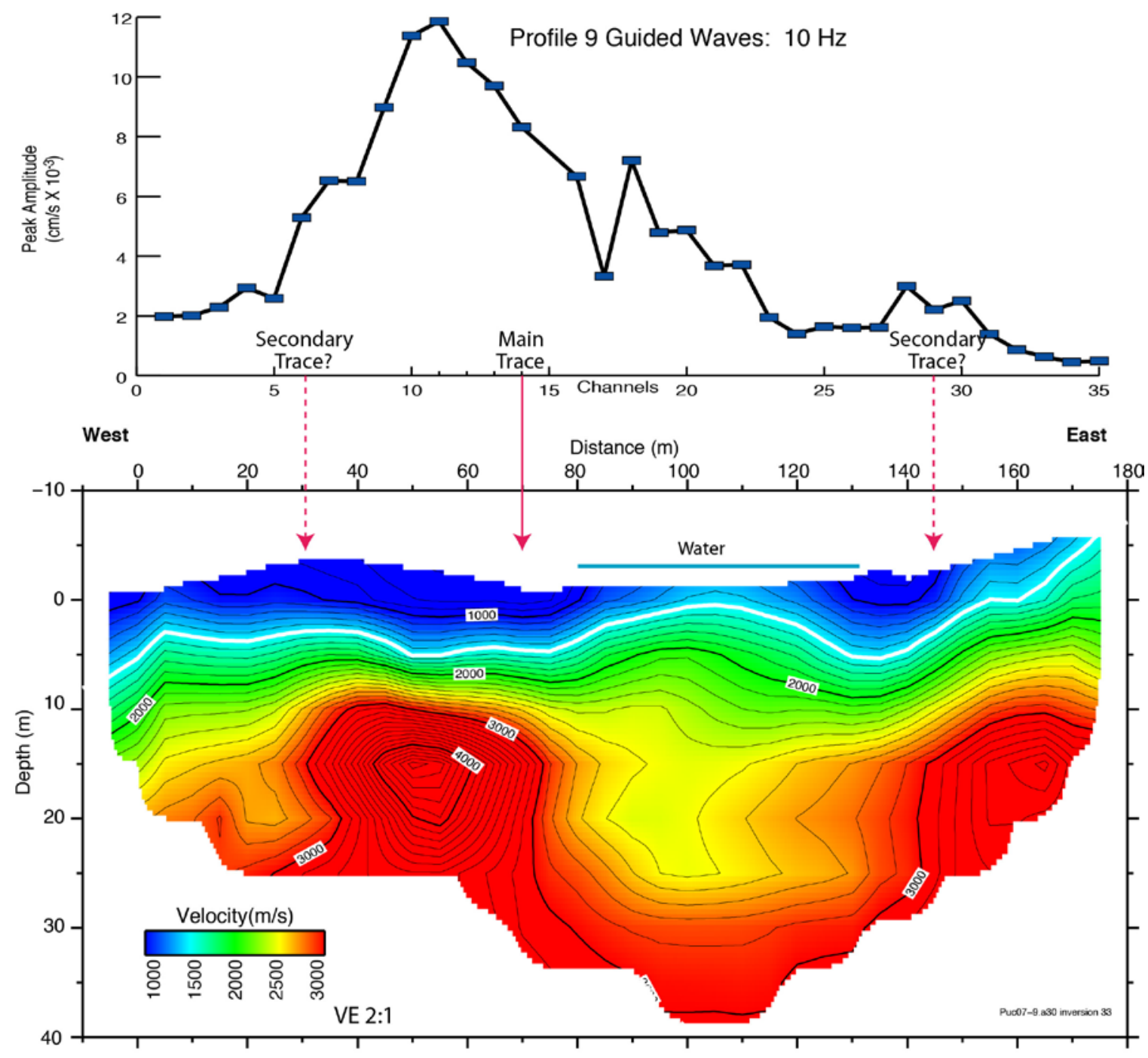

Fig. 17a

Figure 17. A comparison of peak-amplitude (vertical-component) guided waves recorded along profile 9 with the P-wave velocity model for profile 9 . The highest amplitudes coincide with the surface rupture area inferred from geomorphology at predominant frequencies of (a) 10 hertz (Hz), (b) $20 \mathrm{~Hz}$, and (c) $30 \mathrm{~Hz}$. The seismically imaged fault locations are shown by the arrows. 


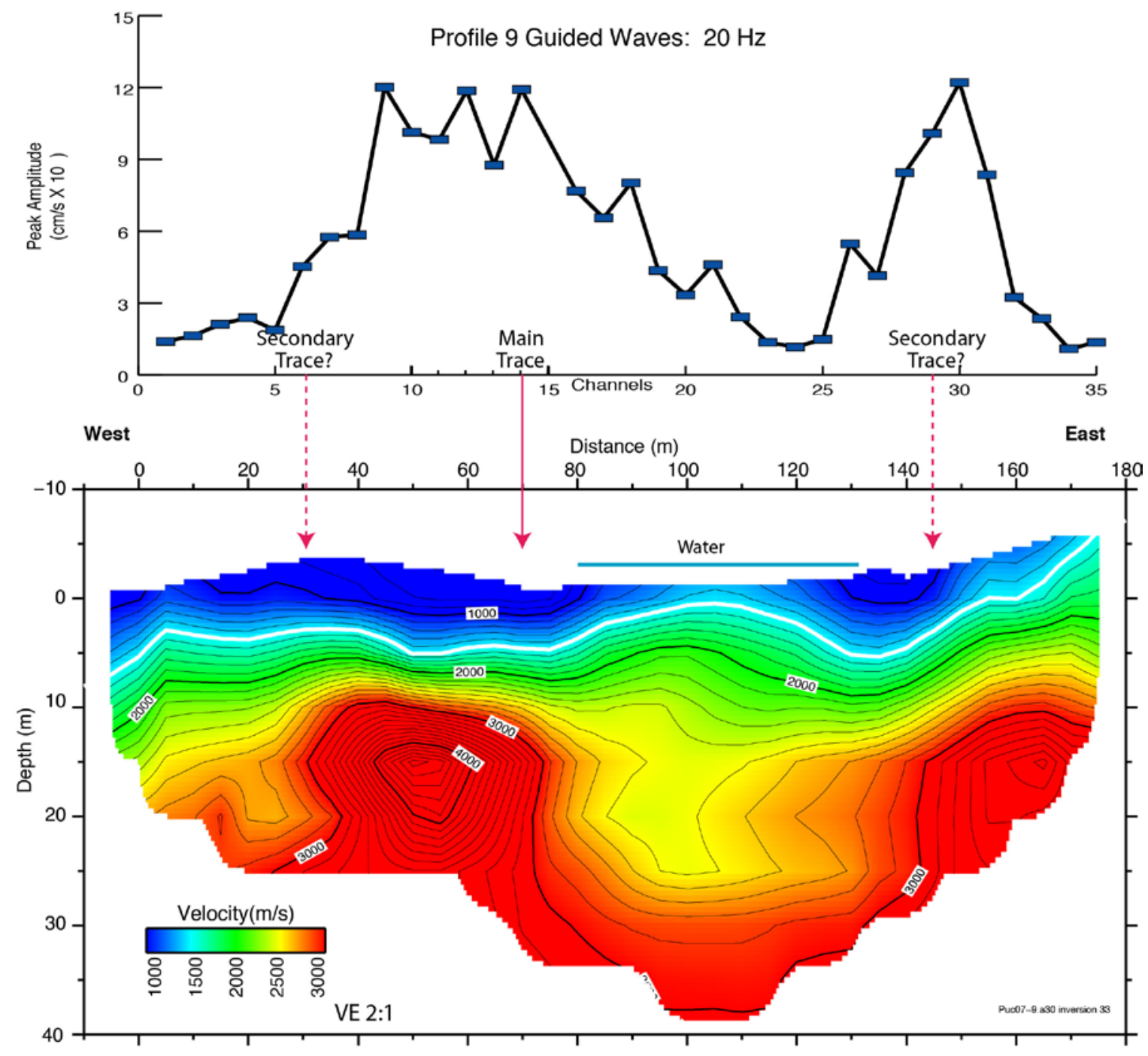

Fig. 17b

Figure 17.-Continued. 


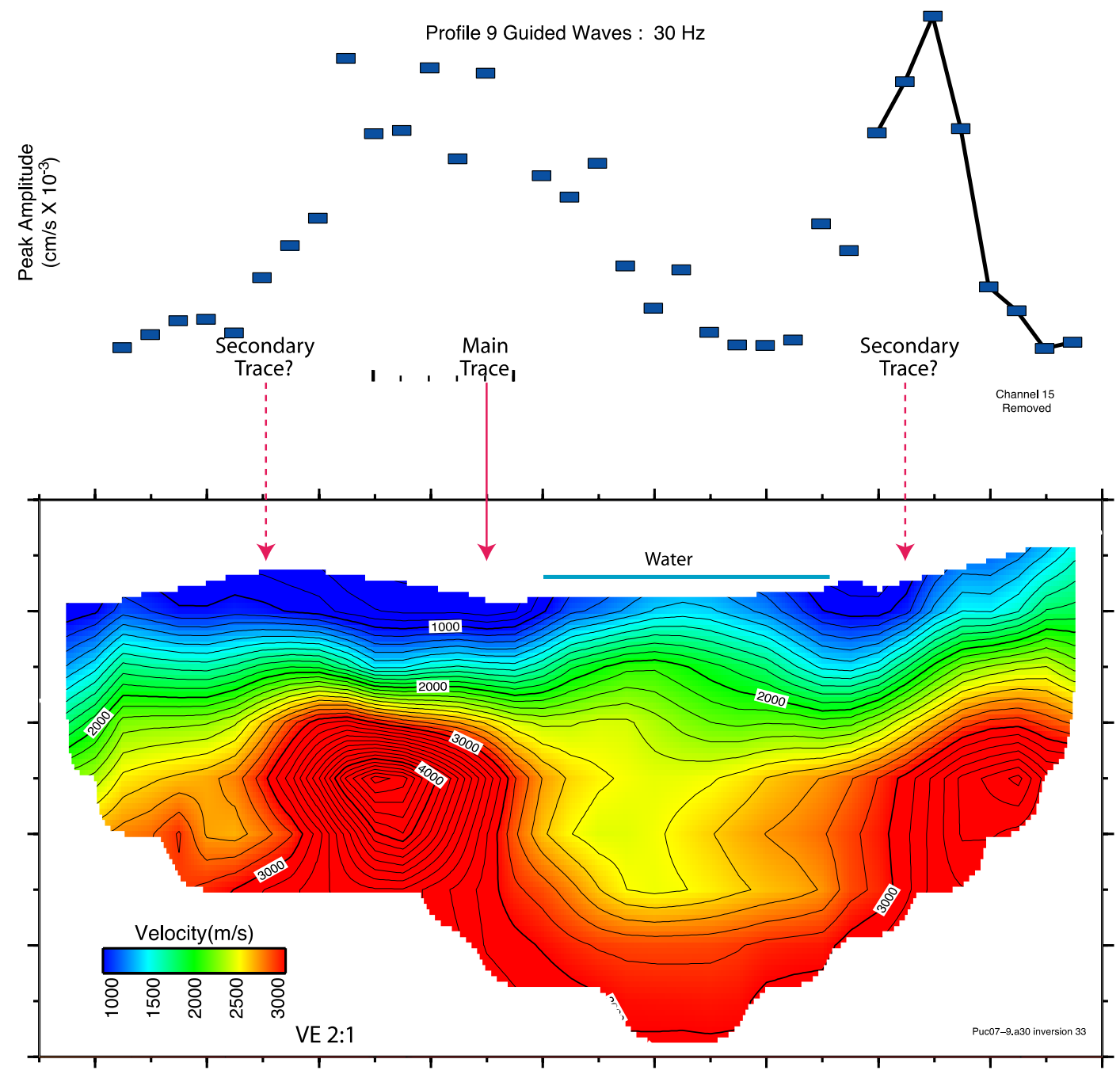

Fig. 17c

Figure 17.-Continued. 


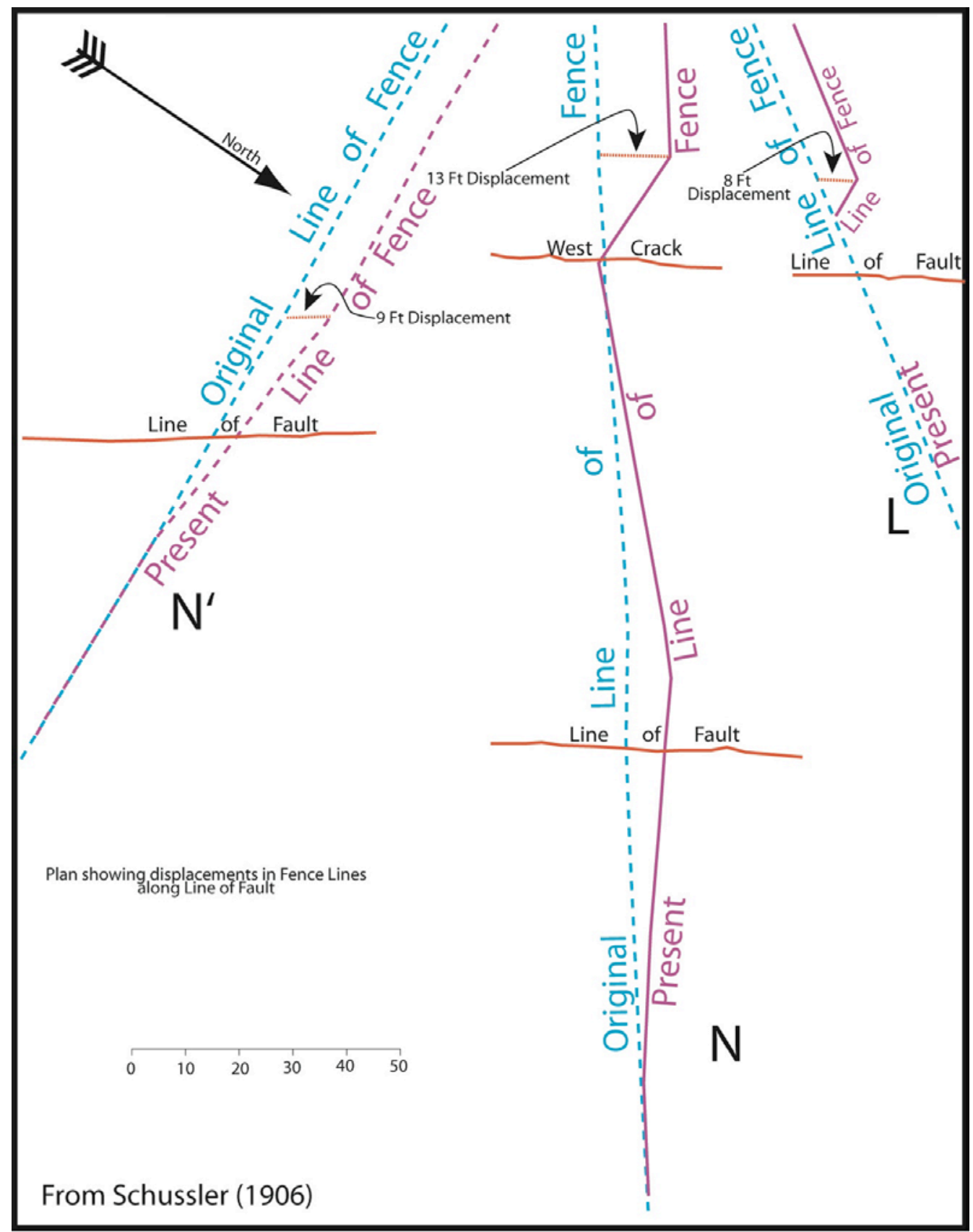

Figure 18. Map from Schussler (1906) showing off-fault displacements associated with the 1906 San Francisco earthquake at three separate locations (profiles L, N, and N') just south of San Andreas Lake (SAL). Profile N' was located at the northern end of Crystal Springs Reservoir (CSR), 2.2 kilometers south of the southern end of SAL. Profile N was located between CSR and SAL, 1.1 kilometers south of the southern end of SAL. Profile $L$ was located between CSR and SAL, $~ 0.55$ kilometers south of the southern end of SAL. There were significant lateral displacements $(\sim 4 \mathrm{~m})$ of fences, with the principal area of displacement as far as 35 meters from the surface rupture associated with the main surface trace of the San Andreas Fault. 


\section{Appendix 1. Acquisition and Geometry for Profile 6a}

\begin{tabular}{|c|c|c|c|c|c|c|c|c|}
\hline Sta.\# & Latitude & Longitude & Northing & Easting & Altitude & Local X & Local Y & Local Z \\
\hline 1 & 37.6005873 & -122.4273313 & 4161655 & 550550.47 & 102.69 & 0 & 0.56 & 0 \\
\hline 2 & 37.60059162 & -122.4273094 & 4161655.49 & 550552.4 & 102.7 & 1.98 & 0.71 & 0.01 \\
\hline 3 & 37.60059045 & -122.4272874 & 4161655.37 & 550554.34 & 102.77 & 3.88 & 0.26 & 0.08 \\
\hline 4 & 37.60059253 & -122.4272654 & 4161655.62 & 550556.28 & 102.76 & 5.83 & 0.17 & 0.07 \\
\hline 5 & 37.60059578 & -122.4272426 & 4161655.99 & 550558.29 & 102.75 & 7.88 & 0.2 & 0.06 \\
\hline 6 & 37.60059854 & -122.4272173 & 4161656.31 & 550560.53 & 102.84 & 10.13 & 0.13 & 0.15 \\
\hline 7 & 37.60060077 & -122.4271968 & 4161656.57 & 550562.33 & 102.88 & 11.95 & 0.08 & 0.19 \\
\hline 8 & 37.6006043 & -122.4271741 & 4161656.97 & 550564.33 & 102.86 & 13.99 & 0.13 & 0.17 \\
\hline 9 & 37.60060591 & -122.4271528 & 4161657.16 & 550566.21 & 102.89 & 15.88 & 0 & 0.2 \\
\hline 10 & 37.60060944 & -122.4271295 & 4161657.57 & 550568.26 & 102.91 & 17.97 & 0.05 & 0.22 \\
\hline 11 & 37.60061215 & -122.4271076 & 4161657.88 & 550570.2 & 102.93 & 19.93 & 0.02 & 0.24 \\
\hline 12 & 37.60061422 & -122.4270857 & 4161658.12 & 550572.13 & 102.92 & 21.88 & -0.07 & 0.23 \\
\hline 13 & 37.60061773 & -122.4270639 & 4161658.52 & 550574.05 & 102.89 & 23.84 & 0 & 0.2 \\
\hline 14 & 37.60062135 & -122.4270412 & 4161658.93 & 550576.06 & 102.91 & 25.89 & 0.06 & 0.22 \\
\hline 15 & 37.60062235 & -122.4270186 & 4161659.06 & 550578.04 & 102.97 & 27.87 & -0.16 & 0.28 \\
\hline 16 & 37.60062622 & -122.4269968 & 4161659.5 & 550579.97 & 103 & 29.84 & -0.05 & 0.31 \\
\hline 17 & 37.60062901 & -122.4269746 & 4161659.82 & 550581.92 & 103.03 & 31.82 & -0.07 & 0.34 \\
\hline 18 & 37.60063163 & -122.4269525 & 4161660.12 & 550583.88 & 103.07 & 33.8 & -0.1 & 0.38 \\
\hline 19 & 37.60063443 & -122.4269303 & 4161660.45 & 550585.84 & 103.1 & 35.79 & -0.12 & 0.41 \\
\hline 20 & 37.60063723 & -122.426908 & 4161660.77 & 550587.8 & 103.13 & 37.77 & -0.14 & 0.44 \\
\hline 21 & 37.60063743 & -122.4268847 & 4161660.8 & 550589.86 & 103.24 & 39.81 & -0.45 & 0.55 \\
\hline 22 & 37.60064051 & -122.4268619 & 4161661.16 & 550591.87 & 103.52 & 41.85 & -0.45 & 0.83 \\
\hline 23 & 37.60064391 & -122.426841 & 4161661.55 & 550593.71 & 103.69 & 43.73 & -0.38 & 1 \\
\hline 24 & 37.60064564 & -122.426818 & 4161661.75 & 550595.74 & 103.99 & 45.77 & -0.52 & 1.3 \\
\hline 25 & 37.60064745 & -122.4267953 & 4161661.96 & 550597.74 & 104.06 & 47.77 & -0.66 & 1.37 \\
\hline 26 & 37.60065043 & -122.4267734 & 4161662.3 & 550599.67 & 104.33 & 49.74 & -0.65 & 1.64 \\
\hline 27 & 37.60065349 & -122.4267514 & 4161662.66 & 550601.61 & 104.61 & 51.71 & -0.63 & 1.92 \\
\hline 28 & 37.60065655 & -122.4267294 & 4161663.01 & 550603.55 & 104.88 & 53.68 & -0.62 & 2.19 \\
\hline 29 & 37.60065962 & -122.4267074 & 4161663.36 & 550605.49 & 105.15 & 55.65 & -0.6 & 2.46 \\
\hline 30 & 37.60066268 & -122.4266856 & 4161663.71 & 550607.41 & 105.42 & 57.61 & -0.59 & 2.73 \\
\hline 31 & 37.60066574 & -122.4266636 & 4161664.06 & 550609.35 & 105.7 & 59.58 & -0.57 & 3.01 \\
\hline 32 & 37.60066872 & -122.4266416 & 4161664.41 & 550611.29 & 105.97 & 61.55 & -0.56 & 3.28 \\
\hline 33 & 37.60067187 & -122.4266197 & 4161664.77 & 550613.22 & 106.24 & 63.52 & -0.54 & 3.55 \\
\hline 34 & 37.60067484 & -122.4265977 & 4161665.11 & 550615.16 & 106.51 & 65.49 & -0.53 & 3.82 \\
\hline 35 & 37.600678 & -122.4265757 & 4161665.47 & 550617.1 & 106.79 & 67.46 & -0.51 & 4.1 \\
\hline 36 & 37.60068097 & -122.4265537 & 4161665.81 & 550619.05 & 107.06 & 69.43 & -0.5 & 4.37 \\
\hline 37 & 37.60068413 & -122.4265318 & 4161666.17 & 550620.98 & 107.33 & 71.4 & -0.48 & 4.64 \\
\hline 38 & 37.6006871 & -122.4265098 & 4161666.52 & 550622.92 & 107.6 & 73.37 & -0.47 & 4.91 \\
\hline 39 & 37.60069025 & -122.4264878 & 4161666.88 & 550624.86 & 107.88 & 75.34 & -0.45 & 5.19 \\
\hline 40 & 37.60069323 & -122.4264659 & 4161667.22 & 550626.79 & 108.15 & 77.3 & -0.44 & 5.46 \\
\hline
\end{tabular}




\begin{tabular}{|c|c|c|c|c|c|c|c|c|}
\hline 41 & 37.60069629 & -122.426444 & 4161667.57 & 550628.72 & 108.42 & 79.27 & -0.42 & 5.73 \\
\hline 42 & 37.60069935 & -122.426422 & 4161667.92 & 550630.66 & 108.69 & 81.24 & -0.41 & 6 \\
\hline 43 & 37.60070242 & -122.4264 & 4161668.27 & 550632.6 & 108.97 & 83.21 & -0.39 & 6.28 \\
\hline 44 & 37.60070548 & -122.4263781 & 4161668.63 & 550634.53 & 109.24 & 85.18 & -0.38 & 6.55 \\
\hline 45 & 37.60070945 & -122.4263555 & 4161669.08 & 550636.52 & 109.64 & 87.21 & -0.27 & 6.95 \\
\hline 46 & 37.60071161 & -122.4263337 & 4161669.33 & 550638.44 & 109.85 & 89.15 & -0.35 & 7.16 \\
\hline 47 & 37.60071576 & -122.4263118 & 4161669.8 & 550640.37 & 110.2 & 91.13 & -0.21 & 7.51 \\
\hline 48 & 37.60071971 & -122.4262903 & 4161670.25 & 550642.27 & 110.49 & 93.08 & -0.09 & 7.8 \\
\hline 49 & 37.60072224 & -122.426268 & 4161670.55 & 550644.24 & 110.9 & 95.07 & -0.14 & 8.21 \\
\hline 50 & 37.60072583 & -122.4262473 & 4161670.95 & 550646.06 & 111.06 & 96.94 & -0.05 & 8.37 \\
\hline 51 & 37.60072916 & -122.4262257 & 4161671.33 & 550647.97 & 111.18 & 98.88 & 0 & 8.49 \\
\hline 52 & 37.6007334 & -122.4262033 & 4161671.82 & 550649.94 & 111.47 & 100.91 & 0.14 & 8.78 \\
\hline 53 & 37.60073647 & -122.4261808 & 4161672.17 & 550651.93 & 111.89 & 102.93 & 0.15 & 9.2 \\
\hline 54 & 37.60073821 & -122.4261623 & 4161672.37 & 550653.55 & 112.17 & 104.56 & 0.07 & 9.48 \\
\hline 55 & 37.60074377 & -122.4261367 & 4161673 & 550655.82 & 112.76 & 106.9 & 0.3 & 10.07 \\
\hline 56 & 37.60074609 & -122.4261163 & 4161673.27 & 550657.61 & 112.95 & 108.72 & 0.26 & 10.26 \\
\hline 57 & 37.60074944 & -122.4260934 & 4161673.66 & 550659.63 & 113.26 & 110.77 & 0.3 & 10.57 \\
\hline 58 & 37.60075368 & -122.426071 & 4161674.14 & 550661.61 & 113.43 & 112.8 & 0.43 & 10.74 \\
\hline 59 & 37.60075594 & -122.4260486 & 4161674.4 & 550663.58 & 113.49 & 114.79 & 0.36 & 10.8 \\
\hline
\end{tabular}

\section{Appendix 2. Acquisition and Geometry for Profile 6b}

\begin{tabular}{|c|c|c|c|c|c|c|c|c|}
\hline Sta \# & Latitude & Longitude & Northing & Easting & Altitude & Local X & Local Y & Local Z \\
\hline 1 & 37.60053137 & -122.4278985 & 4161648.49 & 550500.44 & 97.56 & 0 & 0.22 & 0 \\
\hline 2 & 37.60053239 & -122.4278863 & 4161648.61 & 550501.51 & 97.85 & 1.08 & 0.18 & 0.29 \\
\hline 3 & 37.6005336 & -122.427876 & 4161648.75 & 550502.42 & 97.62 & 2 & 0.18 & 0.06 \\
\hline 4 & 37.60053607 & -122.4278652 & 4161649.03 & 550503.37 & 97.87 & 2.98 & 0.32 & 0.31 \\
\hline 5 & 37.60053602 & -122.4278538 & 4161649.03 & 550504.38 & 97.71 & 3.98 & 0.18 & 0.15 \\
\hline 6 & 37.60053568 & -122.42784 & 4161649 & 550505.6 & 97.93 & 5.18 & -0.03 & 0.37 \\
\hline 7 & 37.60053843 & -122.427831 & 4161649.31 & 550506.39 & 97.72 & 6.01 & 0.16 & 0.16 \\
\hline 8 & 37.60053838 & -122.4278209 & 4161649.31 & 550507.28 & 97.75 & 6.89 & 0.03 & 0.19 \\
\hline 9 & 37.60054013 & -122.4278086 & 4161649.51 & 550508.37 & 97.88 & 8 & 0.07 & 0.32 \\
\hline 10 & 37.60054107 & -122.4277981 & 4161649.62 & 550509.29 & 97.91 & 8.92 & 0.05 & 0.35 \\
\hline 11 & 37.60054201 & -122.4277878 & 4161649.73 & 550510.2 & 97.93 & 9.84 & 0.02 & 0.37 \\
\hline 12 & 37.60054258 & -122.4277758 & 4161649.8 & 550511.26 & 98.13 & 10.9 & -0.06 & 0.57 \\
\hline 13 & 37.60054442 & -122.4277642 & 4161650.01 & 550512.28 & 98.24 & 11.94 & 0 & 0.68 \\
\hline 14 & 37.60054535 & -122.4277531 & 4161650.12 & 550513.26 & 98.38 & 12.92 & -0.04 & 0.82 \\
\hline 15 & 37.60054666 & -122.4277429 & 4161650.27 & 550514.16 & 98.6 & 13.83 & -0.02 & 1.04 \\
\hline 16 & 37.60054822 & -122.4277298 & 4161650.45 & 550515.32 & 98.85 & 15.01 & -0.01 & 1.29 \\
\hline 17 & 37.60054788 & -122.4277172 & 4161650.42 & 550516.43 & 98.93 & 16.1 & -0.2 & 1.37 \\
\hline 18 & 37.60054919 & -122.427708 & 4161650.57 & 550517.24 & 99.09 & 16.93 & -0.17 & 1.53 \\
\hline
\end{tabular}




\begin{tabular}{|c|c|c|c|c|c|c|c|c|}
\hline 19 & 37.60055157 & -122.4276968 & 4161650.84 & 550518.23 & 99 & 17.94 & -0.05 & 1.44 \\
\hline 20 & 37.60055161 & -122.4276852 & 4161650.85 & 550519.25 & 99.29 & 18.95 & -0.19 & 1.73 \\
\hline 21 & 37.60055335 & -122.427674 & 4161651.05 & 550520.24 & 99.36 & 19.96 & -0.13 & 1.8 \\
\hline 22 & 37.60055411 & -122.4276629 & 4161651.14 & 550521.22 & 99.61 & 20.95 & -0.19 & 2.05 \\
\hline 23 & 37.60055657 & -122.4276503 & 4161651.42 & 550522.33 & 99.29 & 22.09 & -0.07 & 1.73 \\
\hline 24 & 37.60055931 & -122.4276394 & 4161651.73 & 550523.29 & 99.86 & 23.08 & 0.09 & 2.3 \\
\hline 25 & 37.60055854 & -122.4276289 & 4161651.65 & 550524.22 & 99.75 & 23.99 & -0.12 & 2.19 \\
\hline 26 & 37.6005594 & -122.4276196 & 4161651.75 & 550525.04 & 99.51 & 24.81 & -0.14 & 1.95 \\
\hline 27 & 37.60056114 & -122.4276074 & 4161651.95 & 550526.11 & 99.77 & 25.9 & -0.1 & 2.21 \\
\hline 28 & 37.6005619 & -122.4275955 & 4161652.04 & 550527.16 & 99.97 & 26.95 & -0.16 & 2.41 \\
\hline 29 & 37.60056428 & -122.4275842 & 4161652.31 & 550528.16 & 99.8 & 27.98 & -0.04 & 2.24 \\
\hline 30 & 37.60056242 & -122.427573 & 4161652.11 & 550529.15 & 99.79 & 28.93 & -0.38 & 2.23 \\
\hline 31 & 37.60056516 & -122.427562 & 4161652.42 & 550530.12 & 99.87 & 29.94 & -0.22 & 2.31 \\
\hline 32 & 37.60056799 & -122.4275511 & 4161652.74 & 550531.08 & 99.95 & 30.93 & -0.04 & 2.39 \\
\hline 33 & 37.60056929 & -122.4275394 & 4161652.89 & 550532.11 & 100 & 31.98 & -0.04 & 2.44 \\
\hline 34 & 37.60056941 & -122.427528 & 4161652.91 & 550533.12 & 100.54 & 32.98 & -0.17 & 2.98 \\
\hline 35 & 37.60057207 & -122.4275181 & 4161653.21 & 550533.99 & 100.26 & 33.88 & 0 & 2.7 \\
\hline 36 & 37.60057354 & -122.427506 & 4161653.38 & 550535.06 & 100.35 & 34.96 & 0.01 & 2.79 \\
\hline 37 & 37.60057557 & -122.4274961 & 4161653.61 & 550535.93 & 100.66 & 35.86 & 0.11 & 3.1 \\
\hline 38 & 37.6005765 & -122.4274846 & 4161653.72 & 550536.94 & 100.49 & 36.87 & 0.08 & 2.93 \\
\hline 39 & 37.60057752 & -122.4274726 & 4161653.84 & 550538 & 100.51 & 37.94 & 0.04 & 2.95 \\
\hline 40 & 37.60057873 & -122.4274609 & 4161653.98 & 550539.03 & 100.54 & 38.98 & 0.03 & 2.98 \\
\hline 41 & 37.60057931 & -122.42745 & 4161654.05 & 550540 & 100.67 & 39.95 & -0.04 & 3.11 \\
\hline 42 & 37.60058097 & -122.4274396 & 4161654.24 & 550540.91 & 101.06 & 40.88 & 0.01 & 3.5 \\
\hline 43 & 37.60058154 & -122.4274277 & 4161654.31 & 550541.96 & 101.06 & 41.93 & -0.07 & 3.5 \\
\hline 44 & 37.60058934 & -122.4274182 & 4161655.18 & 550542.8 & 101.19 & 42.88 & 0.67 & 3.63 \\
\hline 45 & 37.60059217 & -122.4274068 & 4161655.5 & 550543.8 & 101.28 & 43.92 & 0.84 & 3.72 \\
\hline 46 & 37.60058652 & -122.4273954 & 4161654.88 & 550544.81 & 100.96 & 44.83 & 0.08 & 3.4 \\
\hline 47 & 37.60058656 & -122.4273838 & 4161654.89 & 550545.83 & 101.34 & 45.84 & -0.06 & 3.78 \\
\hline 48 & 37.60058704 & -122.4273725 & 4161654.95 & 550546.83 & 101.48 & 46.84 & -0.15 & 3.92 \\
\hline 49 & 37.60058969 & -122.4273606 & 4161655.25 & 550547.88 & 102.03 & 47.92 & 0 & 4.47 \\
\hline 50 & 37.60059036 & -122.4273498 & 4161655.33 & 550548.83 & 102.07 & 48.87 & -0.06 & 4.51 \\
\hline 51 & 37.60059166 & -122.4273397 & 4161655.48 & 550549.72 & 102.03 & 49.77 & -0.04 & 4.47 \\
\hline 52 & 37.60059332 & -122.4273284 & 4161655.67 & 550550.72 & 101.92 & 50.79 & 0 & 4.36 \\
\hline 53 & 37.60059443 & -122.4273166 & 4161655.8 & 550551.76 & 102.32 & 51.84 & -0.02 & 4.76 \\
\hline 54 & 37.60059511 & -122.4273072 & 4161655.88 & 550552.59 & 101.94 & 52.67 & -0.06 & 4.38 \\
\hline 55 & 37.60059612 & -122.4272934 & 4161656 & 550553.81 & 101.94 & 53.9 & -0.12 & 4.38 \\
\hline 56 & 37.60059769 & -122.4272828 & 4161656.18 & 550554.74 & 102 & 54.84 & -0.08 & 4.44 \\
\hline 57 & 37.60059909 & -122.4272722 & 4161656.34 & 550555.68 & 102.04 & 55.8 & -0.06 & 4.48 \\
\hline 58 & 37.60060057 & -122.4272616 & 4161656.51 & 550556.61 & 102.08 & 56.74 & -0.03 & 4.52 \\
\hline 59 & 37.60060231 & -122.4272493 & 4161656.71 & 550557.7 & 101.98 & 57.85 & 0.01 & 4.42 \\
\hline 60 & 37.60060316 & -122.4272392 & 4161656.81 & 550558.59 & 101.96 & 58.74 & -0.02 & 4.4 \\
\hline
\end{tabular}




\section{Appendix 3. Acquisition and Geometry for Profile 6c}

\begin{tabular}{|c|c|c|c|c|c|c|c|c|}
\hline Sta.\# & Latitude & Longitude & Northing & Easting & Altitude & Local X & Local Y & Local Z \\
\hline 1 & 37.60051032 & -122.4281125 & 4161646.04 & 550481.56 & 99.44 & 0 & 0.69 & 0.06 \\
\hline 2 & 37.60051162 & -122.4281014 & 4161646.19 & 550482.54 & 99.52 & 0.99 & 0.68 & 0.14 \\
\hline 3 & 37.60051292 & -122.4280902 & 4161646.34 & 550483.53 & 99.6 & 1.99 & 0.66 & 0.22 \\
\hline 4 & 37.60051422 & -122.428079 & 4161646.49 & 550484.52 & 99.69 & 2.99 & 0.65 & 0.31 \\
\hline 5 & 37.60051551 & -122.428068 & 4161646.64 & 550485.49 & 99.77 & 3.98 & 0.63 & 0.39 \\
\hline 6 & 37.6005169 & -122.4280566 & 4161646.8 & 550486.49 & 99.85 & 4.99 & 0.61 & 0.47 \\
\hline 7 & 37.6005182 & -122.4280455 & 4161646.95 & 550487.47 & 99.93 & 5.98 & 0.59 & 0.55 \\
\hline 8 & 37.6005195 & -122.4280343 & 4161647.1 & 550488.46 & 100.01 & 6.98 & 0.58 & 0.63 \\
\hline 9 & 37.60052223 & -122.4280218 & 4161647.41 & 550489.56 & 100.16 & 8.11 & 0.42 & 0.78 \\
\hline 10 & 37.60052468 & -122.4280074 & 4161647.69 & 550490.83 & 100.3 & 9.41 & 0.32 & 0.92 \\
\hline 11 & 37.60052554 & -122.4279979 & 4161647.79 & 550491.67 & 100.41 & 10.25 & 0.33 & 1.03 \\
\hline 12 & 37.60052757 & -122.427989 & 4161648.02 & 550492.45 & 100.48 & 11.06 & 0.21 & 1.1 \\
\hline 13 & 37.6005284 & -122.4279752 & 4161648.12 & 550493.67 & 100.54 & 12.28 & 0.28 & 1.16 \\
\hline 14 & 37.60052944 & -122.4279662 & 4161648.24 & 550494.46 & 100.64 & 13.08 & 0.26 & 1.26 \\
\hline 15 & 37.60053074 & -122.4279546 & 4161648.39 & 550495.49 & 100.75 & 14.12 & 0.26 & 1.37 \\
\hline 16 & 37.60053194 & -122.4279419 & 4161648.53 & 550496.61 & 100.81 & 15.25 & 0.27 & 1.43 \\
\hline 17 & 37.60053325 & -122.4279328 & 4161648.68 & 550497.41 & 100.87 & 16.06 & 0.23 & 1.49 \\
\hline 18 & 37.60053417 & -122.4279188 & 4161648.79 & 550498.64 & 100.97 & 17.29 & 0.29 & 1.59 \\
\hline 19 & 37.60053611 & -122.4279102 & 4161649.01 & 550499.4 & 101.03 & 18.08 & 0.17 & 1.65 \\
\hline 20 & 37.60053768 & -122.4278984 & 4161649.19 & 550500.44 & 101.08 & 19.13 & 0.13 & 1.7 \\
\hline 21 & 37.60053916 & -122.4278884 & 4161649.36 & 550501.32 & 101.12 & 20.03 & 0.09 & 1.74 \\
\hline 22 & 37.60054037 & -122.427877 & 4161649.5 & 550502.33 & 101.21 & 21.05 & 0.08 & 1.83 \\
\hline 23 & 37.60054184 & -122.4278654 & 4161649.67 & 550503.35 & 101.25 & 22.08 & 0.05 & 1.87 \\
\hline 24 & 37.60054377 & -122.4278542 & 4161649.89 & 550504.34 & 101.3 & 23.09 & -0.03 & 1.92 \\
\hline 25 & 37.6005448 & -122.4278429 & 4161650.01 & 550505.34 & 101.34 & 24.1 & -0.01 & 1.96 \\
\hline 26 & 37.60054618 & -122.4278303 & 4161650.17 & 550506.45 & 101.46 & 25.22 & -0.02 & 2.08 \\
\hline 27 & 37.60054703 & -122.4278203 & 4161650.27 & 550507.33 & 101.49 & 26.11 & 0 & 2.11 \\
\hline 28 & 37.60054914 & -122.4278098 & 4161650.51 & 550508.26 & 101.56 & 27.06 & -0.11 & 2.18 \\
\hline 29 & 37.60055044 & -122.4277989 & 4161650.66 & 550509.22 & 101.6 & 28.03 & -0.13 & 2.22 \\
\hline 30 & 37.60055246 & -122.4277871 & 4161650.89 & 550510.26 & 101.7 & 29.09 & -0.22 & 2.32 \\
\hline 31 & 37.60055341 & -122.4277777 & 4161651 & 550511.09 & 101.75 & 29.93 & -0.21 & 2.37 \\
\hline 32 & 37.60055362 & -122.4277661 & 4161651.03 & 550512.11 & 101.85 & 30.94 & -0.11 & 2.47 \\
\hline 33 & 37.60055527 & -122.4277535 & 4161651.22 & 550513.22 & 101.99 & 32.07 & -0.14 & 2.61 \\
\hline 34 & 37.60055719 & -122.4277409 & 4161651.44 & 550514.33 & 102.19 & 33.2 & -0.21 & 2.81 \\
\hline 35 & 37.6005594 & -122.4277303 & 4161651.69 & 550515.27 & 102.28 & 34.16 & -0.33 & 2.9 \\
\hline 36 & 37.60055917 & -122.4277206 & 4161651.67 & 550516.12 & 102.35 & 35 & -0.2 & 2.97 \\
\hline 37 & 37.60056047 & -122.4277108 & 4161651.82 & 550516.99 & 102.43 & 35.89 & -0.23 & 3.05 \\
\hline 38 & 37.6005614 & -122.4276983 & 4161651.93 & 550518.09 & 102.56 & 36.99 & -0.19 & 3.18 \\
\hline
\end{tabular}




\begin{tabular}{|c|c|c|c|c|c|c|c|c|}
\hline 39 & 37.60056162 & -122.4276881 & 4161651.96 & 550518.99 & 102.63 & 37.89 & -0.09 & 3.25 \\
\hline 40 & 37.60056372 & -122.4276749 & 4161652.2 & 550520.15 & 102.73 & 39.07 & -0.18 & 3.35 \\
\hline 41 & 37.60056458 & -122.4276655 & 4161652.3 & 550520.98 & 102.75 & 39.9 & -0.16 & 3.37 \\
\hline 42 & 37.60056659 & -122.4276533 & 4161652.53 & 550522.06 & 102.9 & 41.01 & -0.24 & 3.52 \\
\hline 43 & 37.60056752 & -122.4276409 & 4161652.64 & 550523.15 & 102.96 & 42.1 & -0.2 & 3.58 \\
\hline 44 & 37.60056847 & -122.4276308 & 4161652.75 & 550524.04 & 103.08 & 43 & -0.19 & 3.7 \\
\hline 45 & 37.60056922 & -122.4276191 & 4161652.84 & 550525.08 & 103.26 & 44.04 & -0.14 & 3.88 \\
\hline 46 & 37.60056926 & -122.4276089 & 4161652.85 & 550525.98 & 103.17 & 44.93 & -0.03 & 3.79 \\
\hline 47 & 37.60057155 & -122.4275966 & 4161653.11 & 550527.06 & 103.26 & 46.04 & -0.14 & 3.88 \\
\hline 48 & 37.60057258 & -122.4275862 & 4161653.23 & 550527.98 & 103.33 & 46.97 & -0.13 & 3.95 \\
\hline 49 & 37.60057495 & -122.427573 & 4161653.5 & 550529.14 & 103.44 & 48.15 & -0.24 & 4.06 \\
\hline 50 & 37.60057598 & -122.4275625 & 4161653.62 & 550530.07 & 103.51 & 49.09 & -0.24 & 4.13 \\
\hline 51 & 37.6005771 & -122.4275524 & 4161653.75 & 550530.96 & 103.57 & 49.99 & -0.24 & 4.19 \\
\hline 52 & 37.60057903 & -122.4275416 & 4161653.97 & 550531.91 & 103.64 & 50.96 & -0.33 & 4.26 \\
\hline 53 & 37.60057951 & -122.4275294 & 4161654.03 & 550532.99 & 103.74 & 52.04 & -0.25 & 4.36 \\
\hline 54 & 37.60058126 & -122.4275185 & 4161654.23 & 550533.95 & 103.81 & 53.02 & -0.31 & 4.43 \\
\hline 55 & 37.60058283 & -122.427508 & 4161654.41 & 550534.87 & 103.86 & 53.95 & -0.37 & 4.48 \\
\hline 56 & 37.6005835 & -122.4274967 & 4161654.49 & 550535.87 & 103.93 & 54.95 & -0.31 & 4.55 \\
\hline 57 & 37.6005839 & -122.4274863 & 4161654.54 & 550536.79 & 103.99 & 55.87 & -0.24 & 4.61 \\
\hline 58 & 37.60058573 & -122.4274744 & 4161654.75 & 550537.84 & 104.08 & 56.94 & -0.3 & 4.7 \\
\hline 59 & 37.60058613 & -122.4274636 & 4161654.8 & 550538.79 & 104.16 & 57.89 & -0.22 & 4.78 \\
\hline 60 & 37.60058752 & -122.427452 & 4161654.96 & 550539.81 & 104.22 & 58.92 & -0.24 & 4.84 \\
\hline 61 & 37.60058854 & -122.4274401 & 4161655.08 & 550540.86 & 104.27 & 59.98 & -0.22 & 4.89 \\
\hline 62 & 37.60058948 & -122.4274293 & 4161655.19 & 550541.82 & 104.33 & 60.94 & -0.2 & 4.95 \\
\hline 63 & 37.60059205 & -122.4274189 & 4161655.48 & 550542.73 & 104.41 & 61.88 & -0.36 & 5.03 \\
\hline 64 & 37.60059361 & -122.4274066 & 4161655.66 & 550543.82 & 104.52 & 62.99 & -0.39 & 5.14 \\
\hline 65 & 37.60059446 & -122.4273959 & 4161655.76 & 550544.76 & 104.58 & 63.93 & -0.37 & 5.2 \\
\hline 66 & 37.60059594 & -122.4273849 & 4161655.93 & 550545.73 & 104.71 & 64.92 & -0.4 & 5.33 \\
\hline 67 & 37.60059688 & -122.4273743 & 4161656.04 & 550546.67 & 104.94 & 65.86 & -0.38 & 5.56 \\
\hline 68 & 37.600596 & -122.4273608 & 4161655.95 & 550547.86 & 105.5 & 67.03 & -0.13 & 6.12 \\
\hline 69 & 37.60059768 & -122.4273534 & 4161656.14 & 550548.51 & 105.51 & 67.7 & -0.23 & 6.13 \\
\hline 70 & 37.60059978 & -122.4273409 & 4161656.38 & 550549.61 & 105.53 & 68.82 & -0.32 & 6.15 \\
\hline 71 & 37.60060044 & -122.4273281 & 4161656.46 & 550550.74 & 105.54 & 69.95 & -0.25 & 6.16 \\
\hline 72 & 37.60059966 & -122.4273169 & 4161656.38 & 550551.73 & 105.55 & 70.92 & -0.03 & 6.17 \\
\hline 73 & 37.60059943 & -122.4273064 & 4161656.36 & 550552.66 & 105.58 & 71.84 & 0.11 & 6.2 \\
\hline 74 & 37.60060001 & -122.4272946 & 4161656.43 & 550553.7 & 105.62 & 72.88 & 0.18 & 6.24 \\
\hline 75 & 37.60060168 & -122.4272859 & 4161656.62 & 550554.47 & 105.62 & 73.67 & 0.1 & 6.24 \\
\hline 76 & 37.60060369 & -122.4272742 & 4161656.85 & 550555.5 & 105.6 & 74.72 & 0.01 & 6.22 \\
\hline 77 & 37.60060265 & -122.427263 & 4161656.74 & 550556.49 & 105.68 & 75.69 & 0.26 & 6.3 \\
\hline 78 & 37.60060277 & -122.4272514 & 4161656.76 & 550557.51 & 105.68 & 76.7 & 0.37 & 6.3 \\
\hline 79 & 37.60060307 & -122.4272389 & 4161656.8 & 550558.61 & 105.7 & 77.8 & 0.48 & 6.32 \\
\hline 80 & 37.60060446 & -122.4272277 & 4161656.96 & 550559.6 & 105.72 & 78.8 & 0.46 & 6.34 \\
\hline 81 & 37.60060619 & -122.4272141 & 4161657.16 & 550560.8 & 105.73 & 80.02 & 0.42 & 6.35 \\
\hline
\end{tabular}




$\begin{array}{lllllllll}82 & 37.60060821 & -122.4272029 & 4161657.39 & 550561.79 & 105.72 & 81.03 & 0.33 & 6.34 \\ 83 & 37.60060763 & -122.4271933 & 4161657.33 & 550562.64 & 105.76 & 81.86 & 0.5 & 6.38 \\ 84 & 37.60060856 & -122.4271823 & 4161657.44 & 550563.61 & 105.79 & 82.84 & 0.53 & 6.41 \\ 85 & 37.60060905 & -122.4271709 & 4161657.5 & 550564.61 & 105.81 & 83.84 & 0.6 & 6.43 \\ 86 & 37.60060981 & -122.427161 & 4161657.59 & 550565.49 & 105.81 & 84.72 & 0.63 & 6.43 \\ 87 & 37.60061102 & -122.4271506 & 4161657.73 & 550566.4 & 105.86 & 85.64 & 0.62 & 6.48 \\ 88 & 37.60061069 & -122.4271368 & 4161657.7 & 550567.62 & 105.82 & 86.85 & 0.81 & 6.44\end{array}$

\section{Appendix 4. Acquisition and Geometry for Profile 8}

\begin{tabular}{|c|c|c|c|c|c|c|c|c|}
\hline Sta \# & Latitude & Longitude & Northing & Easting & Altitude & Local X & Local Y & Local Z \\
\hline 1 & 37.58747374 & -122.416867 & 4160205.79 & 551483.21 & 98.08 & 0 & -0.31 & 0 \\
\hline 2 & 37.58747657 & -122.4168551 & 4160206.11 & 551484.26 & 98.2 & 1.08 & -0.08 & 0.12 \\
\hline 3 & 37.58748067 & -122.4168454 & 4160206.57 & 551485.11 & 98.4 & 2.04 & -0.07 & 0.32 \\
\hline 4 & 37.58748485 & -122.4168357 & 4160207.04 & 551485.97 & 98.69 & 3.02 & -0.06 & 0.61 \\
\hline 5 & 37.58749021 & -122.416825 & 4160207.64 & 551486.91 & 98.97 & 4.14 & -0.13 & 0.89 \\
\hline 6 & 37.58749332 & -122.416816 & 4160207.99 & 551487.7 & 99.18 & 5 & -0.05 & 1.1 \\
\hline 7 & 37.58749696 & -122.4168056 & 4160208.4 & 551488.62 & 99.41 & 6 & 0.04 & 1.33 \\
\hline 8 & 37.5874997 & -122.4167944 & 4160208.71 & 551489.6 & 99.7 & 7.01 & 0.25 & 1.62 \\
\hline 9 & 37.58750544 & -122.4167873 & 4160209.35 & 551490.23 & 99.9 & 7.87 & -0.01 & 1.82 \\
\hline 10 & 37.58750988 & -122.4167751 & 4160209.85 & 551491.3 & 100 & 9.05 & 0.08 & 1.92 \\
\hline 11 & 37.58751407 & -122.4167653 & 4160210.32 & 551492.16 & 100.16 & 10.03 & 0.08 & 2.08 \\
\hline 12 & 37.58751816 & -122.4167533 & 4160210.78 & 551493.22 & 100.48 & 11.18 & 0.2 & 2.4 \\
\hline 13 & 37.58752191 & -122.4167459 & 4160211.2 & 551493.87 & 100.57 & 11.95 & 0.14 & 2.49 \\
\hline 14 & 37.58752672 & -122.4167361 & 4160211.74 & 551494.73 & 100.72 & 12.96 & 0.09 & 2.64 \\
\hline 15 & 37.58753208 & -122.416726 & 4160212.34 & 551495.62 & 100.95 & 14.03 & 0 & 2.87 \\
\hline 16 & 37.58753646 & -122.4167176 & 4160212.83 & 551496.36 & 101.09 & 14.92 & -0.07 & 3.01 \\
\hline 17 & 37.58754101 & -122.4167087 & 4160213.34 & 551497.14 & 101.28 & 15.85 & -0.13 & 3.2 \\
\hline 18 & 37.58754574 & -122.4166991 & 4160213.87 & 551497.99 & 101.4 & 16.85 & -0.19 & 3.32 \\
\hline 19 & 37.58754867 & -122.4166891 & 4160214.2 & 551498.87 & 101.49 & 17.78 & -0.04 & 3.41 \\
\hline 20 & 37.5875533 & -122.4166783 & 4160214.72 & 551499.82 & 101.55 & 18.86 & -0.04 & 3.47 \\
\hline 21 & 37.58755667 & -122.416668 & 4160215.1 & 551500.72 & 101.52 & 19.83 & 0.07 & 3.44 \\
\hline 22 & 37.5875605 & -122.4166573 & 4160215.53 & 551501.67 & 101.46 & 20.87 & 0.15 & 3.38 \\
\hline 23 & 37.58756658 & -122.4166477 & 4160216.21 & 551502.51 & 101.44 & 21.93 & -0.03 & 3.36 \\
\hline 24 & 37.58757086 & -122.4166388 & 4160216.69 & 551503.29 & 101.42 & 22.85 & -0.07 & 3.34 \\
\hline 25 & 37.5875745 & -122.416628 & 4160217.1 & 551504.24 & 101.39 & 23.88 & 0.03 & 3.31 \\
\hline 26 & 37.58757878 & -122.4166178 & 4160217.58 & 551505.14 & 101.36 & 24.9 & 0.05 & 3.28 \\
\hline 27 & 37.58758197 & -122.4166074 & 4160217.94 & 551506.06 & 101.35 & 25.88 & 0.18 & 3.27 \\
\hline 28 & 37.58758734 & -122.4165986 & 4160218.54 & 551506.83 & 101.3 & 26.84 & 0.03 & 3.22 \\
\hline 29 & 37.5875908 & -122.4165873 & 4160218.93 & 551507.83 & 101.32 & 27.91 & 0.18 & 3.24 \\
\hline 30 & 37.58759562 & -122.416578 & 4160219.47 & 551508.64 & 101.34 & 28.88 & 0.1 & 3.26 \\
\hline 31 & 37.5876008 & -122.4165689 & 4160220.05 & 551509.44 & 101.32 & 29.86 & -0.02 & 3.24 \\
\hline
\end{tabular}




\begin{tabular}{|c|c|c|c|c|c|c|c|c|}
\hline 32 & 37.5876048 & -122.4165584 & 4160220.5 & 551510.37 & 101.33 & 30.89 & 0.04 & 3.25 \\
\hline 33 & 37.58760926 & -122.416549 & 4160221 & 551511.19 & 101.35 & 31.85 & 0 & 3.27 \\
\hline 34 & 37.58761363 & -122.4165386 & 4160221.49 & 551512.11 & 101.4 & 32.89 & 0.02 & 3.32 \\
\hline 35 & 37.58761754 & -122.4165281 & 4160221.93 & 551513.03 & 101.42 & 33.91 & 0.08 & 3.34 \\
\hline 36 & 37.58762318 & -122.4165193 & 4160222.56 & 551513.81 & 101.43 & 34.9 & -0.09 & 3.35 \\
\hline 37 & 37.58762736 & -122.4165093 & 4160223.03 & 551514.69 & 101.43 & 35.9 & -0.07 & 3.35 \\
\hline 38 & 37.58763056 & -122.4164993 & 4160223.39 & 551515.57 & 101.49 & 36.84 & 0.04 & 3.41 \\
\hline 39 & 37.58763466 & -122.4164892 & 4160223.85 & 551516.46 & 101.49 & 37.84 & 0.07 & 3.41 \\
\hline 40 & 37.5876392 & -122.416479 & 4160224.36 & 551517.35 & 101.5 & 38.87 & 0.06 & 3.42 \\
\hline 41 & 37.58764366 & -122.4164693 & 4160224.86 & 551518.21 & 101.54 & 39.86 & 0.04 & 3.46 \\
\hline 42 & 37.58764929 & -122.4164596 & 4160225.49 & 551519.06 & 101.55 & 40.91 & -0.1 & 3.47 \\
\hline 43 & 37.58765493 & -122.4164507 & 4160226.12 & 551519.84 & 101.56 & 41.9 & -0.26 & 3.48 \\
\hline 44 & 37.58765776 & -122.4164408 & 4160226.44 & 551520.71 & 101.62 & 42.81 & -0.12 & 3.54 \\
\hline 45 & 37.5876624 & -122.4164308 & 4160226.96 & 551521.59 & 101.67 & 43.84 & -0.15 & 3.59 \\
\hline 46 & 37.58766559 & -122.4164194 & 4160227.32 & 551522.6 & 101.77 & 44.89 & 0.03 & 3.69 \\
\hline 47 & 37.5876695 & -122.4164088 & 4160227.76 & 551523.53 & 101.8 & 45.92 & 0.1 & 3.72 \\
\hline 48 & 37.58767423 & -122.416399 & 4160228.29 & 551524.39 & 101.85 & 46.93 & 0.05 & 3.77 \\
\hline 49 & 37.58767842 & -122.4163897 & 4160228.76 & 551525.21 & 101.88 & 47.87 & 0.04 & 3.8 \\
\hline 50 & 37.5876836 & -122.41638 & 4160229.34 & 551526.06 & 101.92 & 48.9 & -0.05 & 3.84 \\
\hline 51 & 37.58768796 & -122.4163694 & 4160229.83 & 551527 & 101.97 & 49.96 & -0.02 & 3.89 \\
\hline 52 & 37.58769252 & -122.4163606 & 4160230.34 & 551527.77 & 101.98 & 50.88 & -0.1 & 3.9 \\
\hline 53 & 37.5876967 & -122.4163506 & 4160230.81 & 551528.65 & 102.04 & 51.88 & -0.08 & 3.96 \\
\hline 54 & 37.58770098 & -122.4163403 & 4160231.29 & 551529.56 & 102.11 & 52.91 & -0.06 & 4.03 \\
\hline 55 & 37.58770562 & -122.4163305 & 4160231.81 & 551530.42 & 102.15 & 53.91 & -0.09 & 4.07 \\
\hline 56 & 37.58770999 & -122.4163205 & 4160232.3 & 551531.3 & 102.2 & 54.92 & -0.09 & 4.12 \\
\hline 57 & 37.58771238 & -122.4163124 & 4160232.57 & 551532.01 & 102.26 & 55.67 & 0.02 & 4.18 \\
\hline 58 & 37.58771621 & -122.4163023 & 4160233 & 551532.9 & 102.45 & 56.66 & 0.07 & 4.37 \\
\hline 59 & 37.58771948 & -122.4162903 & 4160233.37 & 551533.96 & 102.61 & 57.76 & 0.26 & 4.53 \\
\hline
\end{tabular}

\section{Appendix 5. Acquisition and Geometry for Profile 9}

$\begin{array}{ccccccccc}\text { Sta \# } & \text { Latitude } & \text { Longitude } & \text { Northing } & \text { Easting } & \text { Altitude } & \text { Local X } & \text { Local Y } & \text { Local Z } \\ 1 & 37.59001349 & -122.4191961 & 4160486.29 & 551275.84 & 100.27 & 0 & 0.83 & 0 \\ 2 & 37.590000447 & -122.4191405 & 4160485.32 & 551280.75 & 100.76 & 4.99 & 0.54 & 0.49 \\ 3 & 37.58999546 & -122.4190859 & 4160484.35 & 551285.58 & 101.43 & 9.91 & 0.24 & 1.16 \\ 4 & 37.589986553 & -122.4190296 & 4160483.39 & 551290.56 & 101.75 & 14.97 & -0.03 & 1.48 \\ 5 & 37.58998085 & -122.4189742 & 4160482.79 & 551295.45 & 102.24 & 19.9 & 0.05 & 1.97 \\ 6 & 37.5899739 & -122.4189176 & 4160482.05 & 551300.45 & 102.94 & 24.95 & 0 & 2.67 \\ 7 & 37.58996633 & -122.4188628 & 4160481.24 & 551305.3 & 103.28 & 29.87 & -0.14 & 3.01 \\ 8 & 37.58995902 & -122.4188066 & 4160480.46 & 551310.26 & 103.45 & 34.89 & -0.23 & 3.18 \\ 9 & 37.5899512 & -122.4187559 & 4160479.62 & 551314.74 & 103.33 & 39.44 & -0.45 & 3.06 \\ 10 & 37.58994621 & -122.4186946 & 4160479.1 & 551320.16 & 103.01 & 44.88 & -0.23 & 2.74\end{array}$




\begin{tabular}{|c|c|c|c|c|c|c|c|c|}
\hline 11 & 37.58994089 & -122.418639 & 4160478.54 & 551325.07 & 102.56 & 49.82 & -0.11 & 2.29 \\
\hline 12 & 37.58993466 & -122.4185822 & 4160477.88 & 551330.09 & 102.29 & 54.89 & -0.07 & 2.02 \\
\hline 13 & 37.58992862 & -122.4185265 & 4160477.24 & 551335.01 & 101.83 & 59.85 & -0.03 & 1.56 \\
\hline 14 & 37.58992258 & -122.4184712 & 4160476.6 & 551339.9 & 101.45 & 64.78 & 0 & 1.18 \\
\hline 15 & 37.58991428 & -122.4183978 & 4160475.72 & 551346.38 & 100.49 & 71.32 & 0.02 & 0.22 \\
\hline 16 & 37.5899095 & -122.4183594 & 4160475.21 & 551349.78 & 100.29 & 74.76 & -0.02 & 0.02 \\
\hline 17 & 37.58990218 & -122.4183013 & 4160474.43 & 551354.91 & 101.12 & 79.94 & -0.09 & 0.85 \\
\hline 18 & 37.58989497 & -122.4182462 & 4160473.66 & 551359.78 & 101.03 & 84.87 & -0.19 & 0.76 \\
\hline 19 & 37.5898863 & -122.4181872 & 4160472.73 & 551365 & 100.92 & 90.17 & -0.4 & 0.65 \\
\hline 20 & 37.58988152 & -122.4181327 & 4160472.23 & 551369.81 & 101.08 & 95.01 & -0.23 & 0.81 \\
\hline 21 & 37.58987502 & -122.4180759 & 4160471.54 & 551374.83 & 101.1 & 100.07 & -0.23 & 0.83 \\
\hline 22 & 37.58986754 & -122.4180201 & 4160470.74 & 551379.76 & 101.17 & 105.07 & -0.35 & 0.9 \\
\hline 23 & 37.5898623 & -122.4179638 & 4160470.19 & 551384.74 & 100.91 & 110.07 & -0.21 & 0.64 \\
\hline 24 & 37.58985752 & -122.4179075 & 4160469.69 & 551389.71 & 101.06 & 115.07 & -0.02 & 0.79 \\
\hline 25 & 37.58985184 & -122.4178524 & 4160469.09 & 551394.58 & 101.34 & 119.97 & 0.05 & 1.07 \\
\hline 26 & 37.58984372 & -122.4177966 & 4160468.22 & 551399.51 & 101.27 & 124.98 & -0.14 & 1 \\
\hline 27 & 37.58983938 & -122.4177382 & 4160467.77 & 551404.67 & 101.68 & 130.15 & 0.12 & 1.41 \\
\hline 28 & 37.58983217 & -122.4176839 & 4160467 & 551409.47 & 102.6 & 135.01 & 0.02 & 2.33 \\
\hline 29 & 37.58982603 & -122.4176272 & 4160466.35 & 551414.48 & 101.61 & 140.06 & 0.06 & 1.34 \\
\hline 30 & 37.58982017 & -122.4175715 & 4160465.73 & 551419.4 & 102.35 & 145.02 & 0.12 & 2.08 \\
\hline 31 & 37.58981403 & -122.4175163 & 4160465.08 & 551424.28 & 102.95 & 149.94 & 0.14 & 2.68 \\
\hline 32 & 37.58980799 & -122.4174604 & 4160464.44 & 551429.22 & 103.59 & 154.92 & 0.19 & 3.32 \\
\hline 33 & 37.58980205 & -122.4174067 & 4160463.81 & 551433.96 & 104.26 & 159.7 & 0.21 & 3.99 \\
\hline 34 & 37.58979609 & -122.4173511 & 4160463.18 & 551438.87 & 104.98 & 164.65 & 0.26 & 4.71 \\
\hline 35 & 37.58979014 & -122.4172956 & 4160462.55 & 551443.78 & 105.7 & 169.6 & 0.31 & 5.43 \\
\hline
\end{tabular}

